\title{
Die pseud-athanasianische Homilia de semente. Einleitung, Text und Übersetzung
}

\author{
Annette von Stockhausen
}

Unter dem Namen des Athanasius von Alexandrien ist in nur zwei, noch dazu

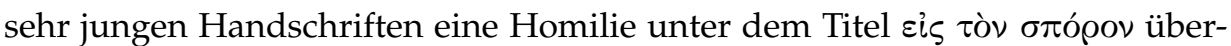
liefert. ${ }^{1}$ Diese Homilie, die im Rahmen eines Gottesdienstes an einem Samstag vorgetragen wurde, ${ }^{2}$ behandelt, größtenteils basierend auf dem Text des LukasEvangeliums, ${ }^{3}$ die beiden Perikopen über das Ährenraufen am Sabbat $(\operatorname{Lk~6,1-5)}$ und über die Heilung der verdorrten Hand am Sabbat (Lk 6,6-11).4

Auf Grund überlieferungsgeschichtlicher und stilistischer Überlegungen wurde die Homilie bereits von den Maurinern in deren Athanasius-Ausgabe 5

$1 \quad$ CPG 2245.

2 Vgl. hom.sem. 1,1 (171,4 [Die Seiten- und Zeilenangaben hier und im folgenden beziehen sich

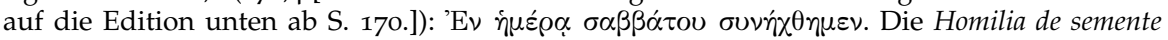
ist somit ein weiteres Zeugnis für die liturgische Praxis eines Gottesdienstes mit Predigt am Samstag, vgl. Willy Rordorf, Der Sonntag. Geschichte des Ruhe- und Gottesdiensttages im ältesten Christentum (AthANT 43), Zürich 1962, 144-151; zu Predigten am Samstag ist außerdem Alexandre Olivar, La Predicación cristiana antigua (Biblioteca Herder. Sección de Teología y Filosofía 189), Barcelona 1991, 645 zu vergleichen.

3 Vgl. unten Anm. 18

4 Die gewählten Perikopen können als Hinweis für die Verortung der Homilie im Kirchenjahr dienen: Nach hom.sem. 1,4 ist die Textauswahl durch eine schon feststehende Leseordnung

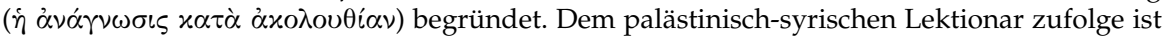
die Perikope Lk 6,1-10 die Lesung für den 4. Samstag nach dem Kreuz-Fest, vgl. Agnes Smith Lewis/Margaret Dunlop Gibson, The Palestinian Syriac Lectionary of the Gospels. Re-edited from two Sinai Mss. and from P. de Lagarde's Edition of the "Evangeliarum Hierosolymitanum", Jerusalem 1971, 103. Zu vergleichen ist auch Juan Mateos (Hrsg.), Le Typicon de la Grande Église. Ms. Saint-Croix n ${ }^{\circ}$ 40, Xe siècle (OCA 166), Rom 1963, 158, wo Lk 6,1-10 als Lesung für den 20. Sonntag nach Pfingsten angeführt wird; zwar ist die Perikope damit nicht Lesung für einen Samstag, aber immerhin ungefähr für die gleiche Jahreszeit vorgesehen, nämlich Mitte

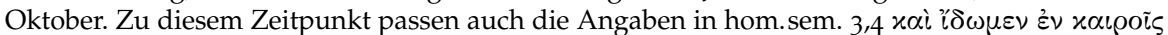

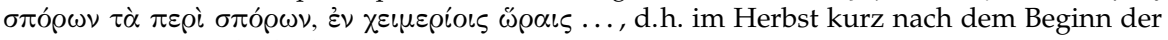
Regenzeit (Ende Oktober).

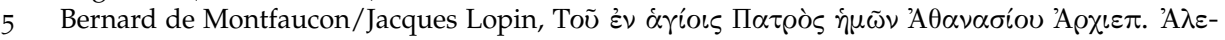
$\xi \alpha \nu \delta \rho \varepsilon i \alpha \varsigma \tau \grave{\alpha} \varepsilon \dot{v} \rho \iota \sigma x o ́ \mu \varepsilon \nu \alpha \pi \alpha ́ \nu \tau \alpha$. Sancti Patris nostri Athanasii Archiep. Alexandrini Opera omnia quae exstant vel quae ejus nomine circumferuntur, Ad mss. codices Gallicanos, Vaticanos, \&c. necnon ad Commelinianas lectiones castigata, multis aucta: nova Interpretatione, Praefationibus, Notis, variis lectionibus illustrata: novà Sancti Doctoris vitâ, Onomastico, \& copiosissimis Indicibus locupletata. Opera \& studio monachorum ordinis S. Benedicti è congretatione Sancti Mauri. Tribus Tomis in folio Graece et Latine, Paris 1698, III 45-55 (= PG 28,144-168). 
unter den Dubia eingereiht und dabei faktisch als unecht beurteilt. ${ }^{6}$ Seither hat der Text infolgedessen nur wenig Beachtung befunden. ${ }^{7}$ Eine Übersetzung in eine moderne Sprache liegt bisher ebensowenig vor wie vor allem eine kritische Edition.

Im Zentrum der vorliegenden Untersuchung steht aus diesem Grund die kritische Edition des Textes und eine deutsche Übersetzung; daneben wird versucht, die klassischen Einleitungsfragen zu beantworten.

\section{Die Überlieferung der Homilie}

Der Text wird durch die beiden Handschriften D, Codex Ambrosianus D 51 sup. $(235)^{8}$, und N, Codex Marcianus gr. Z 50 (coll. 369) ${ }^{9}$, überliefert.

Diese beiden Handschriften enthalten den Text der Homilie jedoch nicht in seinem vollen Umfang: Zwischen Kapitel 7 und $8(180,5)$ ist mit Bernard de Montfaucon ${ }^{10}$ eine Lücke im Text anzunehmen, da mit hom.sem. 8,1 unvermittelt ein neues Thema einsetzt. ${ }^{11}$

6 Vgl. die Ausführungen in der Praefatio (PG 28,13 f.) und in der Admonitio (PG 28,143 f.). Als Hauptgründe werden angeführt, daß die Homilie in keiner der alten Sammlungen zu finden sei, sondern nur im »Codex Anglicanus« (vgl. unten Anm. 9), und daß sie von stilistischen Eigenheiten zeuge, die nicht charakteristisch für Athanasius seien. Der Text werde aber dennoch angeführt, da er zum einen nicht unberedt, zum anderen dem Leser nützlich sei; als positiv wird dabei besonders noch der antijüdischen Unterton der Homilie angeführt. Vgl. zur Frage der Echtheit auch Eduard Schwartz, Der s.g. Sermo maior de fide des Athanasius (SBAW.PPH 1924/6), München 1925, 44 und unten ab S. 166.

7 Vgl. dazu oben auf S. 134. Einzig wegen der Äußerungen des Verfassers zu Sabbat und Sonntag in hom.sem. 1,1 f. $(171,4-12)$ wird auf den Text gelegentlich rekurriert, vgl. Rordorf, Sonntag, und Samuele Bacchiocchi, Du Sabbat au Dimanche. Une recherche historique sur les origines du Dimanche chrétien, Paris 1984.

8 Der Text der Homilia de semente steht auf f. 159b-177a. Die Papierhandschrift stammt aus dem 16. Jh., in ihrem zweiten Teil (f. 241b-303b) ist sie eine Abschrift des Codex Vaticanus gr. 1431. Vgl. Hanns Christof Brennecke/Uta Heil/Annette von Stockhausen, Athanasius Werke II 8. Die »Apologien«, Berlin/New York 2006, liii.

9 Der Text der Homilia de semente steht auf f. 87a-95b. Die Handschrift besteht aus zwei, erst sekundär zusammengebundenen Teilen und stammt aus dem Besitz Bessarions. Der erste Teil (f. 1-95) ist eine Papierhandschrift des 15. Jh.s, der zweite, hier nicht relevante Teil (f. 96-415) eine Pergamenthandschrift des ausgehenden 11. Jh.s, die ihrerseits eine Abschrift des Codex Patmiacus 3 ist. Eine Abschrift des Codex Marcianus gr. Z 50 liegt in Codex Cantabrigiensis (Trinity College B 9.7) gr. 203 (Sigle 44) vor, der bei Montfaucon als »Codex Angelicus« bezeichnet wird. Letzterer bildete die Grundlage der Edition Montfaucons. Vgl. Brennecke/Heil/Stockhausen, Athanasius Werke II 8, liii f.

10 Vgl. PG 28,152 mit n. 30: Hic textus deficit, et, ut videtur, aliunde assuta sunt.

11 Die Größe der Lücke und vor allem ihr Inhalt lassen sich nur annähernd bestimmen: Ein Rückverweis (mit Hilfe von $\mu \varepsilon \grave{v}$ oũv, vgl. hom.sem. 3,3; 7,2; 9,5; 14,5.6) findet sich in hom.sem.

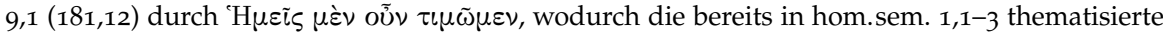
Sabbat/Sonntag-Problematik nochmals anklingt. Das in hom.sem. 8,1-4 angesprochene Thema Tod/Auferstehung klang mit dem Zitat von Joh 12,24 f. vorher schon in hom.sem. 3,1 an, wobei der Verfasser dort auf das Sterben und Fruchtbringen nicht weiter eingegangen war, sondern sich zunächst in hom.sem. 3,1-4,6 dem Gleichnis vom Sämann Mt 13,3-9 und dann 
Darüber hinaus bietet die Handschrift N einen lückenhaften Text. Es fehlen, meist bedingt durch Homoioteleuton, die folgenden Textpassagen:

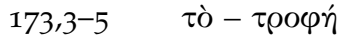

$$
\begin{aligned}
& \text { 173,22-23 o - } \sigma \pi о \rho i ́ \mu \omega \nu \\
& \text { 179,18-21 oủ - } \sigma \pi \circ \rho i ́ \omega \omega \nu
\end{aligned}
$$

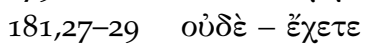

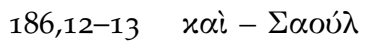

$$
\begin{aligned}
& \text { 186,28-30 } \alpha \lambda \lambda^{\prime}-\Sigma \alpha 0{ }^{\prime} \lambda \\
& \text { 188,7 } \mu \nu \rho \iota \alpha ́ \delta \alpha \varsigma-\tau \grave{\alpha} \varsigma
\end{aligned}
$$

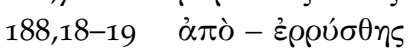

$$
\begin{aligned}
& \text { 191,12-13 } \mu \grave{\eta}-\sigma \alpha ́ \beta \beta \alpha \tau O \nu
\end{aligned}
$$

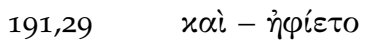

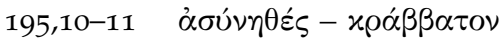

$$
\begin{aligned}
& \text { 195,14-15 ह่x - } \sigma \omega \theta \tilde{\eta} \nu \alpha \iota
\end{aligned}
$$

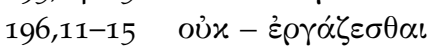

$$
\begin{aligned}
& \text { 197,8-10 он }
\end{aligned}
$$

Überhaupt ist der Text beider Handschriften durch eine hohe Anzahl an Schreibversehen gekennzeichnet, insbesondere solchen, die durch Itazismus bedingt sind. Zwei weitere, gemeinsame Fehler von $\mathrm{D}$ und $\mathrm{N}$ legen nahe, daß die Vorlage der beiden Handschriften eine Maiuskel-Handschrift war:

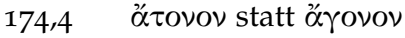

$$
\begin{aligned}
& 174,11 \quad \tau \tilde{\eta} \varsigma \text { statt } \gamma \tilde{\eta} \varsigma^{12}
\end{aligned}
$$

Schließlich findet sich im dritten Teil des Athanasius-Florilegs des Codex Laurentianus IV $23^{13}$ auf f. 120b ein Auszug aus hom.sem. $8(181,23-182,4)^{14}$.

Das Exzerpt im Florileg Gf3 zeigt für die Homilia de semente keine aussagekräftigen variae lectiones, geht aber nach den stemmatischen Untersuchungen von Tetz ${ }^{15}$ anhand anderer Schriften des Athanasius auf denselben Text zurück,

in hom.sem. 4,7-6,3 dem sich im Matthäus-Evangelium bald anschließenden Gleichnis vom Unkraut unter dem Weizen Mt 13,24-30 zugewandt hatte. Vielleicht kam er in der Lücke nun noch auf diesen Aspekt des Verses Joh 12,24 f. zu sprechen und konnte damit (unter Rückgriff auf Ps 87) zugleich an die Sabbat/Sonntag-Thematik anknüpfen, die ja explizit in dem an der Stelle exegetisierten Vers Lk 6,2 angesprochen ist.

12 Eventuell ist auch der unten emendierte Fehler $179,4 \pi \alpha \lambda \alpha \iota \tilde{\omega} \nu$ statt $x \lambda \alpha \dot{\delta} \omega \nu \nu$ auf einen MaiuskelFehler zurückzuführen.

13 Florilegium Athanasianum (CPG 2225); Sigle G. Die Pergamenthandschrift wurde sukzessive im 10. (f. 1-160) bzw. 11. Jh. (f. 161-262) angefertigt. Der dritte Teil des Athanasius-Florilegs (Nr. 79103) hebt sich durch eine andere Form der Lemmata vom Vorangehenden ab; vgl. Martin Tetz, Zur Edition der dogmatischen Schriften des Athanasius von Alexandrien. Ein kritischer Beitrag, ZKG 67 (1955/56), 1-28, hier 8, und auch Schwartz, Sermo maior, 35. Dieser Teil wird von Tetz, Edition, 8 mit der Sigle Gf 3 bezeichnet. Vgl. zur Handschrift auch Brennecke/Heil/Stockhausen, Athanasius Werke II 8, lxvi.

14 Der Text ist abgedruckt bei Henric Nordberg, Athanasiana. Part I: The Texts (Societas Scientarum Fennica. Commentationes Humanarum Litterarum 30,2), Helsinki 1962, 66.

15 Tetz, Edition. 
vom dem auch $\mathrm{D}$ abgeschrieben worden ist. Wie das in $\mathrm{D}$ und $\mathrm{N}$ überlieferte Athanasius-Korpus ${ }^{16}$ und auch die Lesarten in anderen von beiden Handschriften überlieferten Schriften zeigen, gehören beide Handschriften in den antiochenischen Überlieferungszweig der Werke des Athanasius. ${ }^{17}$

Das Verhältnis der Handschriften zueinander läßt sich im nachfolgenden Stemma darstellen:

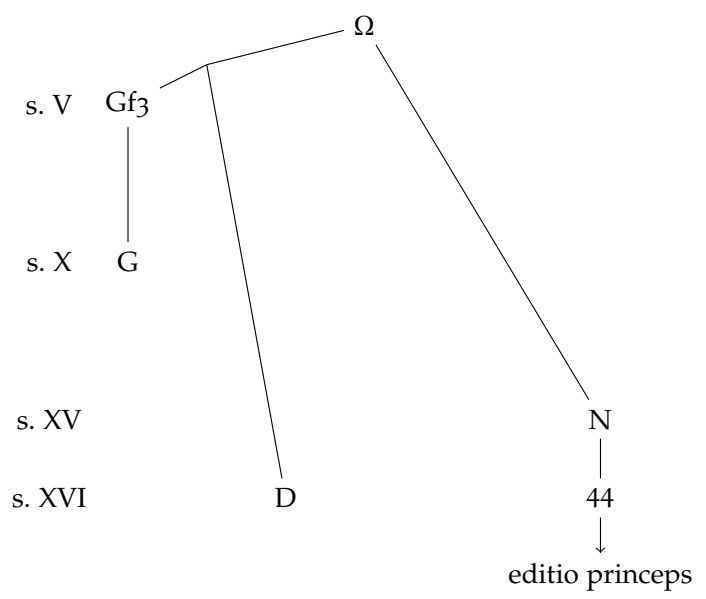

Neben den beiden Handschriften D und N sowie dem Exzerpt im Florileg Gf3 liegt die Homilia de semente weder in einer Übersetzung in eine andere Sprache vor noch wird sie bei anderen Autoren zitiert oder auch nur erwähnt.

\section{Aufbau und Inhalt}

Die Homilie folgt grundsätzlich dem Aufbau der ihr zugrunde liegenden Perikopen Lk 6,1-5 und 6,6-11, ${ }^{18}$ indem sie diese Vers für Vers auslegt. Dabei werden von ihrem Verfasser weitere thematisch naheliegende neutestamentliche Texte durch Stichwortanschluß miteinbezogen und durch kurze, vor allem der bäuerlichen Lebenswelt der Hörer entnommenene Erläuterungen in den Kontext eingebunden, wobei die Auslegung der zweiten Perikope Lk 6,6-11 sehr viel

16 Vgl. die tabellarische Auflistung auf der folgenden Seite, die auch die in Gf3 zitierten Schriften auflistet.

17 Vgl. Brennecke/Heil/Stockhausen, Athanasius Werke II 8, liii-lv.

18 Vgl. die synoptischen Parallelen Mt 12,1-14 und Mk 2,23-3,6. Der Verfasser folgt in seinen direkten Zitaten im großen und ganzen dem Lukas-Text, greift an einigen Stellen aber auch auf den Matthäus-Text zurück. Der Aufbau des Matthäus-Evangeliums scheint auch bei den Rückgriffen auf die weiteren neutestamentlichen Gleichnisse im Kontext des Säens im Hintergrund $\mathrm{zu}$ stehen. 


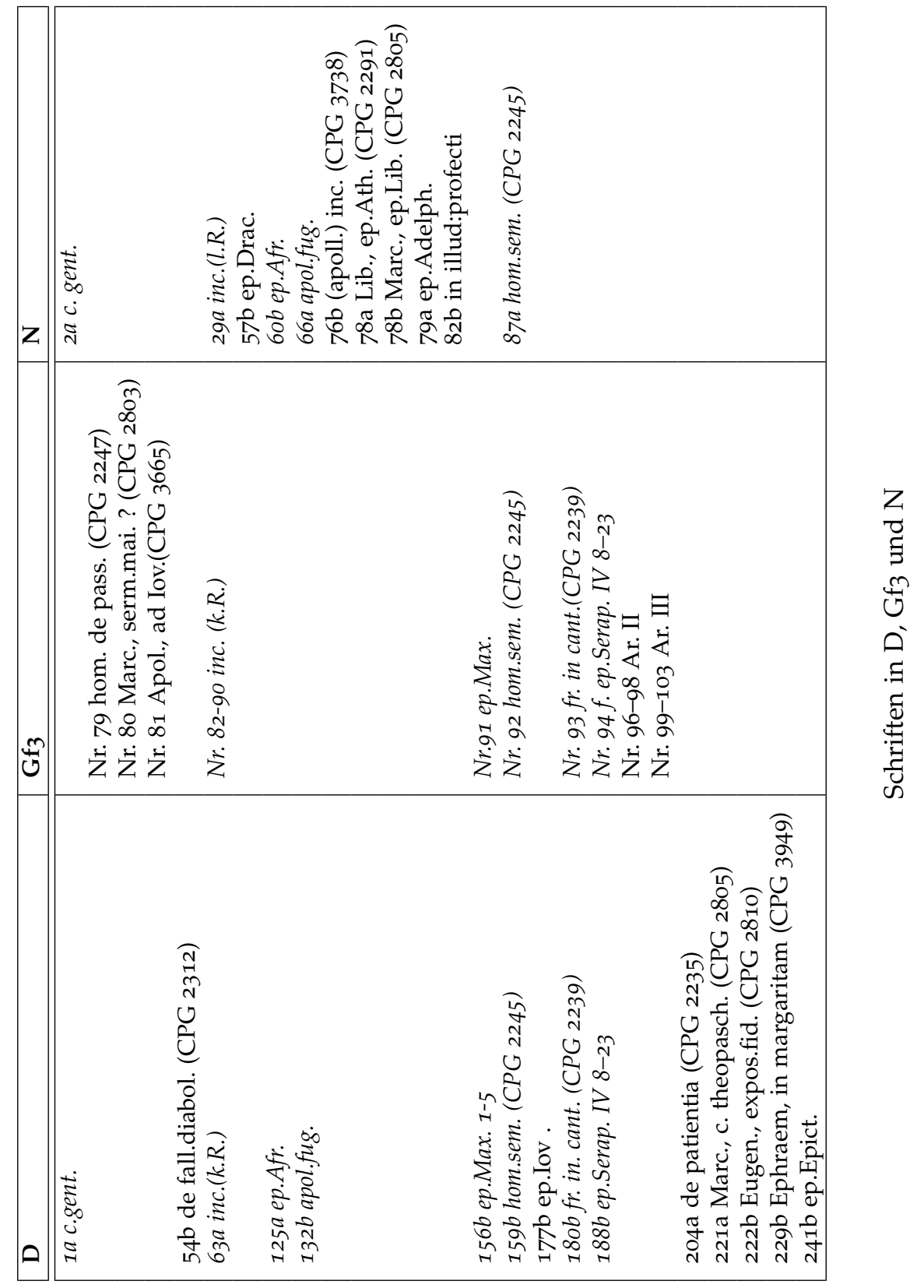


kürzer ist, da der Verfasser offensichtlich merkt, daß seine Homilie zu lang wird. ${ }^{19}$

Die Homilie ist folgendermaßen gegliedert:

I.

$1,1-7,2$

Auslegung der Perikope Lk 6,1-5

1,4

Auslegung von Lk 6,1

Begründung des Gottesdienstes am Sabbat

$2,1-3$

Überleitung zum Predigttext

$3,1-4,6$

Erste Annäherung an den Text: Kritik am Judentum ${ }^{20}$

$(2,4,6$

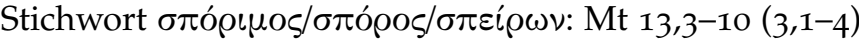

3,1-2 Allegorische Auslegung

3,3-4 Sacherklärende Auslegung

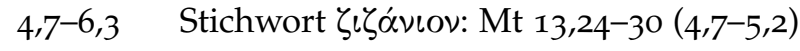

5-6 Pneumatische Auslegung

7,1-2 Rückkehr zum Vers Lk 6,1

7,2-9,2 Auslegung von Lk 6,2

$[7,2 / 8,1 \quad \text { Lücke }]^{21}$

8,1-9,2 Stichwort: vexpós (Ps 87,5)

9,2-14,8 Auslegung von Lk 6,3-4

9,6-14,6 Exkurs: Nacherzählung von 1 Reg 16-18 und 20,24-21,7

11,1-2 Typologischer Vergleich zwischen David und Christus

II.

Auslegung der Perikope Lk 6,6-11 $1^{22}$

15,1-17,1 Auslegung von Lk 6,6-8

15,4-6 Heilungen am Sabbat - Beispiel I: Joh 9

16,1-4 Heilungen am Sabbat - Beispiel II: Joh 5,1-18

17,2-5 Auslegung von Lk 6,9

17,6-7 Auslegung von Lk 6,10

17,7 Auslegung von Lk 6,11

18,1-3 Moralische Auslegung von Lk 6,9-10 mit Ermahnungen

Schluß mit Aufruf zum Gebet

19 Vgl. hom.sem. 15,1.

20 Die Kritik ist durch eine antijudaistische Aktualisierung bei der Auslegung geprägt: Aus den Pharisäern des Evangelientextes werden »die Juden«.

21 Vgl. oben Anm. 11.

22 Die Verknüpfung der zweiten Perikope mit der ersten erfolgt über die David-Saul-Geschichte, vgl. hom. sem. 13,1 und 15,1. 


\section{Datierung}

Äußere, im Ergebnis aber nur sehr ungenaue Anhaltspunkte für die Datierung lassen sich aus der handschriftlichen Überlieferung des Textes erheben. Wenig hilfreich sind hierbei die beiden Handschriften D und N, da sie beide sehr spät, nämlich im 15. (N) bzw. 16. (D) Jahrhundert entstanden sind und damit nur einen sehr weit gefaßten terminus ante quem ergeben. Eine engere Eingrenzung ergibt sich durch das Zitat innerhalb des Athanasius-Florilegs Gf3. Zwar ist dessen Verortung in den christologischen Auseinandersetzungen und damit die Datierung ins 5. Jahrhundert durch Eduard Schwartz ${ }^{23}$ in jüngerer Zeit von Martin Tetz unter Bezugnahme auf eine Bemerkung und einen Brief Marcel Richards in Frage gestellt und das Florileg von Tetz nun vielmehr anti-julianistisch gedeutet und damit in das zweite oder dritte Viertel des 6. Jahrhunderts datiert worden ${ }^{24}$, doch ist dadurch immerhin ein früherer, wenn auch nicht genau zu fassender terminus ante quem gegeben als durch die Abfassungszeit der beiden Handschriften D und N.

Für eine genauere zeitliche Eingrenzung der Abfassung der Homilie können daher nur textimmanente Argumente verwendet werden.

1. Nach hom.sem. 1,1 $(171,4)$ ist die Homilie an einem Samstag gehalten worden. Nach Willy Rordorf ${ }^{25}$ ist der Gottesdienst am Samstag mit Schriftlesung, Predigt und Eucharistie ${ }^{26}$ ein Phänomen, das zwar nicht ausschließlich, aber doch verstärkt im 4. und 5. Jahrhundert auftritt. Trifft dies zu, hat man einen ersten Hinweis für die Datierung.

2. In hom.sem. 1,2 (171,11-12) sagt der Autor der Homilie:

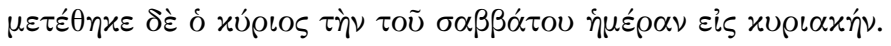

Er spricht also von einer Verschiebung des Sabbats auf den Sonntag. Gemeint ist damit wohl die Verschiebung der ruhetäglichen Funktion des Sabbats auf den Sonntag, die dabei auf Christus selbst rückprojiziert wird. Wie Willy Rordorf $^{27}$ bereits vermutete, könnte hier Konstantins Sonntagsgesetzgebung ${ }^{28}$

23 Schwartz, Sermo maior, 40.

24 Vgl. Tetz, Edition, 27 f. und Marcel Richard, Bulletin de Patrologie. Saint-Athanase, MSR 5 (1948), 123-133, hier 129 Anm. 3.

25 Rordorf, Sonntag, 144.151.

26 Die Homilia de semente enthält dabei jedoch keinen Hinweis, daß auf die Predigt eine Eucharistiefeier gefolgt ist.

27 Rordorf, Sonntag, $168 \mathrm{f}$.

28 CJ III 12,2(3); CTh II 8,1; Eus., v.C. IV 18; l.C. 9,11. Vgl. dazu jetzt mit einer Zusammenfassung des Forschungsstandes Klaus Martin Girardet, Vom Sonnen-Tag zum Sonntag. Der dies solis in Gesetzgebung und Politik Konstantins d. Gr. ZAC 11 (2007), 279-310, der freilich die Festlegung des Sonntags als Ruhetag bereits ins Jahr 312 setzen möchte, was hier nicht diskutiert werden kann. Ich halte mich daher an die eindeutige Datierung durch die Gesetze und durch den zeitlichen Kontext der Bemerkungen Eusebs, die beide in die zoer Jahre des 4. Jahrhunderts gehören. 
im Hintergrund stehen, womit die Homilie frühestens in den $20 e r$ Jahren des 4. Jahrhunderts gehören würde.

Zusätzlich liegt eine enge, zum Teil sogar wörtliche Parallele zur Stelle in hom.sem. 1,2 im Kommentar Eusebs von Caesarea zu Ps 91(92) vor. ${ }^{29}$ Diese Art der Auslegung, die eine Verlegung des Sabbats auf den Sonntag sehr explizit thematisiert, ist bei aller Problematik der Datierung des eusebianischen Psalmenkommentars ${ }^{30}$ sowie von stilistischen Vergleichen generell in der Homilia de semente vorausgesetzt, womit man ebenfalls ungefähr zumindest in die zoer Jahre des 4. Jahrhunderts für die Abfassungszeit der Homilie käme.

3. Ein weiterer Anhaltspunkt für die Datierung ergibt sich aus hom. sem. 8,5 $(182,19-23)$ :

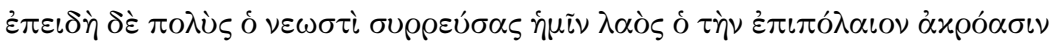

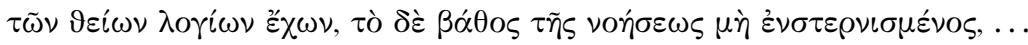

Unter den Zuhörern der Homilie ist dieser Stelle zufolge also eine große Anzahl von Gläubigen, die sich noch nicht lange zum Christentum bekehrt haben und der Kirche zugehören.

Aus dieser Aussage lassen sich natürlich keine festen Daten gewinnen, aber sie deutet bei aller Vorsicht und bei allen geographischen Unterschieden im Grad und in der Schnelligkeit der Christianisierung doch ebenfalls wahrscheinlicher auf eine frühere als auf eine spätere Abfassungszeit der Homilie hin, d.h. mutmaßlich ebenfalls auf das 4. Jahrhundert. Dabei ist besonders das Adverb $v \varepsilon \omega \sigma \tau i$ signifikant, da man es am ehesten wohl mit der schnell ansteigenden Zahl an Christen im Gefolge der »konstantinischen « Wende in Verbindung bringen kann.

4. In hom.sem. 16,1 (194,9-13) schließlich wird vom Autor der Teich Bethes$\mathrm{da}^{3^{1}}$ in Jerusalem erwähnt:

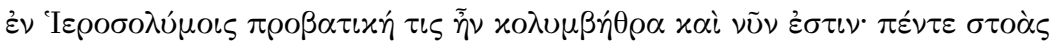

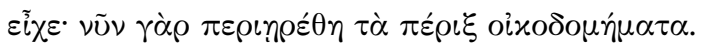

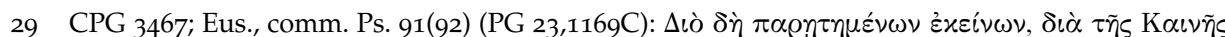

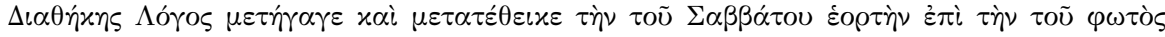

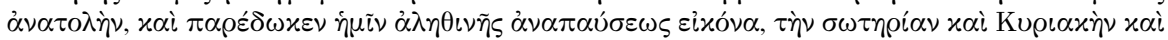

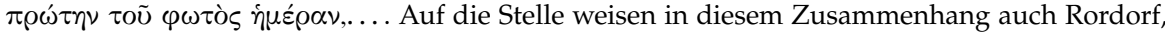
Sonntag, 168 f. und Martin Wallraff, Christus verus sol. Sonnenverehrung und Christentum in der Spätantike (JbAC.E 32), Münster 2001, 100 f. hin.

30 Nach 330 oder sogar erst nach 335, vgl. Marie-Josèphe Rondeau/Jean Kirchmeyer, Eusèbe de Césarée, DSp IV 2 (1961), 1687-169o, hier 1688-169o; Marie-Josèphe Rondeau, Les commentaires patristiques du Psautier. Vol. I (Orientalia christiana analecta 219), Roma 1982, 64-75, zur Datierung vor allem 66-69.

31 Vgl. dazu Klaus Bieberstein/Hanswulf Bloedhorn, Jerusalem. Grundzüge der Baugeschichte vom Chalkolithikum bis zur Frühzeit der osmanischen Herrschaft. Band 3 (BTAVO.B Nr. 10o/3), Wiesbaden 1994, 162-168; John Wilkinson, Jerusalem Pilgrims before the Crusades, Warminster 2002, 346-348; Max Küchler, Jerusalem. Ein Handbuch und Studienreiseführer zur Heiligen Stadt, Göttingen 2007, 313-333. 
Dem Text liegt ganz offensichtlich Joh 5,5 zugrunde, ${ }^{32}$ wobei weniger die wörtlichen Anklänge der Homilie an das Johannes-Evangelium von Interesse sind, als die Differenzen zwischen dem Text des Johannes-Evangeliums und der Homilie. Denn hom.sem. 16,1 ist zu entnehmen, daß zur Zeit der Abfassung der Homilie die auch im Johannes-Evangelium genannten Säulenhallen ${ }^{33}$ offensichtlich nicht mehr existierten, ${ }^{34}$ sondern bereits zerstört sind. ${ }^{35}$

Davon, daß die Säulenhallen zerstört sind, zeugt auch Euseb in seinem Onomastikon. ${ }^{36}$ Denn auch er weicht in seinem Lemma B $\eta \zeta \alpha \theta \alpha \dot{~ v o m ~ J o h a n n e s-~}$

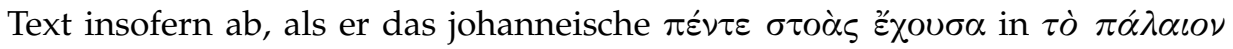

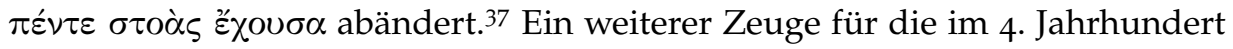
nicht mehr existenten Säulenhallen ist Kyrill von Jerusalem in seiner Homilie zu Joh $5,1-18.3^{8}$

Damit ergibt sich für die Homilie ein terminus post quem vom Ende des $3 .{ }^{39}$ oder Anfang des 4. Jahrhunderts ${ }^{4}$. Zugleich läßt sich aus der Formulierung der

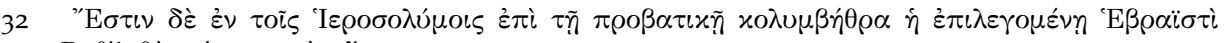

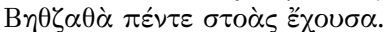

33 Die Säulenhallen stammten aus herodianischer Zeit, vgl. Bieberstein/Bloedhorn, Jerusalem, 162-165 und Küchler, Jerusalem, 319; 323-325.

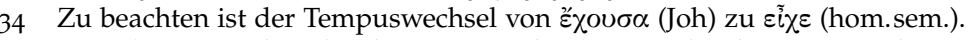

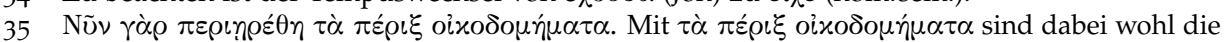

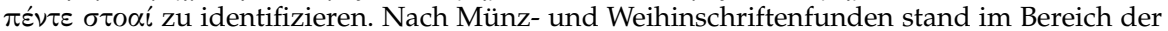
Teiche seit der Herrschaft Trajans ein Asklepios- oder wahrscheinlicher Serapis-Heiligtum, das bis in decische Zeit nachweisbar ist, vgl. Bieberstein/Bloedhorn, Jerusalem, 165-167. Es ist aber

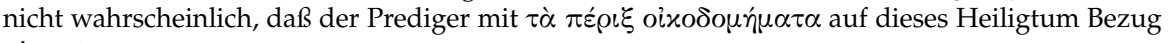
nimmt.

36 Eus., onom., s.v. B $\zeta \zeta \alpha \theta \alpha \dot{\alpha}(58,21-26$ Klostermann).

37 Bestätigt wird dies auch durch die Übersetzung des Hieronymus (59,22-27 Klostermann): haec quinque quondam porticus habuit (Perf.!), ostenduntur (Praes.!) gemini lacus .... Hieronymus weiß also von den ehemals vorhandenen Säulenhallen, gegenwärtig gezeigt werden aber nur noch die beiden Teiche. Dem steht zwar der Bericht des Pilgers von Bordeaux entgegen (Sunt [Praes.!] in hierusalem piscinae magnae duae ad latus templi, id est una ad dexteram, alia ad sinistram, quas salomon fecit, interius uero ciuitati sunt piscinae gemellares quinque porticus habentes [Praes.!], quae appellantur behtsaida. [21,3-6 Geyer]), der im Präsens von den fünf Säulenhallen spricht, Euseb und Hieronymus verdienen hier aber - zumal als Einheimische (zusammen mit dem gleich anzuführenden Kyrill von Jerusalem) und durch ihre übereinstimmende Aussage, die sich nicht einfach auf literarische Abhängigkeiten zurückführen lassen kann - mehr Vertrauen als der Pilger von Bordeaux.

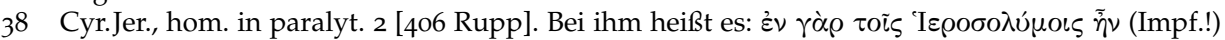

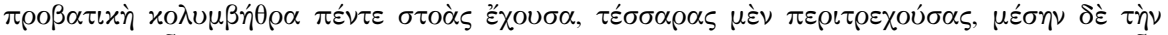

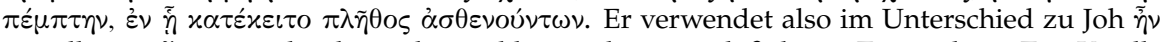
anstelle von है $\sigma \tau \iota \nu$, wodurch wiederum klar markiert ist, daß dieser Zustand zur Zeit Kyrills nicht mehr besteht. Darüber hinaus erfahren wir von ihm erstmals über die Lage dieser fünf Säulenhallen, daß vier um die beiden Teiche herum und eine auf der Trennmauer zwischen den Teichen stand; von dieser Anordnung berichtet auch Orig., comm. in Io. fr. 61 (533,2 f. Preuschen), wobei angesichts der Überlieferung des Johannes-Kommentars und dabei besonders der aus der Johannes-Katene gewonnenen Fragmente (vgl. Preuschen, Origenes Werke IV. Der Johanneskommentar, LXXV f.) offen bleiben muß, ob der Text hier wirklich von Origenes stammt oder nicht vielmehr von Kyrill abhängig ist.

39 Das noch intakte Serapis-Heiligtum, vgl. oben Anm. 35.

40 Die bereits zerstörten fünf Säulenhallen. 
Stelle hom.sem. 16,1 aber auch ein Hinweis erheben, der für die Bestimmung des terminus ante quem verwendet werden kann.

Denn in der ersten Hälfte des 5. Jahrhunderts ${ }^{41}$ wurde auf der Trennmauer zwischen den beiden Teichen eine Kirche zum Gedenken an die Heilung des Gelähmten (bzw. in späteren Nennungen eine Marienkirche) erbaut, die dann immer mehr auch literarische Erwähnung findet. ${ }^{42}$

Da diese Kirche in hom.sem. 16,1 nicht erwähnt wird, vielmehr nur von den Teichen und von zerstörten Gebäuden rings um diese die Rede ist, kann man hier e silentio schließen, daß diese Kirche zur Zeit der Abfassung der Homilie einfach noch nicht existierte. Damit ist eine Entstehung vor dem Bau der Kirche, d.h. spätestens bis in die erste Häfte des 5. Jh.s, wahrscheinlich zu machen.

Die Erwähnung der Bethesda-Teiche in hom.sem. 16,1 ergibt somit als möglichen Zeitraum der Abfassung der Homilie die Zeit vom Anfang des 4. Jahrhunderts bis zur Mitte des 5. Jahrhunderts, wobei man im Blick auf die beiden Textstellen hom.sem. 1,2 und 8,5 die zweite Hälfte des 4. Jahrhunderts wahrscheinlich machen kann.

\section{Der Autor der Homilie}

Wie oben bereits erwähnt wird die Homilie seit der Edition der Mauriner vor allem aus stilistischen Gründen nicht zu den genuinen Werken des Athanasius gerechnet. ${ }^{43}$ Damit ist die Frage aufgeworfen, wer dann statt seiner der Verfasser des Textes gewesen sein könnte.

Im vorliegenden Fall fehlt angesichts der einhelligen Nennung des Athanasius als Verfasser in den Handschriften jeglicher äußere Anhaltspunkt für eine Zuschreibung des Textes an einen anderen Autor. Um die Frage nach

41 Die Datierung ergibt sich Bieberstein/Bloedhorn, Jerusalem, 167 aus der Datierung von Kapitellfragmenten aus der Innenausstattung der Kirche.

42 Sie wird zuerst in Quellen aus der ersten Hälfte des 6. Jahrhunderts erwähnt, so bei Johannes Rufus, pleroph. 18 (»Kirche des Schafteiches«) bzw. v.Petr. (99,12 f. Raabe; »Kirche des Gelähmten«) und im Breviarius de Hierosolyma B 7 (Et est ibi basilica, in tempore ubi se lauabant infirmi et sanebantur [155,11 f. Geyer]). Eine Marienkirche nennen bereits Theodosius, De situ terrae sanctae 8 (142,5 f. Geyer) und der Pilger von Piacenza 27 (Reuertentibus nobis in ciuitatem uenimus ad piscinam natatoria, quae quinque porticus habet; et in uno earum est basilica sanctae mariae, ubi multae fiunt uirtutes. [208,15-17 Geyer]); vielleicht erwähnt auch der Breviarius de Hierosolyma B 7 schon diese Kirche (Et ibi est basilica sanctae Mariae [155,12 Geyer]), wenn der Verfasser sie hier nicht mit dem anschließend genannten Mariengrab (et ibi est sepluchrum eius [155,12 Geyer]) verwechselt. Zum Bau der Kirche vgl. auch Jourdain-Marie Rousée, L'Église Sainte-Marie de la Probatique. Chronologie des sanctuaires à Sainte-Anne de Jérusalem d'après les fouilles récentes, in: Atti del VI Congresso Internazionale di Archeologia Cristiana. Ravenna 23-30 Settembre 1962 (SAC XXVI), Città del Vaticano 1965, 169-176; Yoram Tsafrir, Art. Jerusalem, RBK III (1978), 525-615, hier 611 f. Marie-Joseph Pierre/Jourdain-Marie Rousée, Sainte-Marie de la Probatique, état et orientation des recherches, POC 31 (1981), 23-42; Bieberstein/Bloedhorn, Jerusalem, 167 f.; Küchler, Jerusalem, 332 f.

43 Vgl. oben S. 157 
dem Verfasser zu beantworten, müssen deshalb textimmanente Anhaltspunkte zu Hilfe genommen werden, die als Kriterium für die Zuschreibung dienen können. Geeignet sind dafür insbesondere Übereinstimmungen zwischen der Homilie und Werken des mutmaßlichen Autors im Wortschatz, in der Stilistik und in theologischen Fragen. Dadurch ist allerdings zugleich die Möglichkeit, eine positive Zuschreibung an einen Autor durchzuführen, grundsätzlich eingeschränkt, als überhaupt nur Autoren, deren Werke uns noch in nennenswertem Umfang erhalten sind, für einen solchen Vergleich in Frage kommen, zumal die zu vergleichenden Schriften aufgrund jeweils gattungsspezifischer Eigenheiten idealerweise derselben literarischen Gattung angehören sollten, um zu validen Ergebnissen kommen zu können. ${ }^{44}$

Als bisher einziger hat Marcel Richard es versucht, die Homilie einem Autor zuzuweisen:45 Ihm zufolge ist Markell von Ankyra als der Verfasser anzusehen. Als Grund für diese Zuschreibung nennt er die $\lambda o ́ \gamma o \varsigma-\sigma \alpha ́ \rho \xi$-Christologie, die sich in den mit der homelia de semente in D und dem Florileg Gf3 zusammen überlieferten Schriften sermo de patientia (CPG 2235) und homilia de passione et cruce domini (CPG 2247) feststellen ließe. Doch leider geschieht diese Zuweisung nur mehr oder weniger in einem Nebensatz ohne nähere Erläuterungen.

Da jedoch weder sicher ist, daß die drei Homilien de semente, de patientia und de passione et cruce domini von einem Autor stammen, noch die im 4.Jahrhundert weit verbreitete $\lambda o ́ \gamma o \varsigma-\sigma \alpha ́ \rho \xi$-Christologie überhaupt als sonderlich starkes Argument gewertet werden kann, muß diese Zuschreibung zurückgewiesen werden. Zudem lassen sich zwischen den Werken des Markell und der Homilia de semente keine Parallelen im Stil ${ }^{46}$ oder im Wortschatz feststellen, wie auch sonst in der Homilie keinerlei speziell markellische Theologumena anzutreffen sind.

Es findet sich im Text der Homilie aber auch ein inhaltliches Argument sowohl gegen Markell von Ankyra als auch gegen Athanasius als Autor. In hom.sem. 4,3 f. (177,13-15.22-25) schreibt der Verfasser der Homilie:

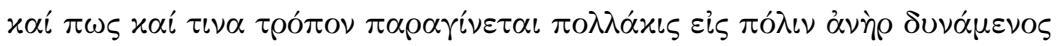

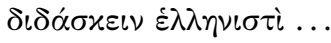

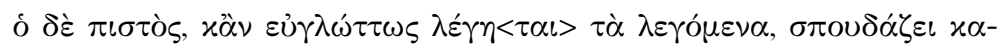

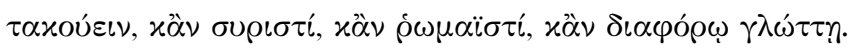

44 Insofern ist es natürlich auch problematisch, Athanasius den Text aus stilistischen Gründen abzuerkennen, da für die Homilia de semente unter den sicher authentischen Werken des Athanasius kein adäquates Vergleichsmaterial vorliegt, da von Athanasius keine Homilien, sondern vor allem apologetisch-polemische Traktate sowie Briefe überliefert sind. Dafür, daß die Homilie nicht von Athanasius stammt, gibt es dennoch einen Hinweis, vgl. dazu auf der folgenden Seite.

45 Richard, Bulletin de Patrologie, 129.

46 Auch von Markell sind keine Homilien überliefert, die als adaequates Vergleichsmaterial heranzuziehen wären. 
Aus diesen Sätzen ist zu schließen, dass die Homilie in einer Gegend gehalten wurde, in der neben griechisch ${ }^{47}$ vor allem syrisch-aramäisch gesprochen wurde und in der gleichzeitig auch die lateinische Sprache durchaus eine Rolle spielte..$^{8}$ Dieser Hinweis auf den Ort trifft nun weder auf das zentralanatolische Ankyra noch auf Alexandrien zu. Wenn der Verfasser der Homilie diese nicht an einem anderen als seinem Heimatort gehalten hat - und dafür gibt es im Text zumindest keinen Hinweis - dann scheiden sowohl Athanasius als auch Markell von Ankyra als Autoren aus.

Aus zwei anderen Stellen läßt sich eventuell noch etwas über den Ort der Predigt erschließen: 1. In hom.sem. 11,1 $(186,20)$ warnt der Verfasser davor,

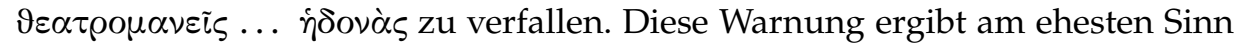
in einer städtischen Umgebung, wo das Theater als Institution existiert.

2. Die oben bereits angeführte Stelle hom.sem. 16,1 (194,9-13) mit der Nennung des Bethesda-Teiches wird so ohne weitere Erläuterungen zur Örtlichkeit eingeführt, daß sie eine gewisse Vertrautheit der Zuhörer mit der Topographie Jerusalems vorraussetzt, also vielleicht in Jerusalem selbst zu verorten ist. ${ }^{49}$

Als möglicher Verfasser der Homilie kommen somit Bischöfe (oder Presbyter) einer Stadt im syrisch-palästinischen Raum (Jerusalem?) in Frage. Unter den uns bekannten Autoren, von denen auch Schriften (und idealerweise Homilien) erhalten sind, ist m.E. jedoch kein einziger, der bei einem Vergleich für eine Identifizierung ausreichend große Übereinstimmungen aufzeigt..$^{50}$ Die Frage nach dem Autor muß daher als offen gelten.

\section{Beobachtungen zum Stil}

1. Charakteristisch für den Stil des Autors ist die breite Verwendung von anaphorisch eingesetzten Leitworten, die den Text zugleich gliedern.

47 Die griechische Sprache und vor allem Rhetorik wird dabei vom Verfasser trotz seiner eigenen, in der Homilie deutlich zu Tage tretenden rhetorischen Fähigkeiten an der Stelle pejorativ gebraucht.

48 Ein erhellendes Beispiel für die gleichzeitige Verwendung von Griechisch, Syrisch und Latein in Jerusalem bietet Egeria, itin. 47,3 f.

49 Der Autor nennt zwar Jerusalem mit Namen, was auffällig ist, wenn Jerusalem der Ort der Homilie ist. Die Nennung des Ortsnamens ist an der Stelle aber darin begründet, daß der Autor Joh 5,2 zitiert, wo Jerusalem ebenfalls explizit genannt ist.

50 Die größten wörtlichen Berührungen liegen mit einigen von Kyrill von Jerusalems Taufkatechesen und mit seiner Homilia in paralyticum juxta piscinam jacentem vor, die aber meist in denselben behandelten Bibelstellen ihre Ursache haben, auf der stilistischen Ebene finden sich am ehesten Parallelen zu Hesych von Jerusalem, allerdings nicht auf der Ebene des Wortschatzes. Wohl nicht zufällig sind beide Autoren, von denen uns fast ausschließlich Homilien und Predigten überliefert sind. Bei dem für Pseud-Athanasiana gerne verdächtigten Apolinaris von Laodicaea, von dem nun allerdings auch wieder keine Homilien erhalten sind, finden sich demgegenüber keinerlei Parallelen zur Homilia de semente. 
So sind z.B. im Abschnitt hom.sem. 3,1-4,7 seine Ausführungen durch den Begriff $\sigma \pi$ ópo $\varsigma$ und seine Derivate geprägt, in hom.sem. 4,7-6,3 ist das leitende

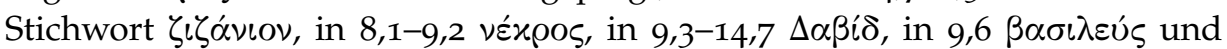
$\beta \alpha \sigma i \lambda \varepsilon i \alpha$ und in $11,1-2 \chi \rho i \sigma i \varsigma$ und $\chi \rho i \omega$.

2. Darüber hinaus macht der Autor die Gliederung des Textes durch die Wiederaufnahme von Formulierungen für den Zuhörer transparent.

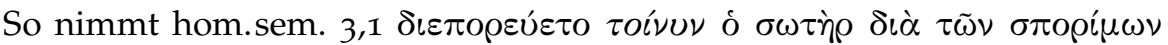

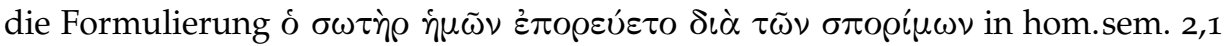

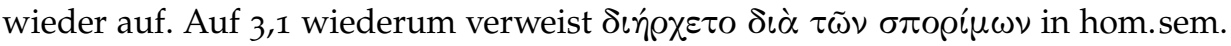

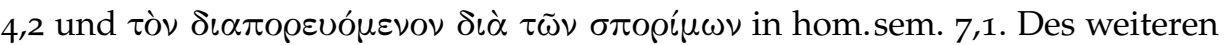

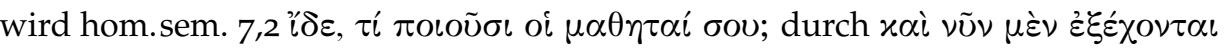

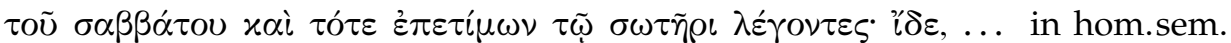

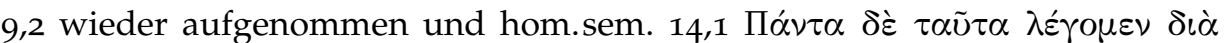

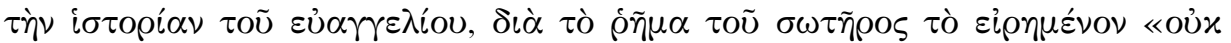

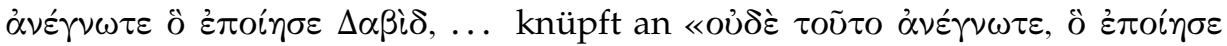
$\Delta \alpha \beta i \delta$; » in hom.sem. 9,2 an, während schließlich hom.sem. 14,8 'E $\pi \varepsilon i$ oũv oi

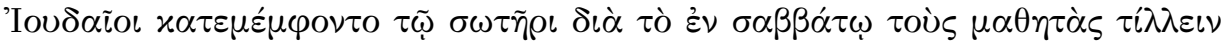

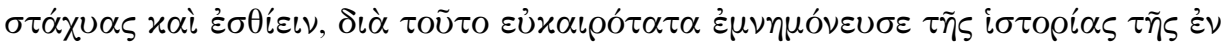

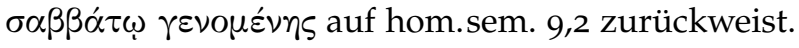

3. Der Autor der Homilia de semente gebraucht daneben auch anaphorische Reihungen von Fragesätzen zur Stilisierung des Textes:

* hom.sem. 2,1

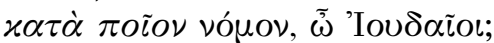

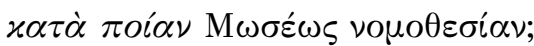

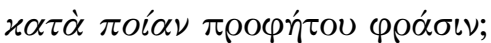

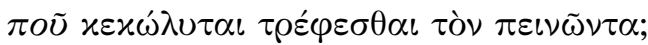

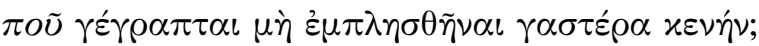

* hom.sem. 2,3

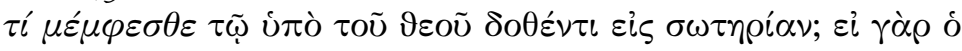

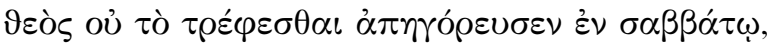
* hom. sem. 12,6

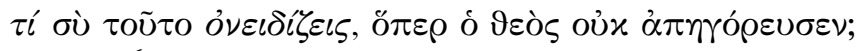

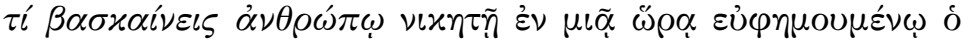

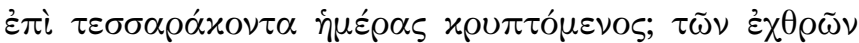

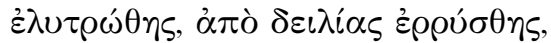

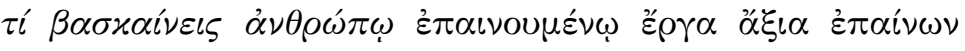

$$
\begin{aligned}
& \varepsilon \rho \gamma \alpha \sigma \alpha \mu \varepsilon ́ v \omega
\end{aligned}
$$

4. Der Stil des Autors ist insgesamt von kolloquialen Eigenheiten wie vielen mit $x \alpha i$ verbundene Reihungen, ${ }^{51}$ kurzen, asyndetisch angeschlossenen Sätzen ${ }^{2}$,

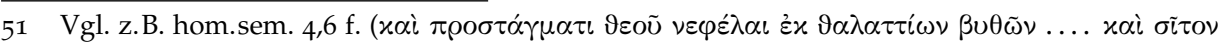

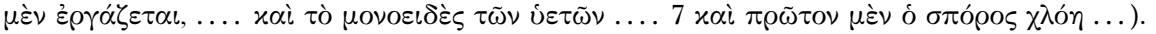

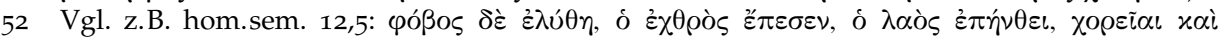

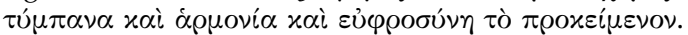


Ausrufen ${ }^{53}$ sowie immer wieder eingestreuten direkten Anreden der Zuhörer ${ }^{54}$ gekennzeichnet.

\section{Edition}

Um den textkritischen Apparat nach Möglichkeit zu entlasten, wurden in der vorliegenden Edition Varianten nicht angeführt, sofern sie durch offensichtliche Schreibfehler, durch Itazismen, durch Wortwiederholungen, durch das Setzen oder Weglassen von $\nu$-ephelkystikon und von $\varsigma$ bei oü $\tau \omega \varsigma$ bedingt sind oder die Akzentsetzung betreffen.

Die Kapiteleinteilung folgt weitgehend der Edition Montfaucons, 55 die Einteilung in Paragraphen wurde neu eingerichtet.

Zitierte oder im Rahmen von Anspielungen referenzierte Bibelstellen werden im Text kursiv wiedergegeben, direkte Rede im Text wird durch Anführungszeichen markiert.

Im Anschluß an die Edition ist, um den Zugang zum Text zu erleichtern, zudem ein Index wichtiger griechischer Begriffe abgedruckt.

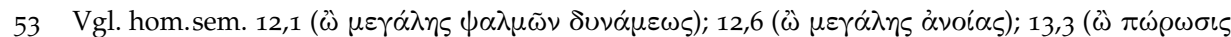
$\beta \alpha \sigma x \alpha \nu i \alpha \varsigma) ; 15,5$ (

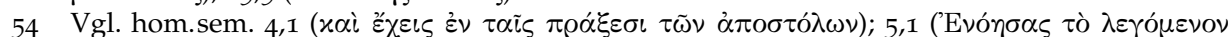

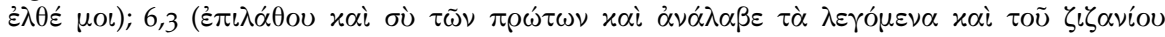

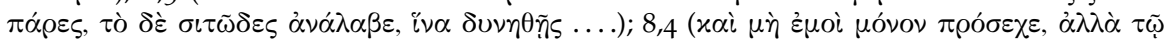

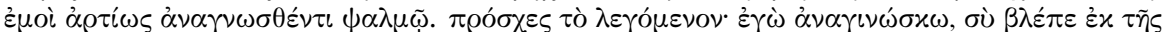

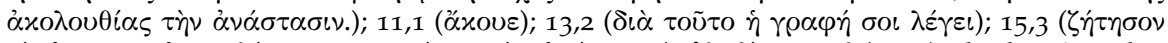

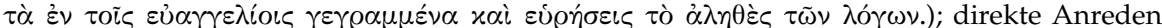
verbunden mit $\beta \lambda \varepsilon \dot{\pi} \varepsilon$ ( $\mu \mathrm{ol})$ : hom.sem. 10,6; 13,1; 17,6.

55 Die Kapiteleinteilung Montfaucons ist jeweils am rechten Rand vermerkt. 
[Toũ $\alpha \cup ่ \tau o \tilde{u}$ 'A $\theta \alpha \nu \alpha \sigma i ́ o v$

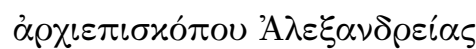

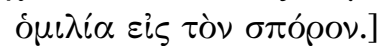

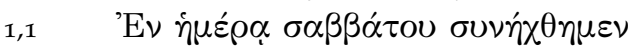

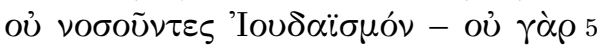
$\varepsilon \varphi \alpha \pi \tau o ́ \mu \varepsilon \theta \alpha \quad \sigma \alpha \beta \beta \alpha ́ \tau \omega \nu \quad \psi \varepsilon v \delta \tilde{\omega} \nu-$,

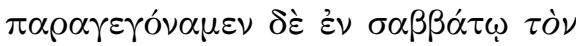

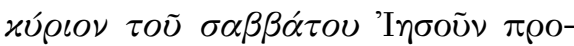

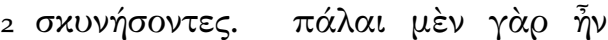

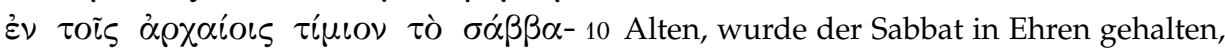

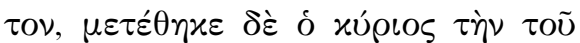

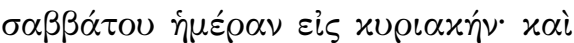

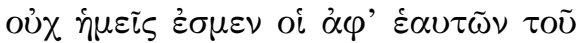

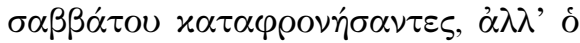

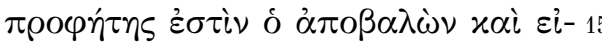

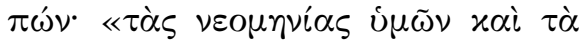
$3 \sigma \alpha ́ \beta \beta \alpha \tau \alpha \mu \iota \sigma \varepsilon \tilde{\imath} \dot{\eta} \psi v \chi \dot{\eta} \mu O v . \gg \mu \varepsilon-$

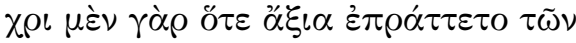

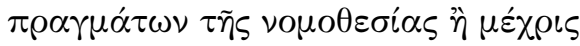

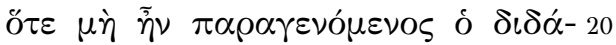

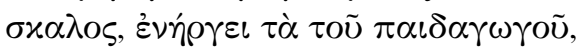

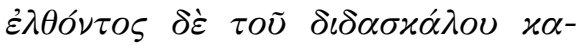

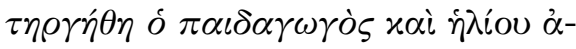

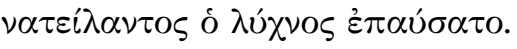

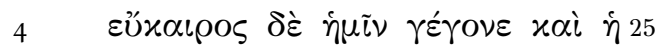

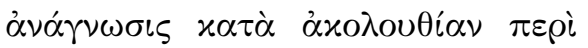

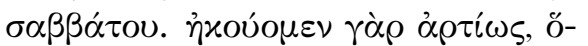

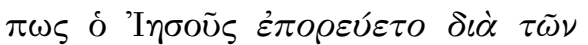

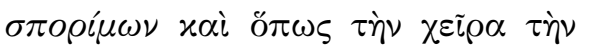

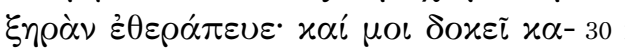

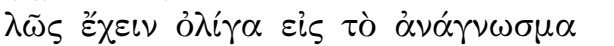

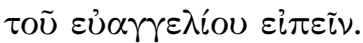

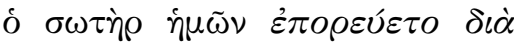

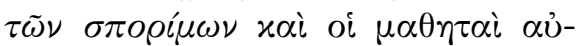

[Predigt desselben Athanasios, des Erzbischofs von Alexandria, über die Aussaat]

Am Tag des Sabbats haben wir uns ver- $1 \mathrm{M}$. sammelt, kranken aber nicht am Judaismus denn wir haben nichts mit falschen Sabbaten zu tun -, sondern wir sind am Sabbat zusammengekommen, um Jesus, den Herrn des Sabbats, anzubeten. Denn einst, bei den der Herr aber hat den Tag des Sabbats auf den Herrentag verlegt; und nicht wir sind es, die von uns aus den Sabbat mißachtet haben, sondern der Prophet ist es, der ihn verworfen und gesagt hat: »Eure Neumonde und Sabbate haßt meine Seele«. Denn solange das getan wurde, was dem Gesetz entsprach, bzw. solange der Lehrer (noch) nicht gekommen war, galten die Bestimmungen des Zuchtmeisters. Als der Lehrer aber gekommen war, ist der Zuchtmeister beseitigt worden, und als die Sonne aufgegangen war, ist der Leuchter gelöscht worden.

Gerade zum rechten Zeitpunkt kam uns so die Lesung nach der Ordnung über den Sabbat. Denn wir hörten eben, daß Jesus durch die Saatfelder ging und daß er die gelähmte Hand heilte. Und mir scheint es nun angezeigt, ein paar Worte zur Evangelienlesung zu sagen.

Unser Heiland ging durch die Saatfelder, und seine Jünger folgten ihm, rauf-

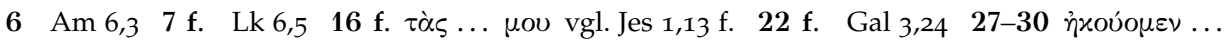
$\dot{\varepsilon} \theta \varepsilon \rho \alpha ́ \pi \varepsilon v \sigma \varepsilon$ vgl. Lk 6,1-10 par 33 f. Mt 12,1

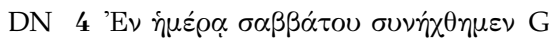

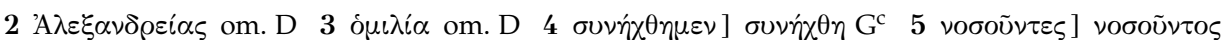

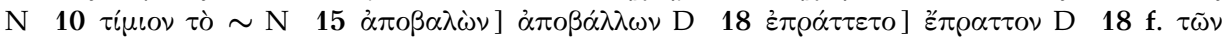

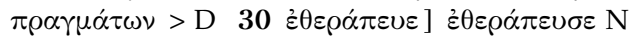




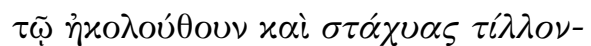

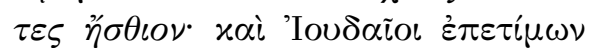

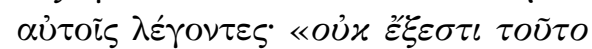

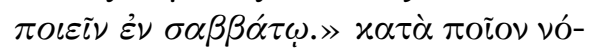

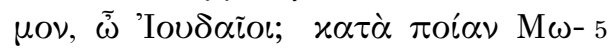

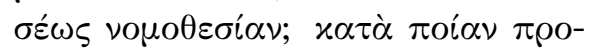

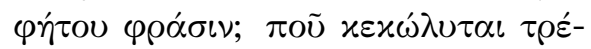

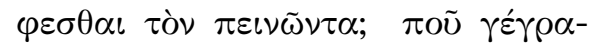
$\pi \tau \alpha l \quad \mu \grave{\eta} \varepsilon \dot{\varepsilon} \mu \lambda \eta \eta \sigma \theta \tilde{\eta} \nu \alpha \iota \quad \gamma \alpha \sigma \tau \varepsilon \dot{\varepsilon} \rho \alpha \quad x \varepsilon-$

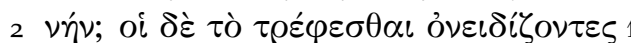

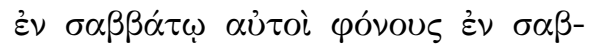

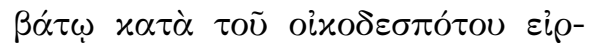

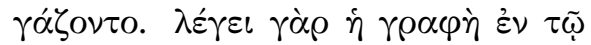

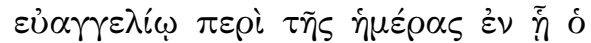

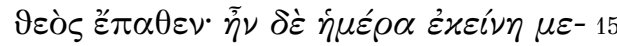

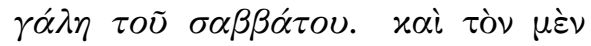

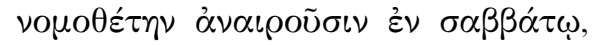

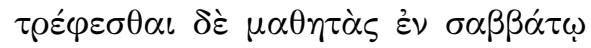

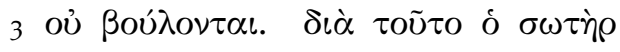

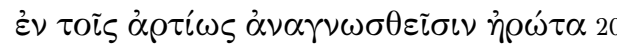

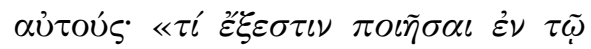

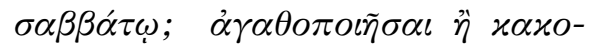
$\pi \circ \iota \tilde{\eta} \sigma \alpha l ; \quad \psi v \chi \grave{\eta} \nu \quad \sigma \tilde{\omega} \sigma \alpha \iota \dot{\eta} \dot{\alpha} \pi 0 \lambda \varepsilon-$

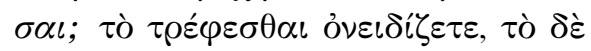

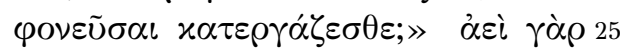

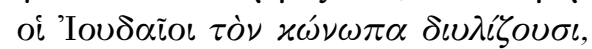

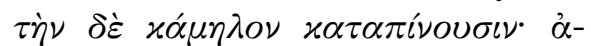

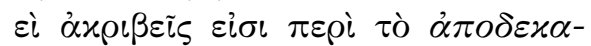

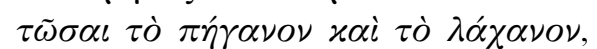

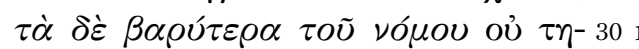

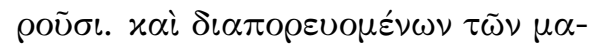

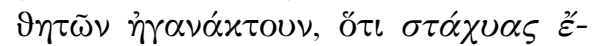

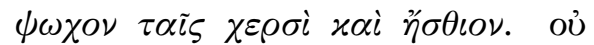

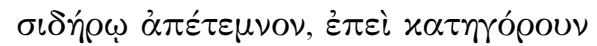

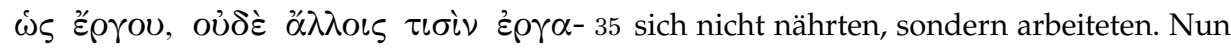

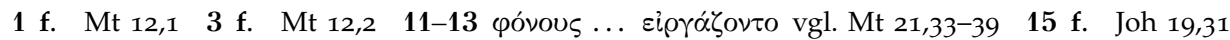
21-24 Lk 6,9; Mk 3,4 26 f. Mt 23,24 28 f. Lk 11,42 30 Mt 23,23 32 f. $\quad$ Lk 6,1 172.33

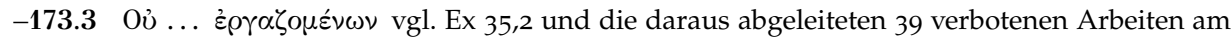
Sabbat in mShab VII 2.

\section{$\mathrm{DN}$}

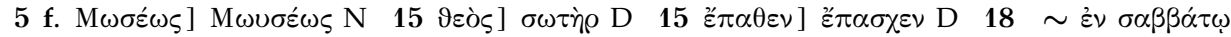

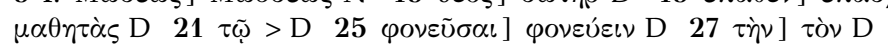

ten Ähren aus und aßen sie; und die Juden machten ihnen Vorwürfe und sagten: »Man darf das nicht am Sabbat tun!« Nach welchem Gesetz, ihr Juden? Nach welcher Gesetzgebung des Mose? Nach welchem Prophetenwort? Wo ist verhindert, daß der Hungernde sich ernährt? Wo steht geschrieben, daß ein leerer Magen nicht gefüllt werde? Die aber tadeln, daß man am Sabbat ißt, haben selbst am Sabbat einen Mord gegen den Hausherrn ins Werk gesetzt! Denn die Schrift sagt im Evangelium über den Tag, an dem Gott litt: Es war aber jener Tag ein großer Tag des Sabbats. Den Gesetzgeber also töten sie am Sabbat, daß sich aber die Jünger am Sabbat nähren, wollen sie nicht. Deswegen fragte sie der Heiland in dem eben verlesenen Text: »Was darf man am Sabbat tun? Gutes oder Schlechtes? Leben (a) Denn immer sieben die Juden die Mücke aus, das Kamel aber trinken sie; immer sind sie genau, wenn es um das Verzehnten der Raute und des Kohls geht, die gewichtigesicht. als sie (durch die Felder) gingen, die Ähren mit ihren Händen zerrieben und aßen. Nicht Sichel haben sie sie abgeschnitten, es sich um Arbeit gehandelt, und sie haben auch keine anderen Werkzeuge verwendet, damit sie nicht angeklagt würden, daß sie 


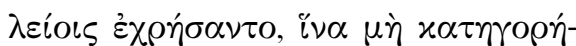
$\sigma \omega \sigma \iota \nu \hat{\omega} \varsigma \mu \grave{\eta} \tau \rho \varepsilon \varphi O \mu \varepsilon \dot{\varepsilon} \omega \nu, \dot{\alpha} \lambda \lambda \lambda^{\prime} \dot{\varepsilon} \rho-$

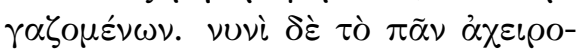

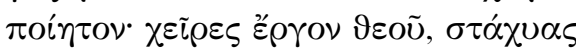

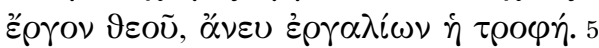

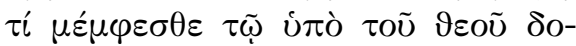

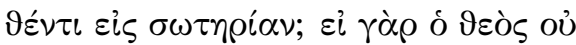

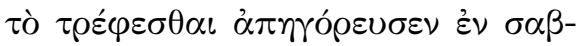

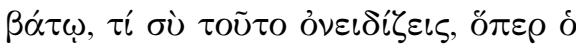

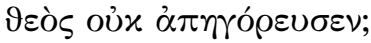

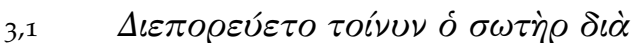

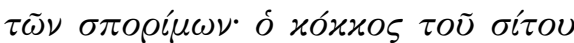

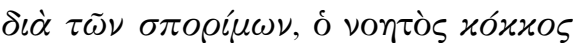

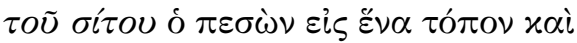

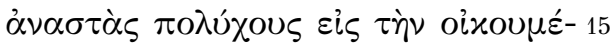

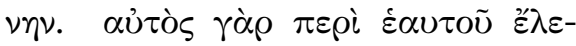

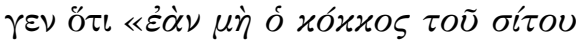

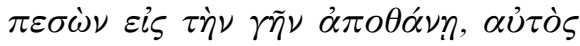

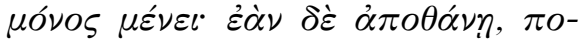

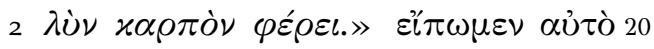

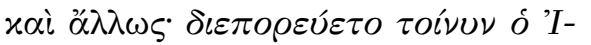

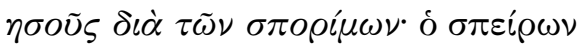

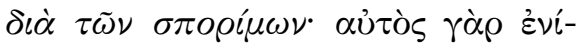

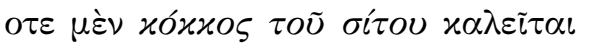

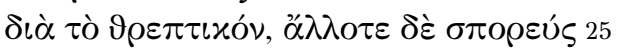

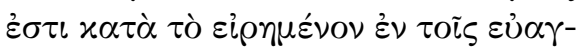

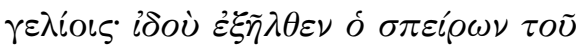

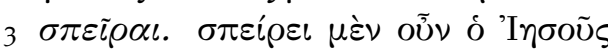

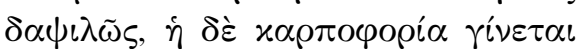

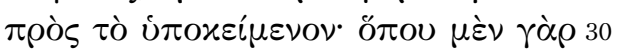
$\pi \varepsilon \tau \rho \omega \dot{\delta} \eta \varsigma \dot{\eta} \gamma \tilde{\eta}, \varepsilon \dot{u} \mu \alpha \rho \tilde{\omega} \varsigma \xi \eta \rho \alpha i v \varepsilon \tau \alpha l$

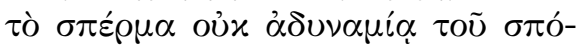

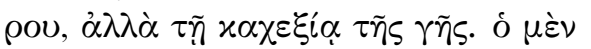

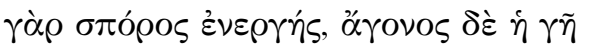

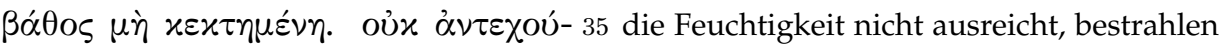

3 f. $\dot{\alpha} \chi \varepsilon\llcorner\rho o \pi$ oíntov vgl. 2Kor 5,1 11 f. Lk 6,1 12 Joh 12,24 17-20 Joh 12,24 f. 21 f. Lk 6,1

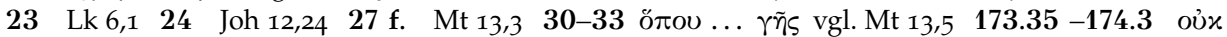
... $\sigma \pi$ ó $\rho$ ov vgl. Mt 13,6

DN

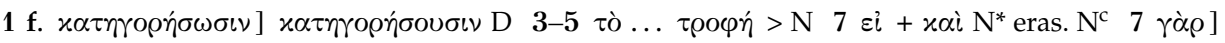

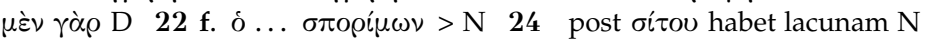

aber ist das alles nicht von Hand gemacht: die Hände sind ein Werk Gottes, die Ähren sind ein Werk Gottes, ohne Werkzeuge ist die Nahrung (hergestellt). Warum tadelt ihr den, dem von Gott etwas zur Rettung gegeben wurde? Denn wenn Gott nicht verboten hat, sich am Sabbat zu nähren, warum tadelst du das, was Gott nicht verboten hat?

Der Heiland ging also durch die Saatfel- $2 \mathrm{M}$. der; das Getreidekorn ging durch die Saatfelder, das geistig wahrnehmbare Getreidekorn, das an eine Stelle fiel und vielfältig auferstand in die ganze bewohnte Welt hinein. Denn er selbst sagte über sich: »Falls das Getreidekorn nicht in die Erde fällt und stirbt, bleibt es allein; falls es aber stirbt, bringt es viel Frucht.« Laßt uns das noch Saatfelder; der Saman ging also durch die Saatfelder; der Sämann durch die Saatfelder; denn er selbst wird manchmal Saatkorn genannt wegen seiner Eignung zum Nähren, manchmal aber ist er der Säer gemäß dem Wort in den Evangelien: Siehe, der Sämann ging hinaus, um zu säen. Jesus sät also im Überfluß, der Ertrag aber ist abhängig vom Untergrund: Denn wo der Boden felsig ist, vertrocknet der Same leicht, nicht rund der Schwäche des Samens, sonaufgrund des schlechten Zustandes des Bodens; denn der Same ist fruchtbar, der Boden aber ist unfruchtbar, weil er nicht tief genug ist. Wenn aber der Boden für . 
$\sigma \eta \varsigma \delta \grave{\varepsilon} \tau \tilde{\eta} \varsigma \gamma \tilde{\eta} \varsigma \pi \rho \grave{s}$ ن $\gamma \rho \alpha \sigma i \alpha \nu \pi \lambda \varepsilon \tilde{\imath} 0 \nu$

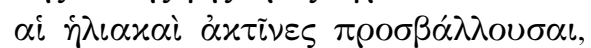

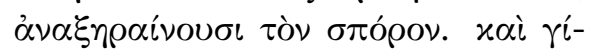

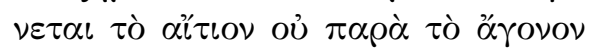

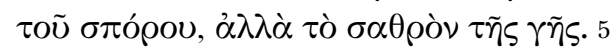

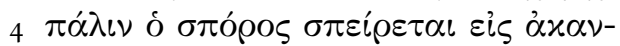

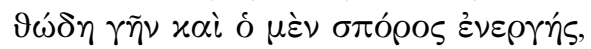

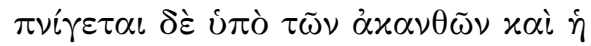

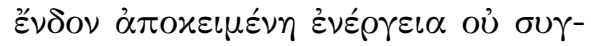

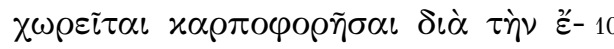

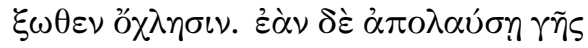

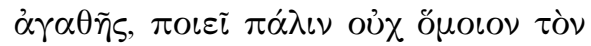

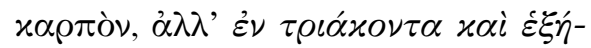

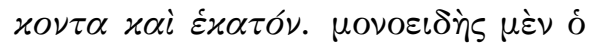

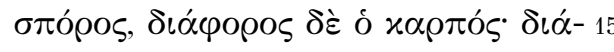

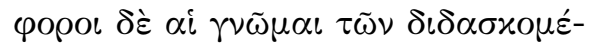
$\nu \omega \nu$.

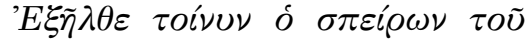

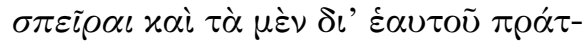

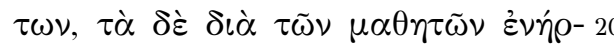
Ү

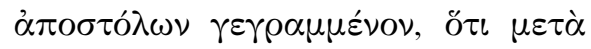

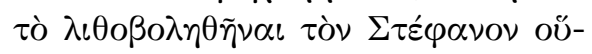

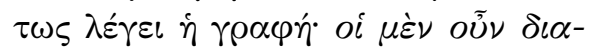

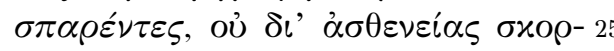

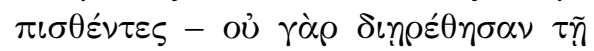

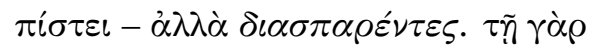

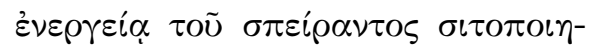

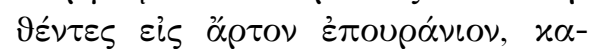

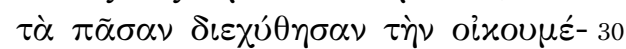

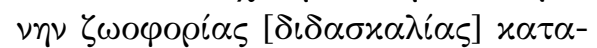

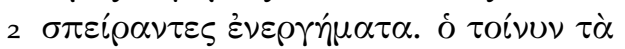

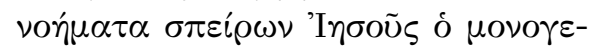

ihn die Sonnenstrahlen stärker und trocknen den Samen aus. Und die Ursache liegt nicht in der Unfruchtbarkeit des Samens, sondern in der Schadhaftigkeit des Bodens. Ein anderes Mal wird der Same in dornigen Boden gesät, und der Same ist zwar fruchtbar, wird aber von den Dornen erstickt, und der ihm innewohnenden Fruchtbarkeit wird es nicht gestattet, Frucht zu tragen wegen 0 der Bedrängung von außen. Falls er aber in den Genuß guten Bodens gelangt, bringt er wiederum nicht in gleichem Maße Frucht, sondern dreißig-, sechzig und hundertfach. Der Same ist eingestaltig, die Frucht aber 5 ist davon unterschieden; unterschiedlich ist aber auch das Erkenntnisvermögen derer, die belehrt werden.

Es ging also der Sämann aus, um zu 3 M. säen, und das eine tat er durch sich selbst, 0 das andere aber bewirkte er durch die Jünger. Du hast auch in den Akten der Apostel geschrieben, daß nach der Steinigung des Stephanus die Schrift folgendermaßen sagt: Die wurden also ausgestreut, nicht durch 5 Schwachheit zerstreut - denn sie wurden nicht im Glauben auseinandergeteilt -, sondern ausgestreut. Denn durch die Kraft dessen, der gesät hatte, wurden sie zu himmlischem Brot gemacht und über die bewohnte Welt ausgegossen und säten so Taten der Lebensspendung aus. Jesus also, der eingeborene Sohn Gottes, der die geistige Erkenntnis aussät, ging durch die Saatfelder,

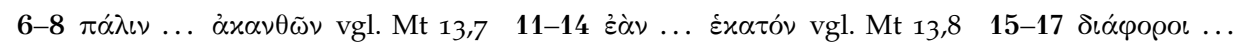
$\delta เ \delta \alpha \sigma \varkappa o \mu \varepsilon ́ v \omega \nu$ vgl. Mt 13,10 18 f. Mt 13,3 24 f. Apg 8,4 27 Apg 8,4

$\mathrm{DN}$

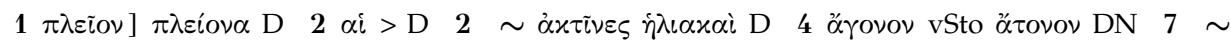

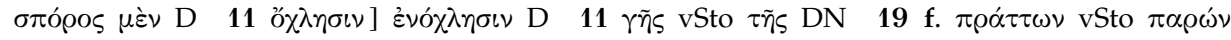

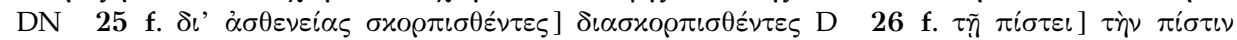

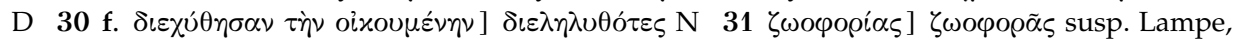
Patristic Greek Lexicon, s.v. $31 \delta\llcorner\delta \alpha \sigma x \alpha \lambda i \alpha \varsigma$ del. vSto (glossa?) $\delta \iota \delta \alpha \sigma \varkappa \alpha \lambda i \alpha \nu$ N 


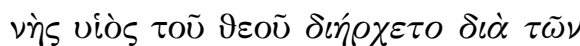

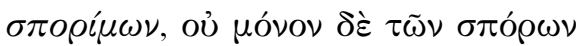

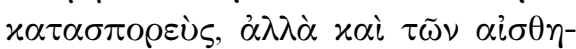

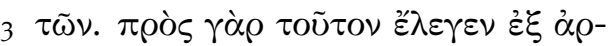

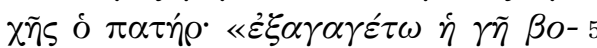

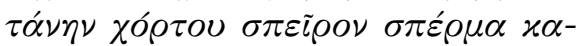

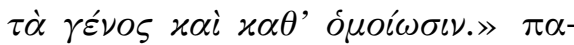

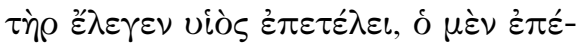

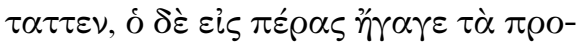

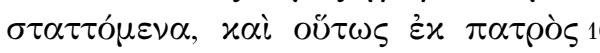

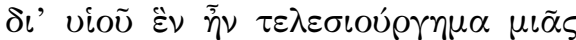

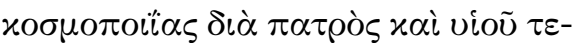

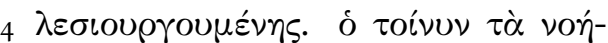

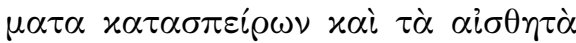

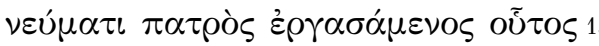

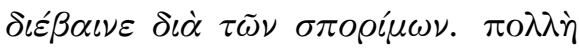

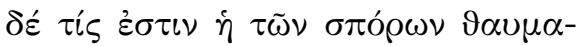

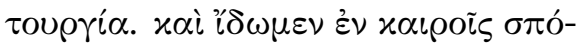

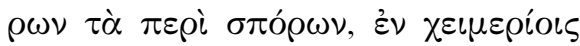

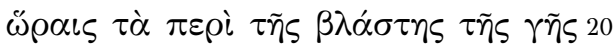

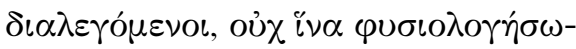

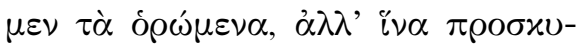

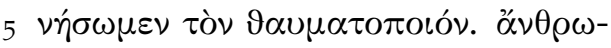

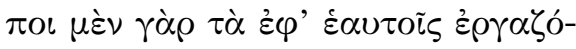

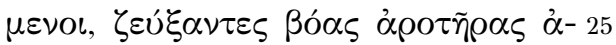

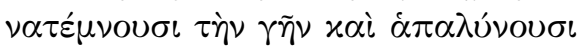

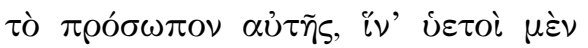
$\mu \grave{n} \pi \alpha \rho \alpha \delta \rho \alpha \dot{\alpha} \mu \omega \sigma \iota, \dot{\alpha} \lambda \lambda \lambda^{\prime} \dot{\varepsilon} \mu \beta \alpha \theta u \nu o ́ \mu \varepsilon-$

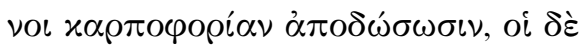

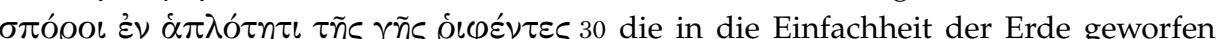

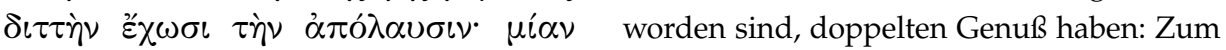

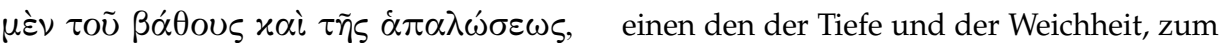

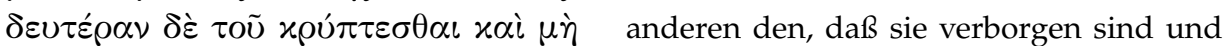

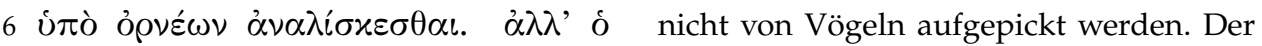

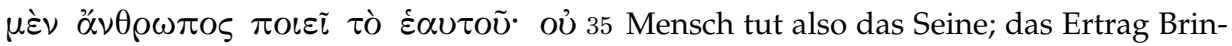

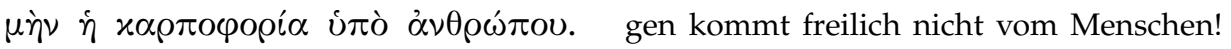

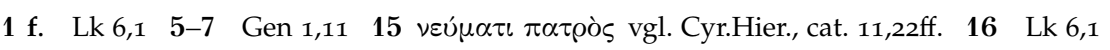

$\mathrm{DN}$

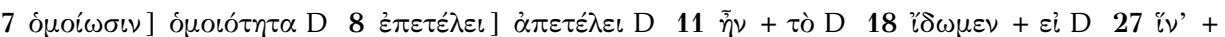

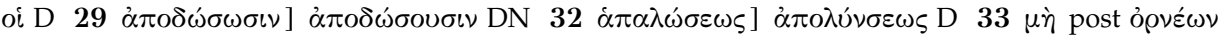
$\mathrm{D}$

Aussäer nicht nur der Saat, sondern auch der wahrnehmbaren Dinge. $\mathrm{Zu}$ ihm sagte nämlich von Anfang an der Vater: "Die Erde soll hervorbringen eine Weide von Futter, säenden Samen je nach Art und nach Ähnlichkeit.« Der Vater sprach, der Sohn führte es aus, der eine ordnete es an, der andere aber führte das Angeordnete bis zum Ende durch. Und so war es aus dem Vater Weltschöpfung, der durch Vater und Sohn vollendet wurde. Derjenige also, der die geistig wahrnehmbaren Dinge aussät und die sinnlich wahrnehmbaren auf einen Wink Aussaat das betrachten, was die Samen betrifft, indem wir in den winterlichen Zeiten de bert, nas das Wachstum der Ernaturkundlich untersuchen, sondern damit wir den Wundertäter anbeten. Denn wenn Menschen das arbeiten, was an ihnen selbst liegt, schneiden sie, nachdem sie Pflugstiere chen ihre Oberfläche, damit die Regengüsse nicht vorbei laufen, sondern in die Tiefe gehen und so Frucht geben, die Samen aber, 


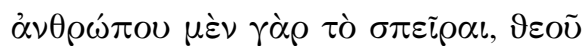

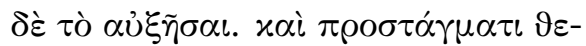

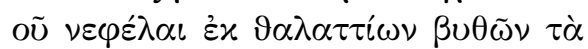

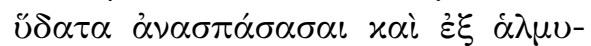

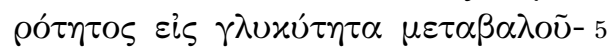

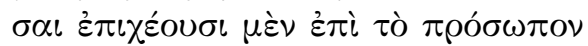

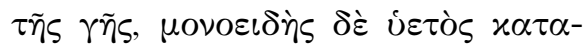

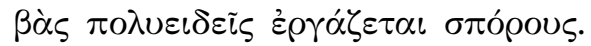

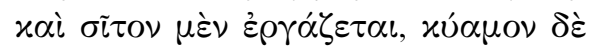

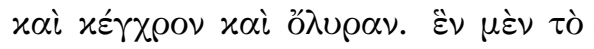

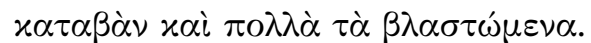

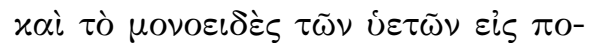

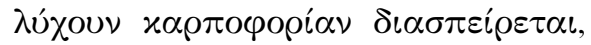

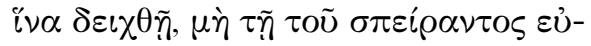

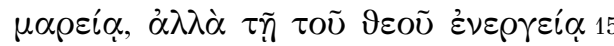

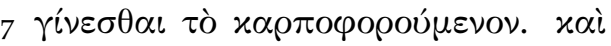

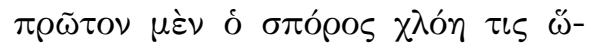

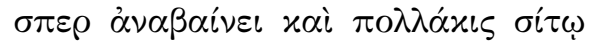

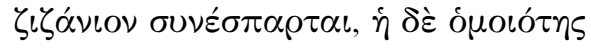

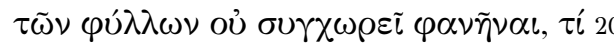

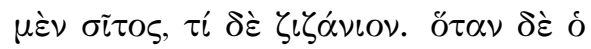

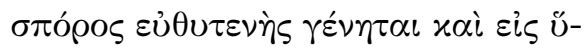

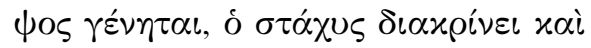

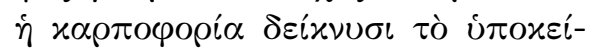

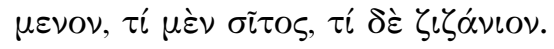

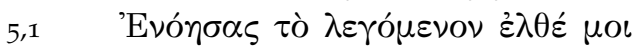

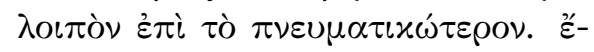

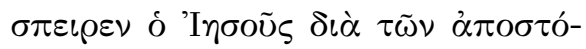

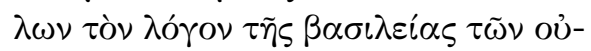

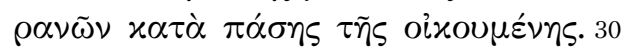

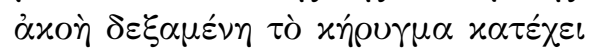

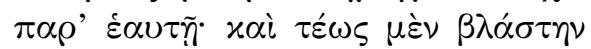

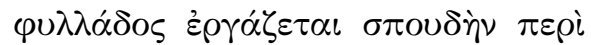

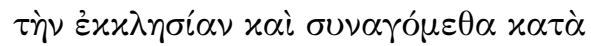

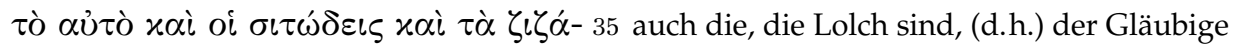

Des Menschen ist das Säen, Gottes aber das Wachsenlassen. Und auf Befehl Gottes ziehen Wolken aus den Meerestiefen das Wasser empor, verwandeln es aus salzigem in süßes (Wasser) und gießen es dann auf die Oberfläche der Erde; der Regen aber, der in einer Gestalt herabgeht, bewirkt dann vielgestaltige Samen. Und er macht Getreide, Bohnen, Hirse und Dinkel. Es ist eines, was herabkommt und vieles, was sproßt. Und das Eingestaltige des Regens wird zu vielfältiger Frucht ausgesät, damit gezeigt werde, daß nicht durch die Gewandtheit des Säenden, sondern durch die Wirkkraft Gottes das Frucht Tragen geschieht. Und zuerst tritt der Samen wie ein Gras hervor, und oftmals wird mit dem Getreide Lolch ausgesät, und die Gleichheit der Blätter läßt es nicht zu, daß deutlich zu Tage tritt, was 20 Getreide und was Lolch ist. Wenn aber der Sprößling sich aufrichtet und in die Höhe wächst, läßt die Ähre eine Unterscheidung zu und die Frucht zeigt was zugrunde liegt, was Getreide und was Lolch ist. 25

Wenn du das Gesagte begriffen hast, 4 M. schreite mit mir nun noch zum geistlicheren Sinn. Jesus säte durch die Apostel das Wort vom Himmelreich in der gesamten bewohn0 ten Welt. Das Gehör empfängt die Botschaft und behält sie dann bei sich; und bis zum Sprießen eines Blattes ist es mit Eifer um die Kirche bemüht, und wir versammeln uns einmütig: sowohl die Getreideartigen als

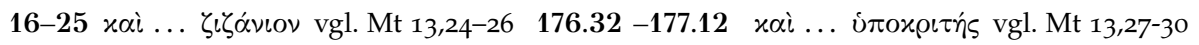
DN

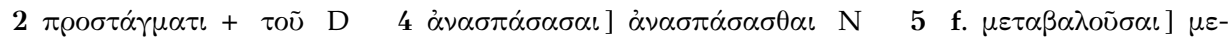

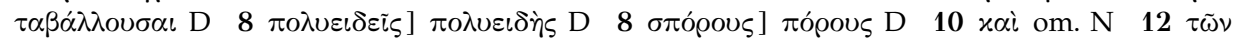

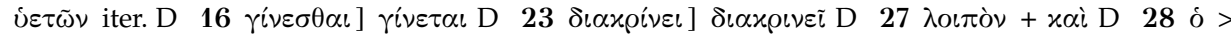

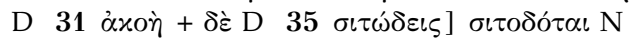




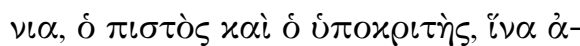

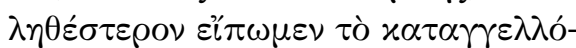

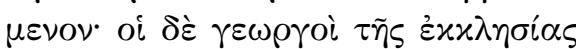

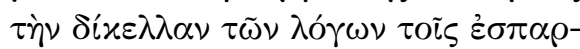

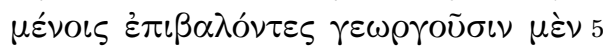

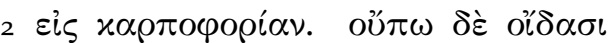

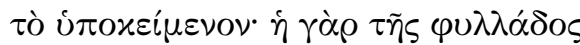
ó $\pi \rho 0 \varepsilon \sigma \tau \tilde{\omega} \tau \alpha \varsigma$. Oั $\tau \alpha \nu \delta \dot{\varepsilon} \dot{\eta} \delta \iota \delta \alpha \sigma x \alpha \lambda i \alpha$

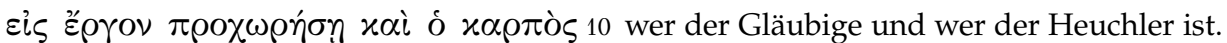

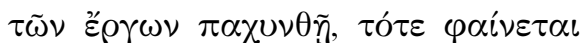

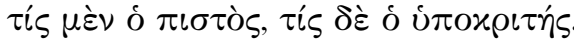

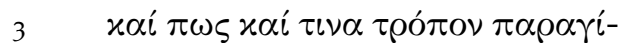

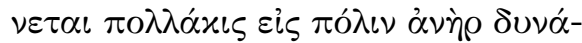

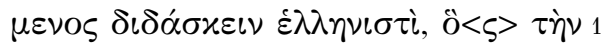

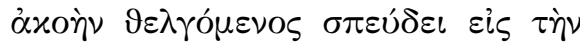

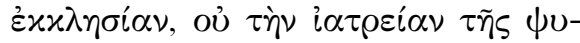

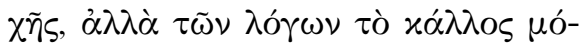

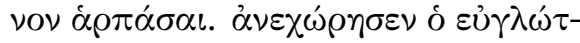

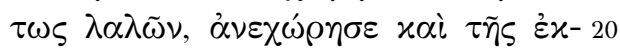

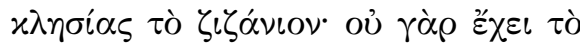

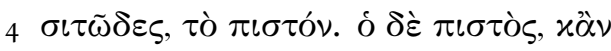

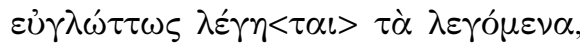

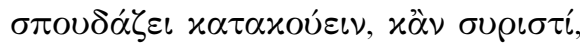

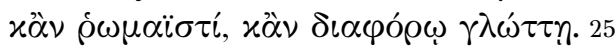

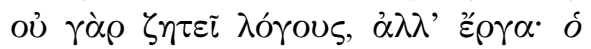

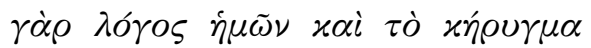

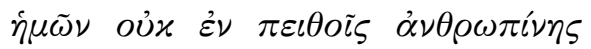

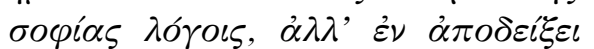

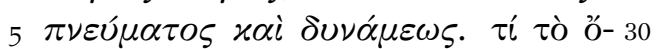

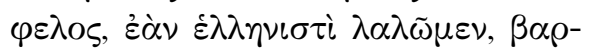

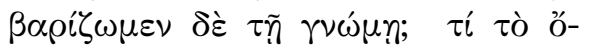

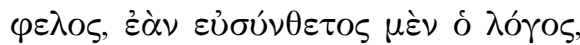

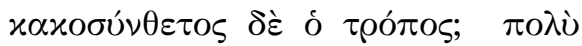

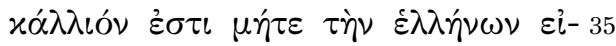

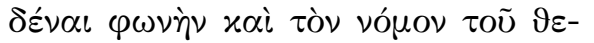

26-30 1 Kor 2,4

$\mathrm{DN}$

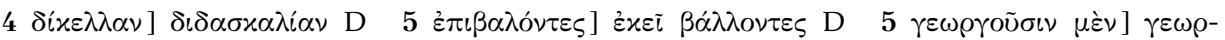

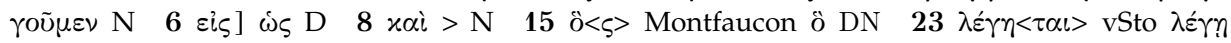
DN 31 f. $\beta \alpha \rho \beta \alpha \rho i \zeta \omega \mu \varepsilon \nu] ~ \beta \alpha \rho \beta \alpha \rho i \zeta o \mu \varepsilon \nu N$ und der Heuchler, damit wir das GemeinKirche bearbeiten mit der Hacke des Wortes die Ausgesäten und bestellen sie, damit sie Frucht bringen. Noch kennen sie aber die Substanz nicht; denn die Ähnlichkeit des Blattes täuscht oft auch die Vorsteher. Wenn aber die Lehre zum Werk schreitet und die Frucht der Arbeit reif wird, dann wird klar, Und irgendwie und auf irgendeine Weise kommt oftmals ein Mann in eine Stadt, der griechisch lehren kann, der das Gehör bezaubert und in die Kirche eilt, nicht um die Heilung der Seele, sondern nur um die Schönheit der Worte zu ergreifen. Ist der, der mit geübter Zunge redet, hinausgegangen, ist auch der Lolch der Kirche hinausgegangen; denn er hat nichts Getreidehaftes an sich, nichts Gläubiges. Der Gläubige aber, selbst wenn das Gesagte mit geübter Zunge gesprochen wird, bemüht sich, genau hinzuhören, sei es syrisch, sei es lateinisch, sei es in irgendeiner anderen Sprache. Denn er sucht nicht Worte, sondern Werke. Denn unsere Rede und unsere Botschaft liegen nicht in überzeugenden Worten menschlicher Weisheit, sondern im Aufweis des Geistes und der Kraft. Was ist der Nutzen, wenn wir griechisch reden, aber in unserer Gesinnung barbarisch sind? Was ist der Nutzen, wenn die Rede wohlgefügt, der Charakter aber schlecht zusammengefügt ist? Denn viel schöner ist es, die Sprache der te richtiger benennen. Und die Bauern der 


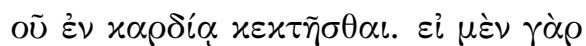

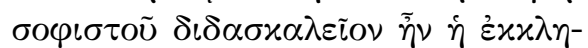

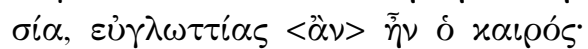

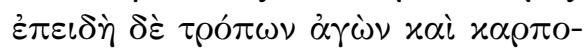

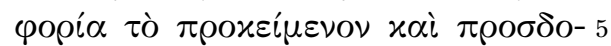

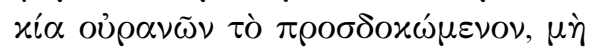
$\gamma \lambda \tilde{\omega} \tau \tau \alpha \zeta \eta \tau \varepsilon i \sigma \theta \omega, \dot{\alpha} \lambda \lambda \lambda^{\prime} \dot{o} \tau \rho o ́ \pi \circ \varsigma$ $\varkappa \alpha-$

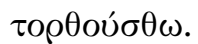

6

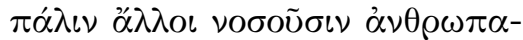


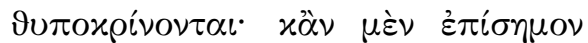
$\pi \rho o ́ \sigma \omega \pi \sigma \nu \grave{\eta} \varepsilon \dot{\varepsilon} x \pi \lambda \alpha \tau \varepsilon i \tilde{\omega} \nu \grave{\eta} \dot{\varepsilon} \xi \alpha \nu-$

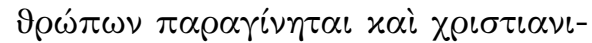

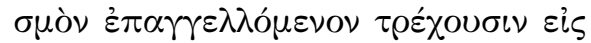
$\tau \grave{\eta} \nu \dot{\varepsilon} x \alpha \lambda \eta \sigma i \alpha \nu, i \nu \alpha \dot{\alpha} \nu \theta \rho \omega \pi \omega \delta \varepsilon i \xi \omega \sigma \iota 15$

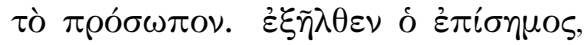

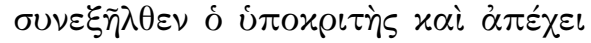

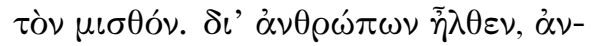

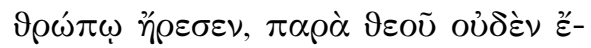

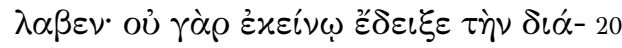

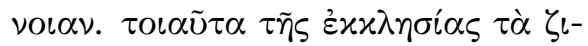

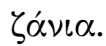

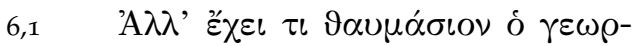

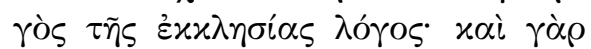

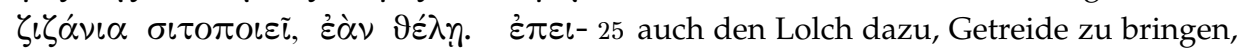

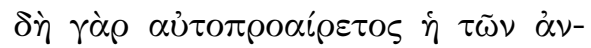

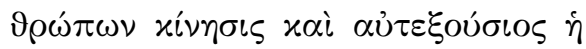

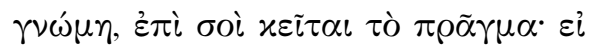

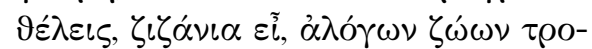

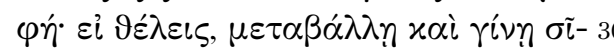

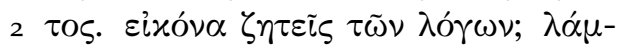

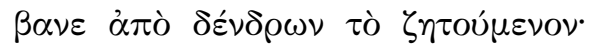

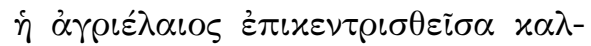

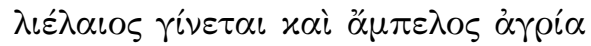

Griechen nicht zu kennen, das Gesetz Gottes aber im Herzen zu haben. Denn wenn die Kirche eine Sophistenschule wäre, wäre sie der rechte Ort für Zungenfertigkeit. Da es aber um den Kampf um den Charakter und um das Fruchtbringen geht und da das, was erwartet wird, die Erwartung der Himmel ist, soll nicht Sprache gesucht, sondern der Charakter gerade gerichtet werden.

Andere wiederum kranken an der Sucht, anderen Menschen zu gefallen, und deuten den rechten Zeitpunkt nicht richtig; auch wenn ein von den Plätzen oder von den Menschen bekanntes Gesicht kommt und das Christentum verkündet, laufen sie 5 in die Kirche, damit sie einem Menschen ihr Gesicht zeigen. Geht dann der Berühmte hinaus, geht auch der Heuchler mit hinaus und erhält seinen Lohn. Wegen der Menschen kam er und gefiel einem Menschen, 20 von Gott hat er nichts erhalten; denn jenem zeigte er nicht seine Gesinnung. Solches ist der Lolch der Kirche.

Doch das bäuerliche Wort der Kirche $5 \mathrm{M}$. hat etwas Wunderbares: es bringt nämlich wenn es will. Denn da ja die Bewegung der Menschen aus eigenem Willen geschieht und die Gesinnung selbstbestimmt ist, liegt die Sache an dir; wenn du willst, bist du Lolch, die Nahrung unvernünftiger Tiere; wenn du willst, verwandelst du dich und wirst Getreide. Du suchst ein Bild für meine Worte? Nimm das gesuchte (Bild) von den Bäumen! Der wilde Ölbaum wird, wenn

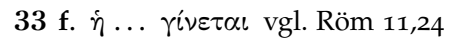

$\mathrm{DN}$

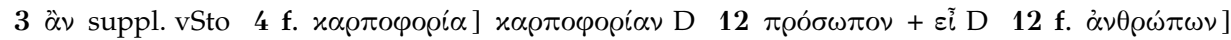

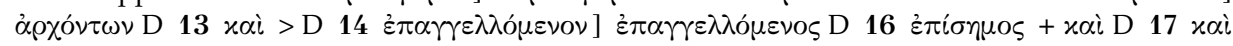

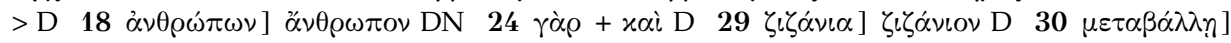

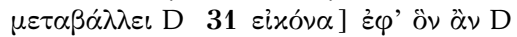




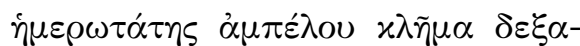

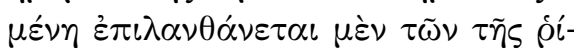

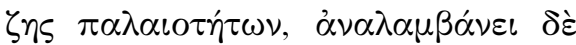

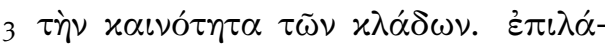

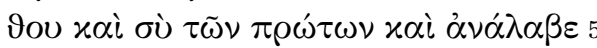

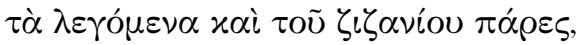

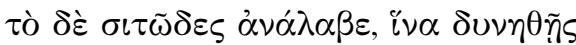

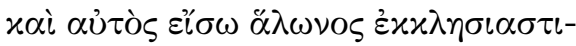

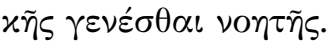

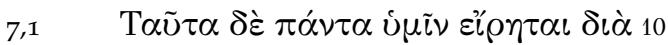

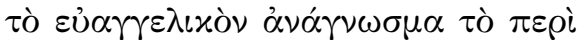

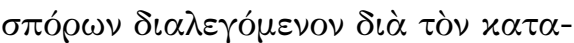
$\sigma \pi \varepsilon i \rho \alpha \nu \tau \alpha$ हे $\tau \alpha \tilde{i} \varsigma \psi v \chi \alpha \tilde{i} \varsigma, \tau \tilde{\omega} \nu \psi v-$

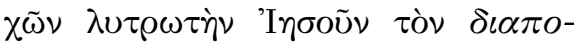

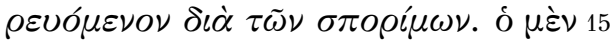

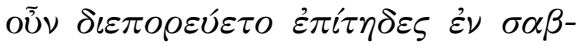

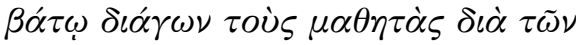

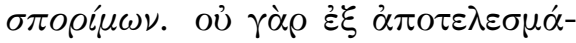

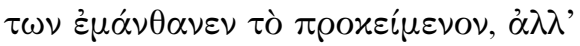

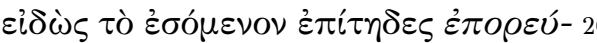
$\varepsilon \tau o \delta \iota \grave{\alpha} \tau \tilde{\omega} \nu \sigma \pi o \rho i \mu \omega \nu$.

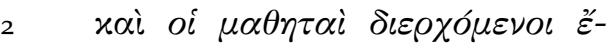

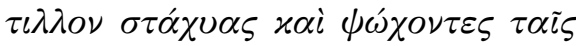

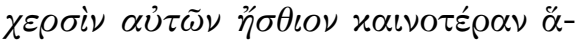

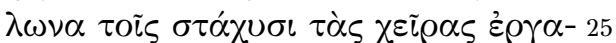

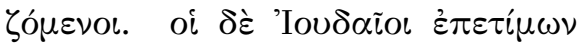

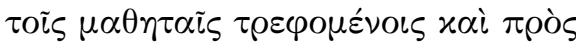

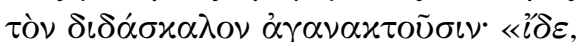

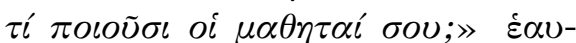

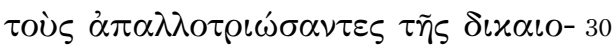

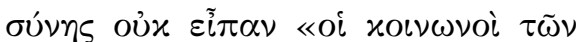

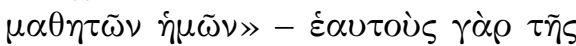

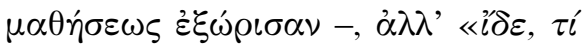
$\pi \circ \iota 0 \tilde{\sigma} \sigma \nu$ oi $\mu \alpha \theta \eta \tau \alpha i$ $\sigma o v . » \delta \varepsilon \iota \varkappa \nu \cup ́-$

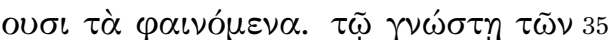

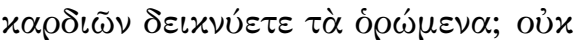

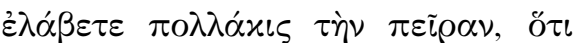

er gepfropft wird, ein veredelter Ölbaum, und ein wilder Wein vergißt, wenn er eine Rebe eines ganz milden Weines annimmt, den alten Zustand der Wurzel und nimmt die Neuheit der Zweige an. Vergiß auch du das Frühere, nimm das Gesagte an und laß den Lolch sein, was Getreide bringt aber nimm an, damit auch du selbst in die geistige kirchliche Tenne hineinkommen kannst.

Das alles wird euch durch die Evan- $6 \mathrm{M}$. gelienlesung gesagt, die über die Samen spricht wegen dessen, der in den Seelen sät, den Erlöser der Seelen, Jesus, der durch die Saatfelder geht. Der ging also absichtlich am Sabbat durch die Saatfelder und führte die Jünger hindurch; denn nicht aus der Vollendung lernte er (im Nachhinein) den gegenwärtigen Zustand, sondern weil er die Zukunft kannte, ging er absichtlich durch die Saatfelder.

Und die Jünger gingen hindurch, rauften Ähren aus, zerrieben sie mit ihren Händen und aßen sie, indem sie ihre Hände zu einer ziemlich neuartigen Tenne für die Ähren machten. Die Juden aber tadelten die Jünger, die sich nährten, und äußerten ihren Unwillen gegenüber dem Lehrer: »Siehe, was deine Jünger tun!« Weil sie sich selbst der Gerechtigkeit entfremdet hatten, sagten sie nicht: »die Genossen unserer Jünger « denn sich selbst haben sie aus der Jüngerschaft verbannt -, sondern "sieh, was deine Jünger tun«. Sie zeigen das Offensichtliche. Dem Kenner der Herzen zeigt ihr das Gesehene? Habt ihr nicht oftmals den Beweis erhalten, daß er auch die Gedanken der Her-

14 f. Lk 6,1 16-18 Lk 6,1 22-24 Lk 6,1 28 f. Mt 12,2 33 f. Mt 12,2

$\mathrm{DN}$

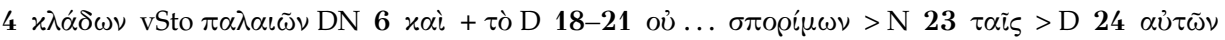

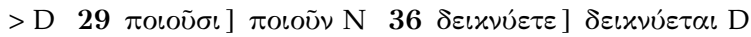




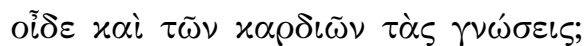

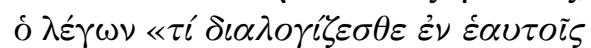

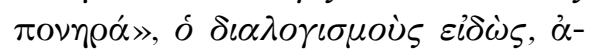

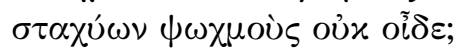

$$
<\ldots>
$$

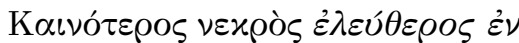

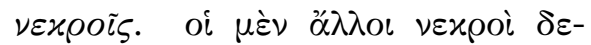

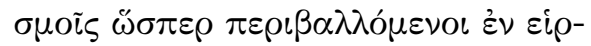

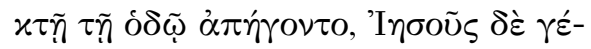

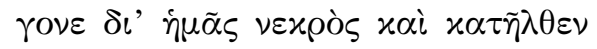

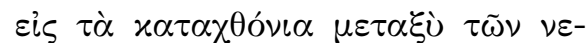

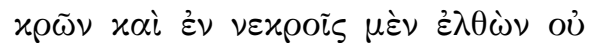

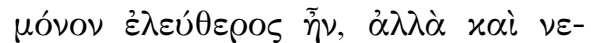

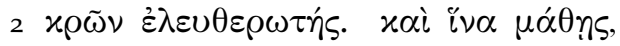

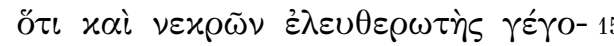

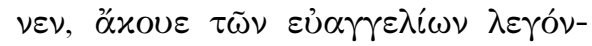
$\tau \omega \nu \cdot \ll \varkappa \alpha i \quad \pi o \lambda \lambda \dot{\alpha} \sigma \omega \mu \alpha \tau \alpha \tau \tilde{\omega} \nu$ $\varkappa \varepsilon-$

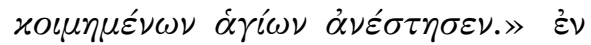

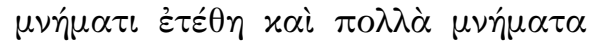

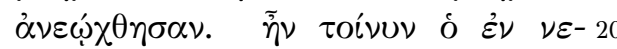

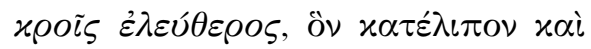

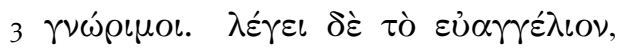

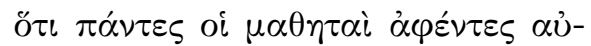

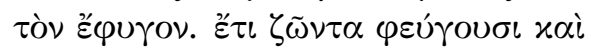

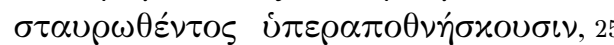

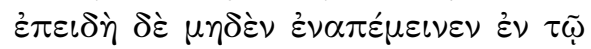

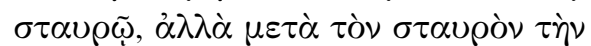

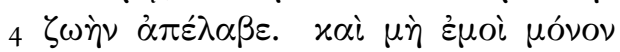

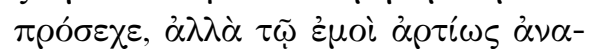

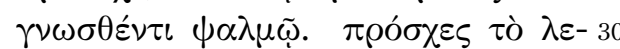

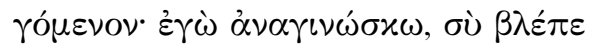

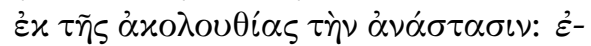

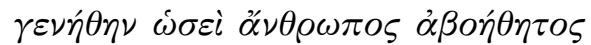

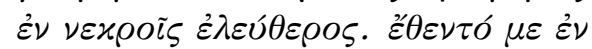

zen kennt? Der, der sagte: »Was redet ihr unter euch Schlechtes?«, der, der Unterredungen kennt, weiß nichts vom Zerreiben der Ähren?

$5<\ldots>$

Ein recht außerordentlicher Toter ist frei $7 \mathrm{M}$. unter den Toten. Die anderen Toten wurden gleichsam mit Fesseln gefesselt auf einem eingezäunten Weg weggeführt, Jesus aber 0 wurde unseretwegen ein Toter und stieg in die Unterwelt zwischen den Toten hinab und ging unter den Toten und war nicht nur frei, sondern auch Befreier der Toten. Und damit du lernst, daß er auch der Befreier 5 der Toten wurde, höre die Evangelien sagen: Und viele Leiber der entschlafenen Heiligen hat er erweckt. Er wurde in ein Grab gelegt und viele Gräber wurden geöffnet. Er war also der Freie unter den Toten, den auch die Schüler verließen. Es sagt aber das Evangelium, daß alle Jünger ihn im Stich ließen und flohen. Als er noch lebte, flohen sie, und nachdem er gekreuzigt war, da sterben sie für den Gekreuzigten, da ja nichts an 5 dem Kreuz (hängen) blieb, sondern nach dem Kreuz das Leben empfing. Und höre nicht nur auf mich, sondern auf den eben von mir vorgelesenen Psalm! Achte auf das Gesagte; ich lese es, erkenne du aus der Rei30 henfolge der Worte die Auferstehung: »Ich wurde wie ein unbekannter Mensch unter den Toten frei. Sie legten mich in die unterste Grube«, wie wir sagten. Und danach: »Ich aber bin in meinem Gebet bei dir, Herr «

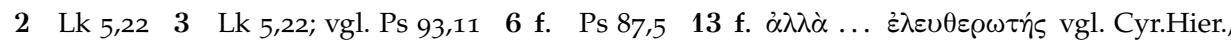

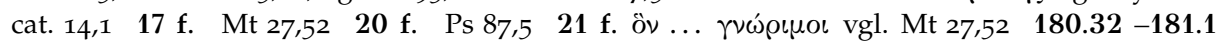
Ps $87,5 \cdot 7$

$\mathrm{DN}$

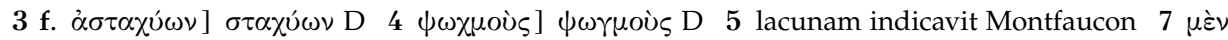

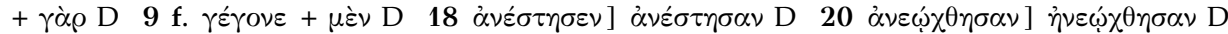

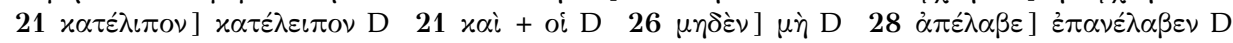

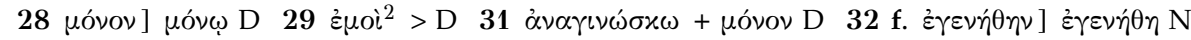




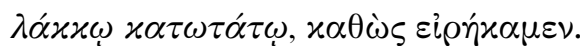

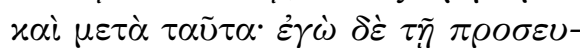
$\chi \tilde{n} \mu o v \pi \rho \grave{\zeta} \sigma \dot{\varepsilon}$, $\dot{\eta} \pi \rho \circ \sigma \varepsilon v \chi \dot{\eta} \mu о \nu \pi \rho \circ \varphi \theta \dot{\alpha} \sigma \varepsilon l \sigma \varepsilon . \quad \delta$

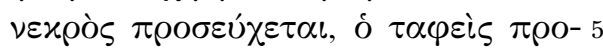

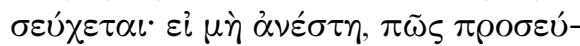

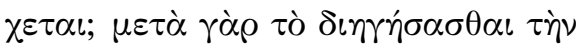

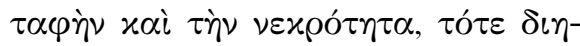

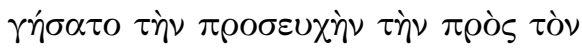

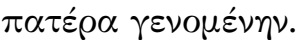

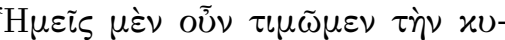


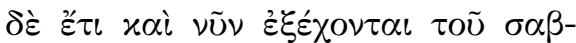

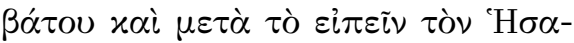
$\dddot{\imath} \alpha \nu \cdot \ll \alpha i \grave{\imath} \sigma \alpha \dot{\alpha} \beta \beta \alpha \tau \alpha \dot{v} \mu \tilde{\omega} \nu \mu \iota \sigma \varepsilon \tilde{\imath} \dot{\eta}$

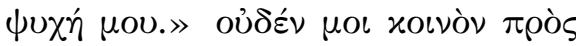

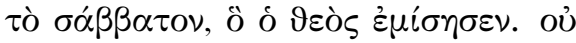

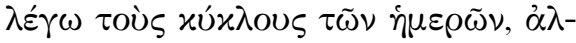

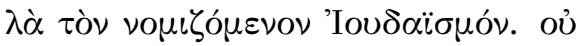

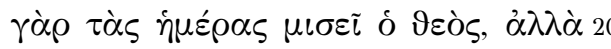

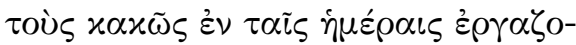

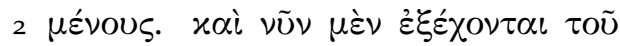

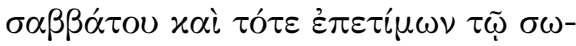

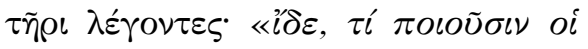

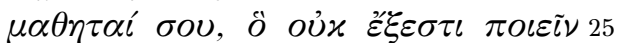

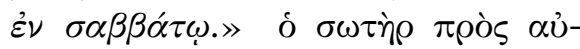

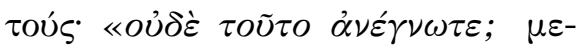

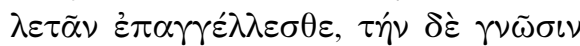

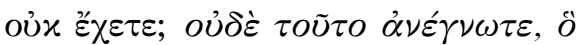

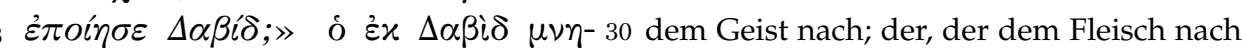

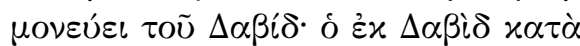

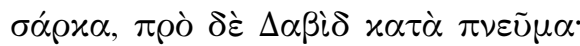
o $x \alpha \tau \grave{\alpha} \sigma \alpha ́ \rho x \alpha \mu \dot{\nu} \nu \tau o \tilde{v} \Delta \alpha \beta i \delta$ viós,

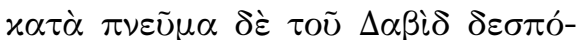

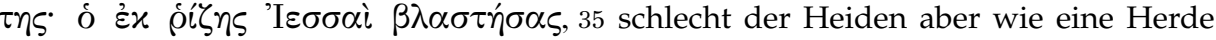

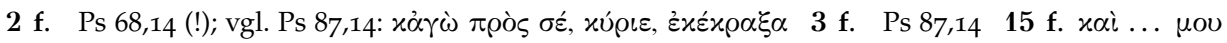
vgl. Jes 1,13 f. 24-26 Lk 6,3 $27 \quad$ Lk 6,3 29 f. $\quad$ Lk 6,3

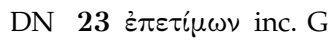

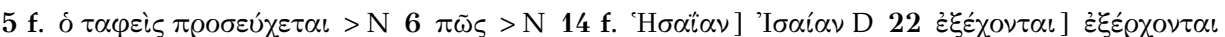

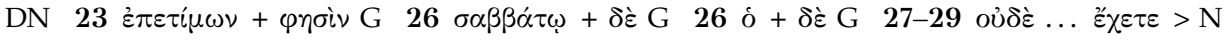
$34 \sim \delta \varepsilon \grave{\pi} \pi \nu \tilde{u} \mu \alpha \mathrm{G}$

und »dem Morgen möge mein Gebet zu dir zuvorkommen«. Der Tote betet; der Bestattete betet; wenn er nicht auferstanden ist, wie betet er? Denn nachdem er die Bestattung und den Tod berichtet hatte, dann erst berichtet er über das Gebet zum Vater.

Wir also ehren den Herrentag wegen $8 \mathrm{M}$. der Auferstehung, die Juden aber hängen auch jetzt noch am Sabbat, selbst nachdem Jesaja gesagt hat: »Und eure Sabbate haßt nannten Judaismus. Denn nicht die Tage haßt der Herr, sondern die, die an den TaSabbat und damals tadelten sie den Heiland und sagten: "Sieh, was tun deine Jünger, was man am Sabbat nicht tun darf.« Der Heiland zu ihnen: »Habt ihr das nicht gelesen? Ihr verkündet, euch zu sorgen, habt abe keine Erkenthis? Habt ihr das nicht Davids gedenkt Davids, der, der nach Dazwar Sohn Davids war, dem Geist nach aber Herr Davids; der, der aus der Wurzel Jesse sproßte, der wunderbare Stab, der das Geschlecht der Juden zerschmettert, das Ge-

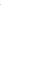
. 


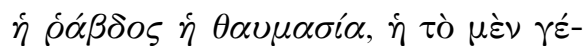

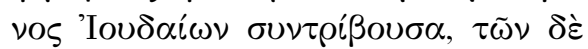

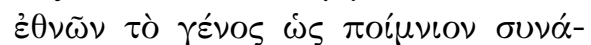

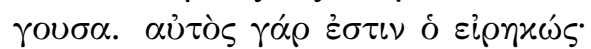

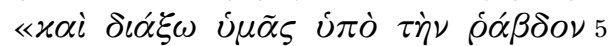

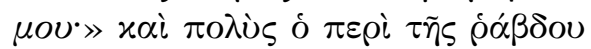

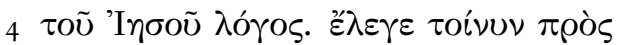

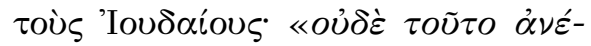

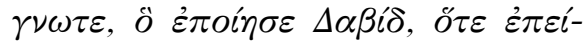

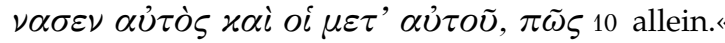

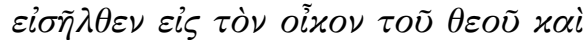

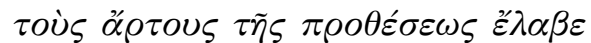

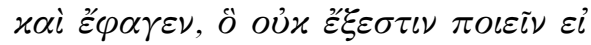

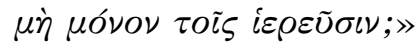

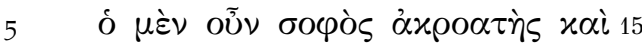

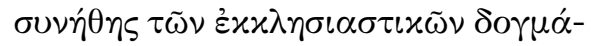

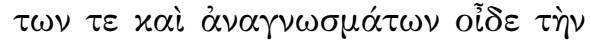

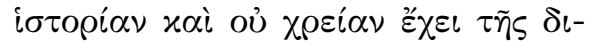

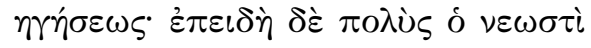

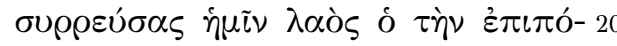

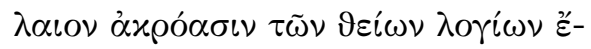

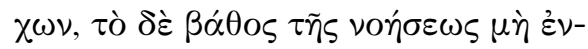

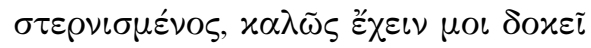

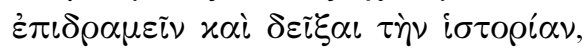
allein.» zusammenführt. Denn er selbst ist es, der sagt: "Und ich werde euch unter meinen Stab hinüberführen «; und zahlreich sind die Worte Jesu über den Stab. Er sagte also zu den Juden: »Habt ihr auch das nicht gelesen, was David tat, als er und seine Leute Hunger hatten? Wie er in das Haus Gottes hineinging und die Schaubrote nahm und aß, was keiner tun darf außer die Priester

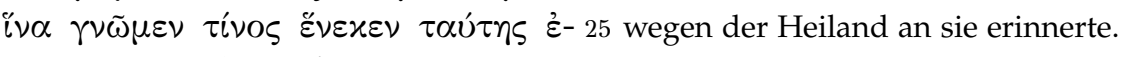

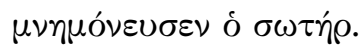

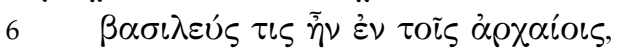

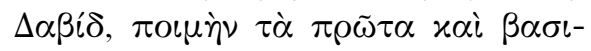

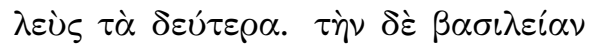
oủx ع́ $\lambda \alpha \beta \varepsilon \nu \dot{\alpha} \rho \pi \alpha ́ \sigma \alpha \varsigma, \dot{\alpha} \lambda \lambda \dot{\alpha} \tau o \tilde{u} \Sigma \alpha-30$ dem er sie geraubt hatte, sondern, nachdem

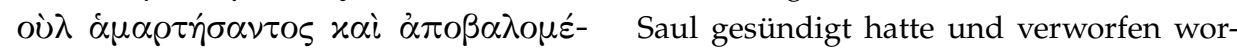

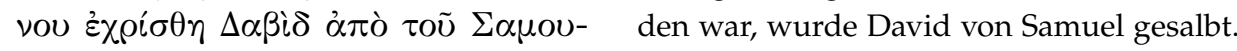

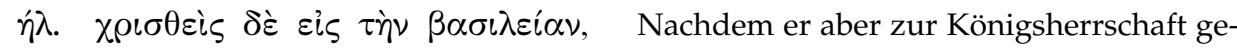

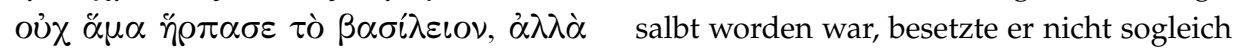

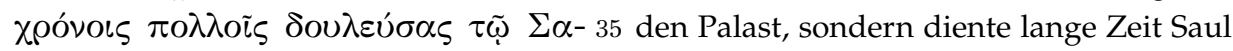

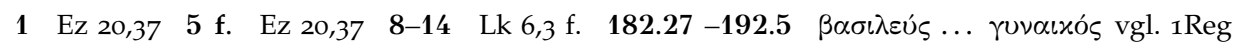
$16-18.20,24-21,7$

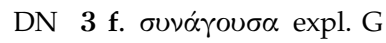

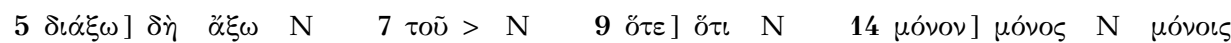

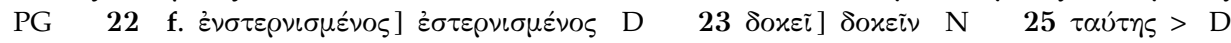

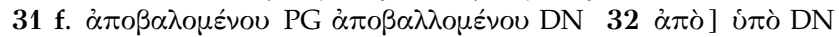




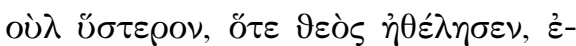

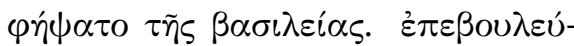

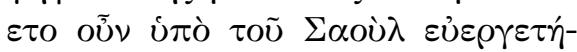

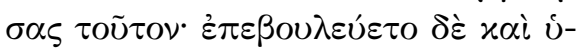

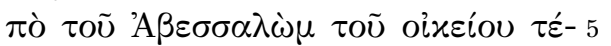
xของ.

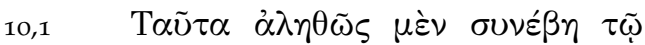

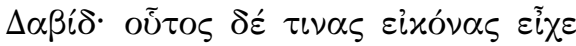

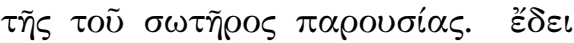

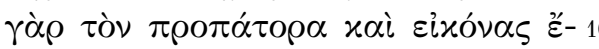

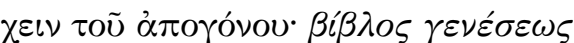

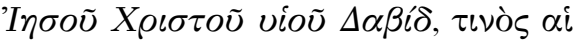

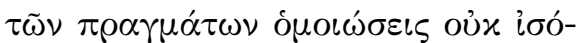

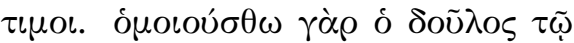

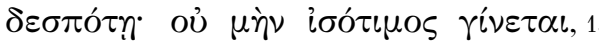

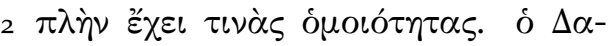

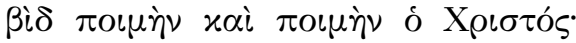

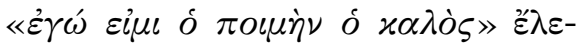

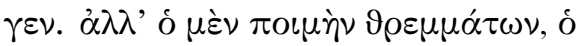

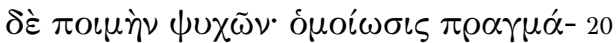
$\tau \omega \nu, \pi 0 \lambda \lambda \dot{\eta} \delta \varepsilon \dot{\varepsilon} \pi \alpha \rho \alpha \lambda \lambda \alpha \gamma \grave{\eta} \tau o \tilde{u} \alpha \xi \xi \omega^{\prime}-$

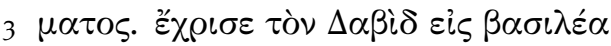

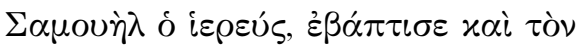

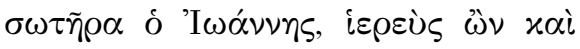

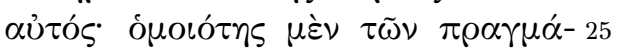
$\tau \omega \nu, \pi \circ \lambda \lambda \grave{\eta} \delta \varepsilon \dot{\varepsilon} \delta\llcorner\alpha \varphi \circ \rho \grave{\alpha} \tau \tilde{\omega} \nu$ i $\pi 0 x \varepsilon \iota-$

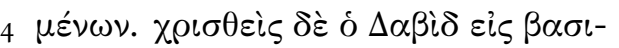

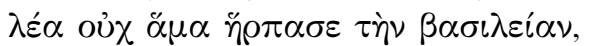

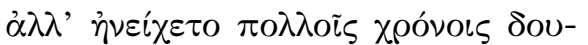

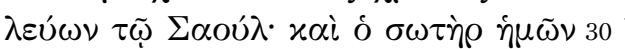
$\gamma \varepsilon \nu \nu \eta \theta \varepsilon i \varsigma s \beta \alpha \sigma \lambda \varepsilon \dot{\jmath} \varsigma \pi \rho \grave{~} \tau \tilde{\omega} \nu \alpha i \omega \nu \omega \nu$

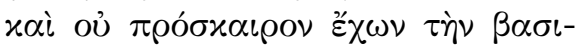
$\lambda \varepsilon i \alpha \nu, \dot{\alpha} \lambda \lambda \lambda \dot{\alpha} \pi \rho o ̀ ~ \pi \alpha ́ \nu \tau \omega \nu ~ \alpha i \omega ́ \omega \omega \nu \beta \alpha-$

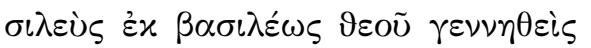

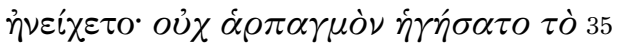

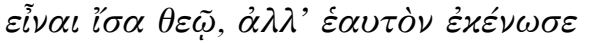
11 f. Mt 1,1 18 Joh 10,11 183.35 -184.1 Phil 2,6 f.

\section{DN}

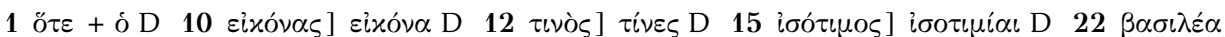

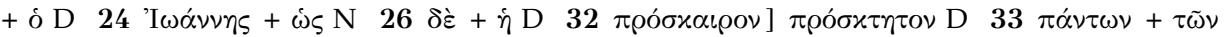
$\mathrm{N}$ und ergriff erst später die Königsherrschaft, als Gott es wollte. Es wurde ihm also von Saul nachgestellt, dem er Gutes getan hatte; es wurde ihm aber auch von Absalom nachgestellt, seinem eigenen Sohn.

Das widerfuhr wirklich David; der aber $9 \mathrm{M}$. hatte einige Bilder für das Kommen des Heilands. Denn es mußte der Vorvater auch Bilder des Nachkommen haben: Buch des Werdens Jesu Christi, des Sohnes Davids. Die sachlichen Ähnlichkeiten sind nicht gleichwertig. Denn es soll der Diener mit dem Herrn verglichen werden; freilich ist er nicht gleichwertig, doch er hat einige Ähnlichkeiten. David war Hirte und Hirte war Christus: »Ich bin der gute Hirte« sagte er. Doch der eine ist Hirte von Tieren, der andere Hirte von Seelen. Eine sachliche Ähnlichkeit, aber ein großer Unterschied in der Ehre. Es salbte aber David zum König der Priester Samuel, und es taufte den Heiland Johannes, auch er ein Priester; eine sachliche Ähnlichkeit, aber ein großer Unterschied in den Substanzen. Nachdem aber David zum König gesalbt worden war, riß er nicht zugleich die Königsherrschaft an sich, sondern wartete lange Zeit und diente Saul; und unser Heiland wurde als König vor den Zeiten geboren und hatte die Königsherrschaft nicht augenblicklich, sondern wartete, obwohl er vor allen Zeiten als König vom König Gott geboren wurde: Er hielt es nicht für einen Raub, Gott gleich zu sein, sondern entäußerte sich selbst und nahm Knechtsgestalt an, damit er die Heilsordnung vollende. Saul 


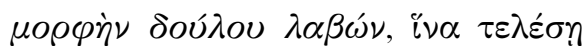

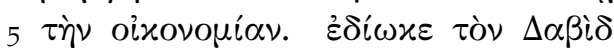

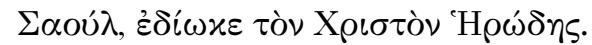

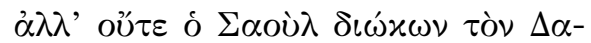

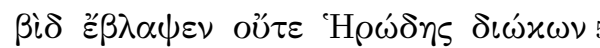

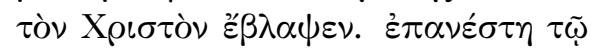

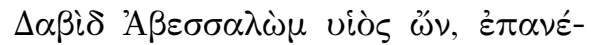

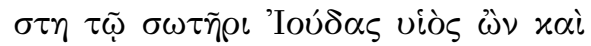

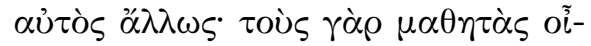

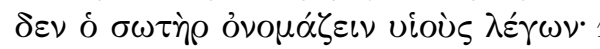

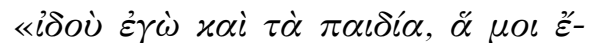

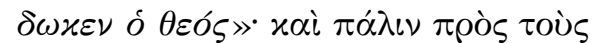

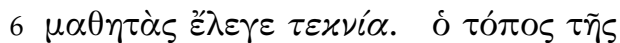

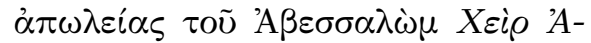

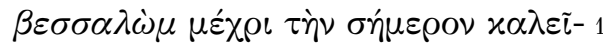

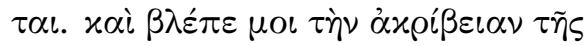

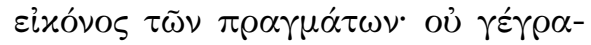

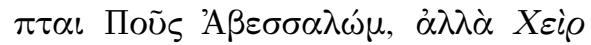

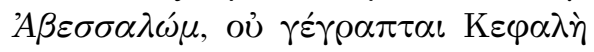

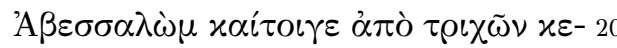

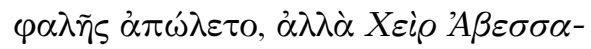
$\lambda \omega \mu . \quad \pi \rho \omega \dot{\tau} \eta \eta \dot{\alpha} \rho \tilde{\eta} \nu \dot{\eta} \tau \tilde{\eta} s \quad x \varepsilon \varphi \alpha \lambda \tilde{\eta} s$

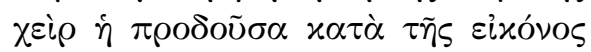

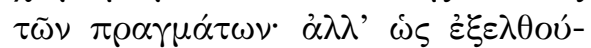

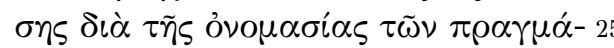

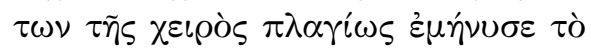

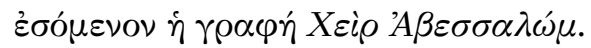

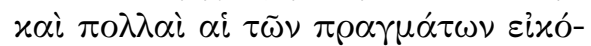

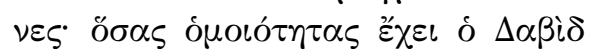

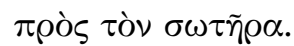

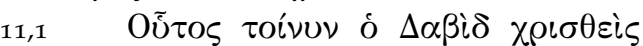

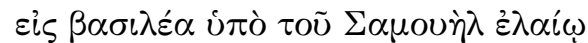

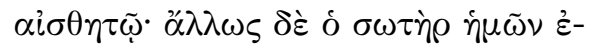

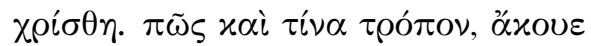

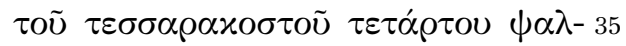

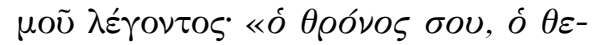
... 'А $\beta \varepsilon \sigma \sigma \alpha \lambda \omega \mu$ vgl. Lk 22,21 $27 \quad{ }_{2} \operatorname{Reg} 18,18 \quad 184.36-185.7 \quad$ Ps $44,7 \mathrm{f}$.

DN

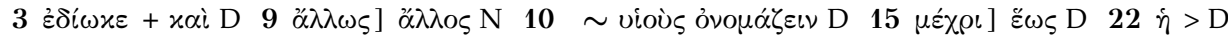

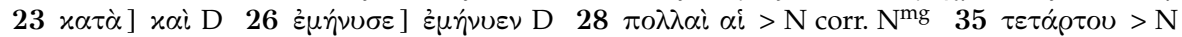

verfolgte David, den Christus verfolgte Herodes. Doch weder schädigte Saul David, als er ihn verfolgte, noch schädigte Herodes Christus, als er ihn verfolgte. Es erhob sich gegen David Absalom, obwohl er sein Sohn war; es erhob sich gegen den Heiland Judas, obwohl auch er ein Sohn war, (freilich) auf andere Weise; denn die Jünger pflegte der Heiland Söhne zu nennen, indem er sagte: 0 "Siehe, ich und die Kinder, die mir Gott gegeben hat.« Und wiederum sagte er zu den Jüngern: »Kinder«. Der Ort, an dem Absalom zugrundeging, wird bis heute Hand Absaloms « genannt. Nun schau mir die Genauigkeit des Bildes für die Ereignisse an! Es steht nicht geschrieben »Fuß Absaloms", sondern »Hand Absaloms«; es steht nicht geschrieben "Haupt Absaloms «, obwohl er an den Haaren seines Kopfes zugrundeging, sondern »Hand Absaloms«. Denn als erstes war es die Hand, die zum Kopf gehört, die Verrat übte gemäß dem Abbild der Sache; aber da ja die Hand wegen der Benennung der Sache es vollbringen sollte, zeigte die Schrift versteckt die Zukunft: "Hand Absaloms«. Es gibt viele Abbilder der Ereignisse; so viele Ähnlichkeiten hat David mit dem Heiland!

Dieser David nun wurde von Samuel $10 \mathrm{M}$. mit sichtbarem Öl zum König gesalbt; anders aber wurde unser Heiland gesalbt. Wie und auf welche Art? Höre den 44. Psalm sagen: »Dein Thron, Gott, in alle Ewigkeiten; ein Stab der Rechtschaffenheit ist der 


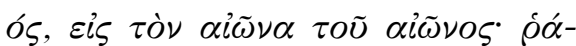

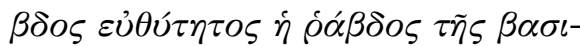

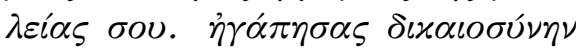

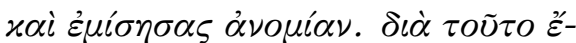

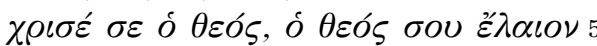

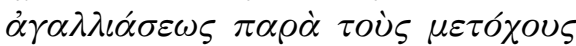

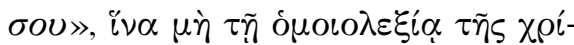

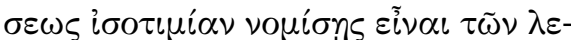

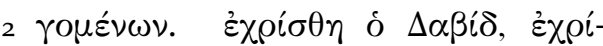

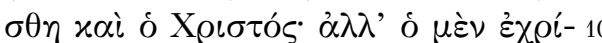

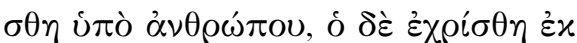

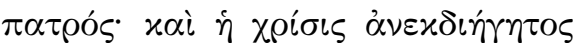

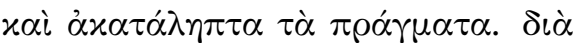

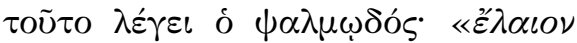

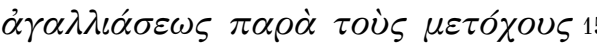

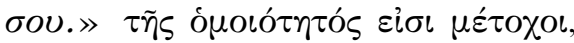

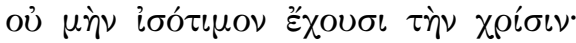

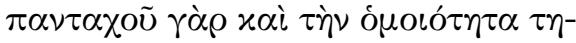

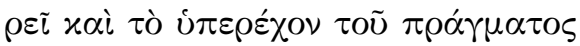

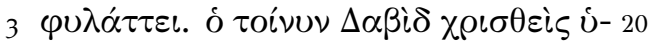

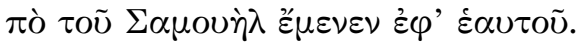

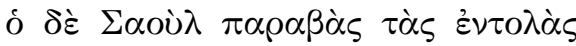

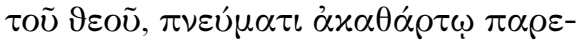

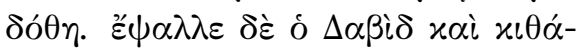

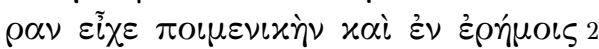

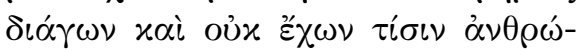

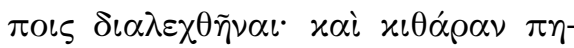

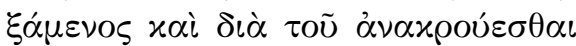

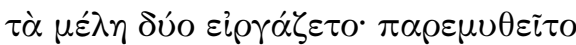

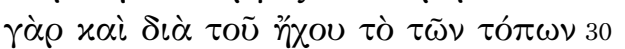

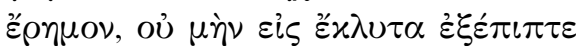

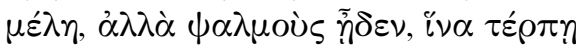

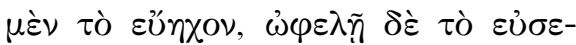

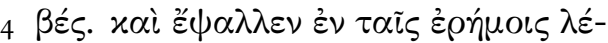

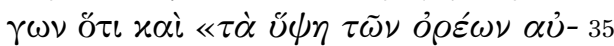

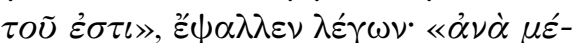

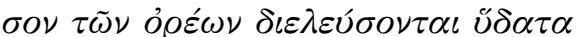
14-16 Ps 44,835 f. Ps $94,4 \quad 185.36$-186.3 Ps 103,10

$\mathrm{DN}$

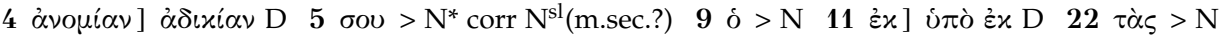

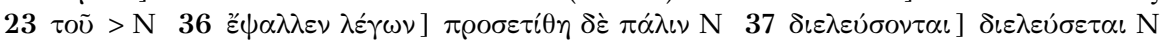

Stab deines Königtums. Du liebst Gerechtigkeit und haßt Gesetzlosigkeit. Deswegen salbte dich Gott, dein Gott, mit Öl der Freude vor deinen Genossen«, damit du nicht glaubst, durch den Gleichklang der Salbung bestünde eine Gleichwertigkeit des Gesagten. Es wurde David gesalbt, es wurde auch Christus gesalbt; doch der eine wurde von einem Menschen gesalbt, der andere aber wurde vom Vater gesalbt; und die Salbung war unaussprechlich und die Sache ist nicht fassbar. Deswegen sagt der Psalmist: Öl der Freude vor deinen Genossen. Sie sind Genossen in der Ähnlichkeit, haben aber freilich keine gleichwertige Salbung; denn überall bewahrt sie einerseits die Ähnlichkeit und wahrt andererseits den Unterschied in der Sache. Nachdem David also von Samuel gesalbt worden war, blieb er an seinem Platz. Saul aber übertrat die Gebote Gottes und wurde daraufhin einem unreinen Geist übergeben. David aber sang Psalmen und hatte eine Hirtenzither, als er sich in der Wüste aufhielt und nicht wußte, mit welchen Menschen er sich unterhalten sollte; und er schlug die Zither und dichtete zwei Lieder durchs Anstimmen; denn er besänftigte schon durch den Klang die Ödnis des Ortes, verfiel jedoch nicht in leichte Lieder, sondern sang Psalmen, damit er im Blick auf den Wohlklang erfreue, im Blick auf die Frömmigkeit aber nutze. Und er sang Psalmen in der Wüste und sprach: »Auch die Höhen der Berge sind sein«. Und er sang Psalmen und sprach: »In Mitten der Berge gehen die Wasser hindurch und tränken alle Tiere der Wildnis. Er wird auch die Vögel 


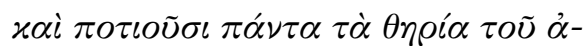

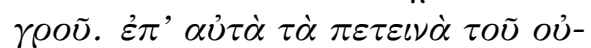


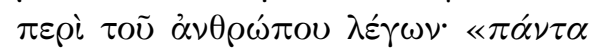

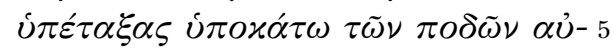

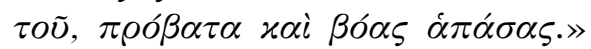

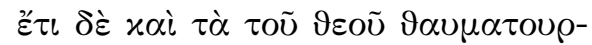

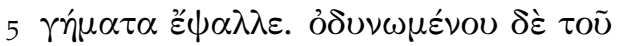

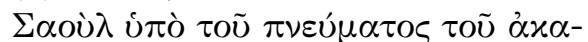

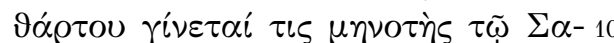

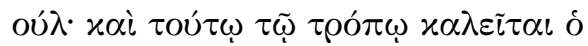

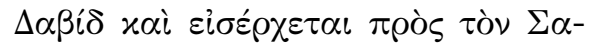

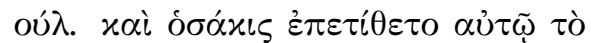

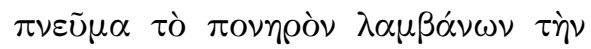

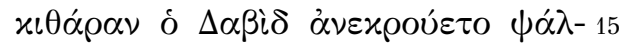

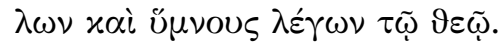

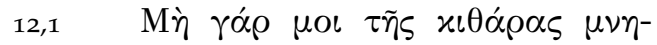

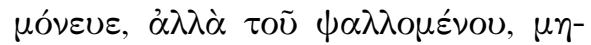

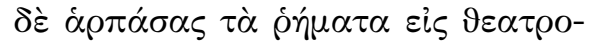

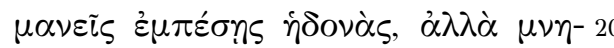
$\mu o v \varepsilon v ́ \sigma \alpha \varsigma \tau \tilde{\omega} \nu \psi \alpha \alpha \lambda \mu \tilde{\omega} \nu \tau \tilde{\eta} \varepsilon \dot{\varepsilon} x \lambda \eta \sigma i \alpha$.

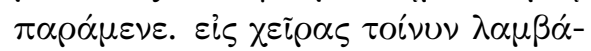

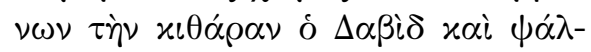

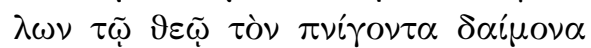

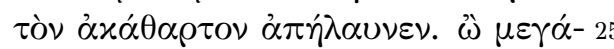

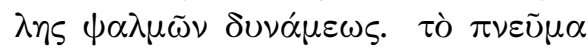

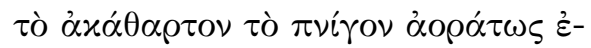

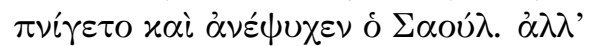

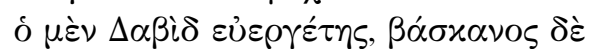

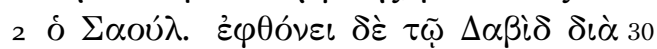

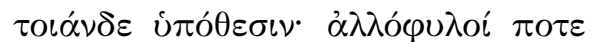

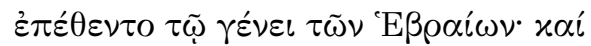

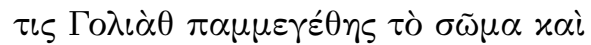

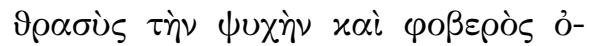

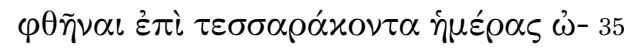

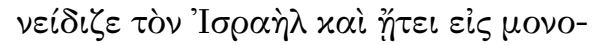

4-6 Ps 8,8

$\mathrm{DN}$

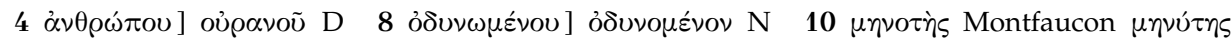

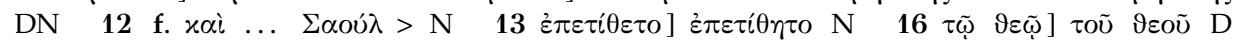

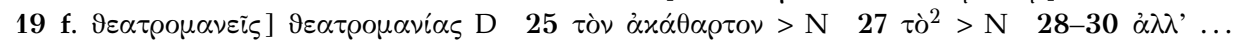

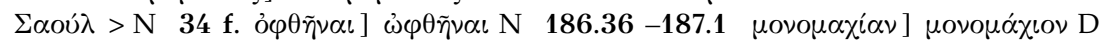

des Himmels beschatten.« Er sang Psalmen über den Menschen und sprach: »Alles hast du unter seine Füße gestellt, Schafe und alle Rinder.« Dazu sang er auch Psalmen über die Wundertaten Gottes. Als aber Saul Schmerzen hatte von dem unreinen Geist, überkam ihn ein Zorn; und so wird David gerufen und geht zu Saul hinein. Und sooft ihm der böse Geist zusetzte, nahm David 0 die Zither, schlug sie und sang Gott Psalmen und Hymnen.

Gedenke mir aber nicht der Zither, son- $11 \mathrm{M}$. dern dessen, dem Psalmen gesungen werden! Und nimm nicht die Worte her und falle in theaterverrückte Freuden, sondern gedenke der Psalmen und bleibe in der Kirche! David nahm also die Zither in die Hände, sang Gott Psalmen und vertrieb so den würgenden, unreinen Dämon. Oh du große Kraft der Psalmen! Der unreine, würgende Geist wurde unsichtbar erwürgt, und Saul lebte auf. Doch David war ein Wohltäter, ein Neider aber Saul. Er beneidete aber David aus folgendem Grund: Einst griffen Fremde das Volk der Hebräer an; und ein gewisser Goliath, mit einem überaus großem Körper, wildem Geist und furchtbar anzusehen, verhöhnte vierzig Tage lang Israel und forderte zum Einzelkampf heraus. Dabei hatte er einen überaus großen Schild umgehängt, einen Speer gezückt und furchtbare Bein-

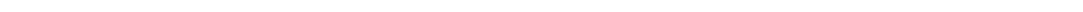




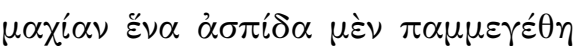

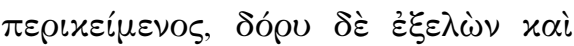


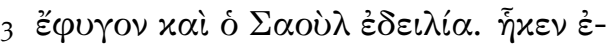

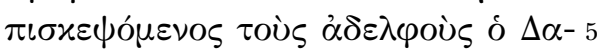

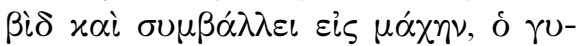

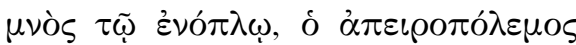

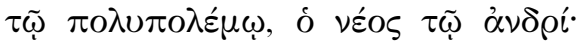

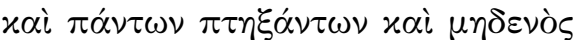

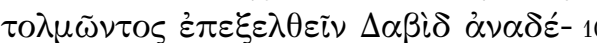

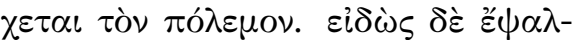

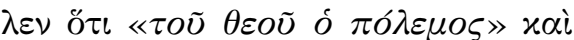

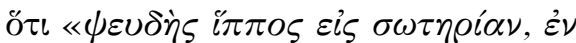

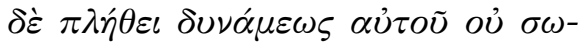

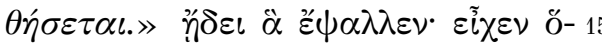

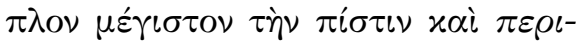

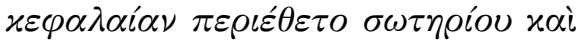

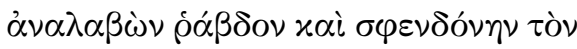

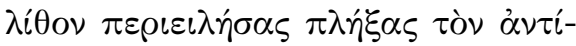

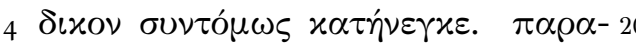

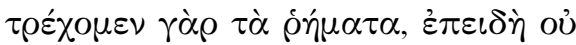

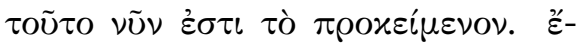

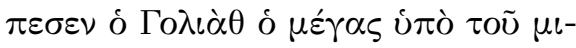

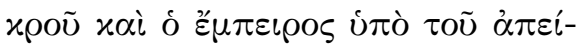

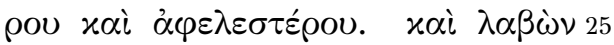

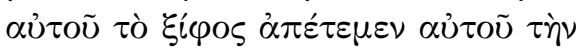

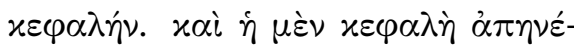
$\chi \theta \eta \dot{\varepsilon} \nu$ 'I

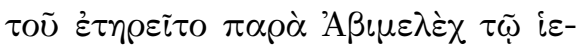

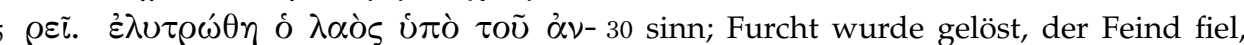

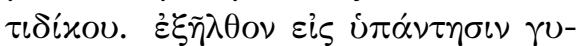

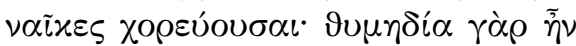

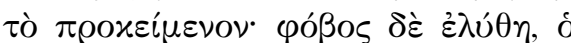

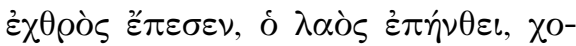

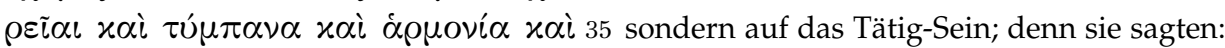

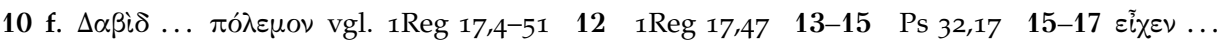
$\sigma \omega \tau \eta$ oíou vgl. Eph 6,16 f. 16 f. Jes 59,17

$\mathrm{DN}$

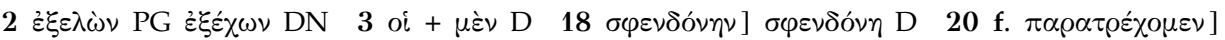

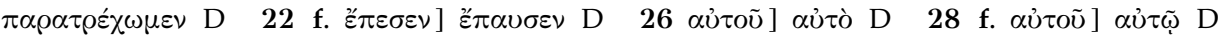

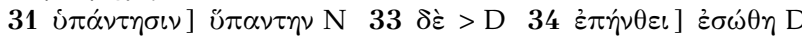

schienen; und die ihn sahen, flohen, und Saul war furchtsam. David kam, um seine Brüder zu beobachten, und da traf in der Schlacht der Nackte mit dem Bewaffneten zusammen, der Unerfahrene im Krieg mit dem erfahrenen Krieger, der Jüngling mit dem Mann; und als alle Furcht hatten und keiner hinauszugehen wagte, nahm David den Krieg auf. Weil er es aber wusste, sang ge seines Heers wird er nicht gerettet werden«. Er wußte, was er sang; er hatte als größte Waffe den Glauben und er setzte den zog er den Stein auf, traf den Gegner und schlug ihn auf einmal zu Boden. Übergehen wir die Worte; denn das ist jetzt nicht unser Kleinen und der Erfahrene durch den Unerfahrenen und recht Einfachen. Und er nahm sein Schwert und trennte ihm damit den Kopf ab. Und sein Kopf wurden nach Jerude bei Abimelech, dem Priester, aufbewahrt. Es wurde das Volk von dem Widersacher befreit. Zur Begrüßung gingen die Frauen das Volk freute sich: Tänze und Trommeln und Einmütigkeit und Freude sind das Thema. Die Tanzenden aber sangen, indem sie ihren Blick nicht auf das Ansehen richteten,

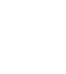




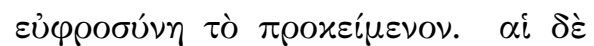

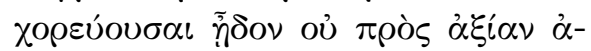


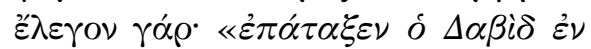

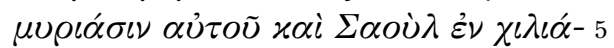

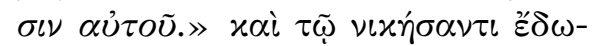

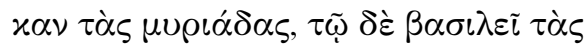

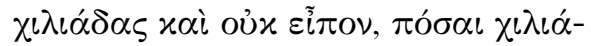

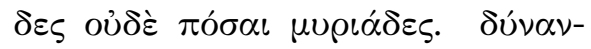

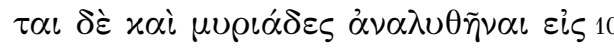

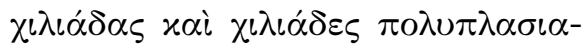

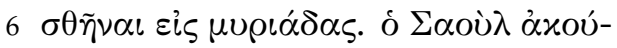

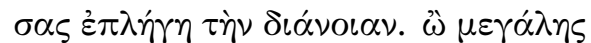

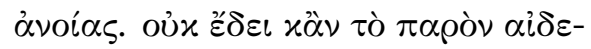
$\sigma \theta \tilde{\eta} \nu \alpha l ; \quad \tau i \quad \beta \alpha \sigma x \alpha i v \varepsilon l \varsigma \alpha \dot{\alpha} \nu \theta \omega \dot{\pi} \pi \omega \nu l-15$

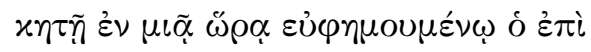

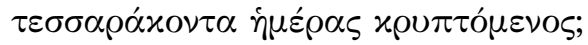

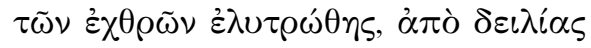

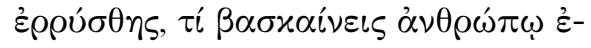

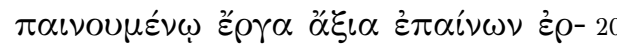

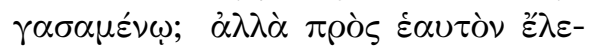

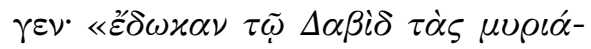

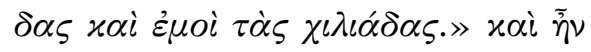

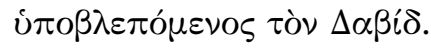

13,1 B В

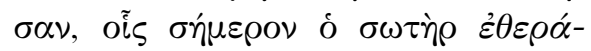

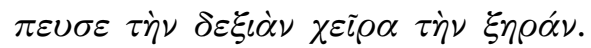

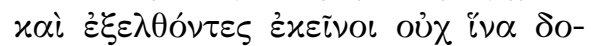

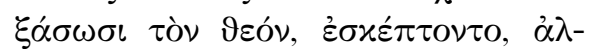

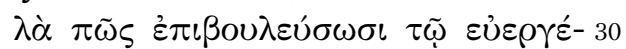

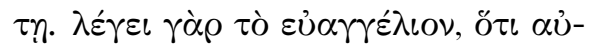

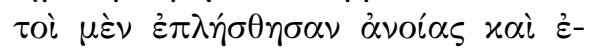

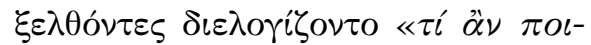

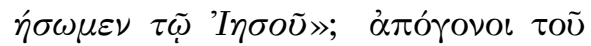

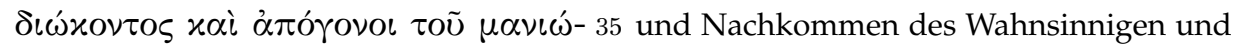

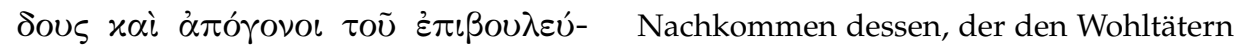
4-6 $1 \operatorname{Reg} 18,7 \quad 22$ f. $\quad 1 \operatorname{Reg} 18,8 \quad 26$ f. $\quad$ Lk 6,6 33 f. $\quad$ Mt 12,14

$\mathrm{DN}$

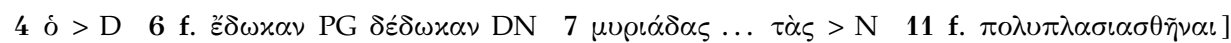

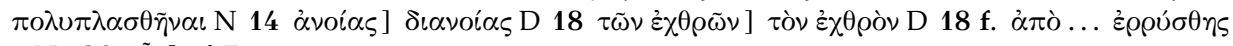
$>\mathrm{N} 26$ oís] of $\mathrm{D}$

»David schlug sie in ihren Zehntausenden und Saul in ihren Tausenden.« Und dem Sieger gaben sie die Zehntausende, dem König aber die Tausende und sagten nicht, wie viele Tausende und wie viele Zehntausende. Es können nämlich auch Zehntausende in Tausende aufgelöst und Tausend in Zehntausende vervielfacht werden. Als Saul das hörte, wurde er in seinem Sinn geschlagen. Oh, welch große Torheit! Mußte er nicht wenigstens das Gegenwärtige berücksichtigen? Was beneidest du, der du dich vierzig Tage verborgen hast, einen siegreichen Menschen, der in einer Stunde gepriesen wird? Von den Feinden wurdest du befreit, von der Feigheit erlöst, was beneidest du einem Menschen, der gelobt wird, weil er lobenswerte Taten vollbracht hat? Doch zu sich selbst sagte er: "Sie gaben dem David die Zehntausenden und mir die Tausenden.« Und er schaute David ständig mißgünstig an.

Schau, ob die nicht seine Nachkommen $12 \mathrm{M}$. waren, denen heute der Heiland die rechte Hand, die verdorrte, heilte. Und auch als jene hinausgingen, wurden sie nicht dabei beobachtet, daß sie Gott priesen, sondern wie sie dem Wohltäter nachstellten. Denn das Evangelium sagt, daß sie mit Unverstand gefüllt wurden und hinausgingen und sich unterhielten: »Was sollen wir dem Jesus tun?« Nachkommen des Verfolgers Nachkommen dessen, der den Wohltätern 


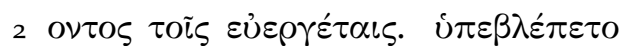

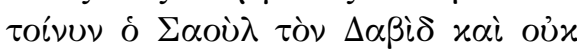

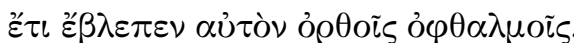

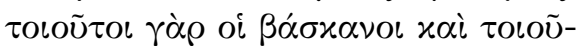

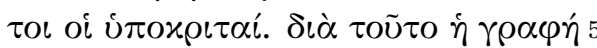

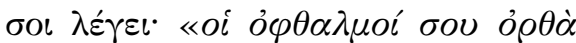
$\beta \lambda \varepsilon \pi \varepsilon \tau \omega \omega \alpha \nu \gg \mu \eta \delta \dot{\varepsilon} \nu \pi \lambda \alpha \dot{\gamma} \iota \nu \mu \eta \delta \grave{\varepsilon}$

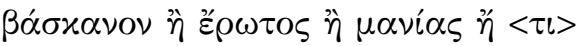

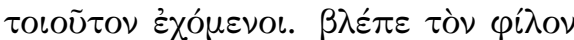

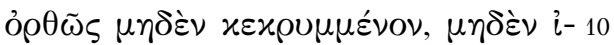

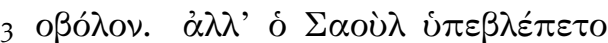

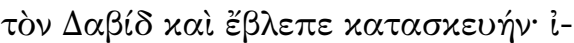

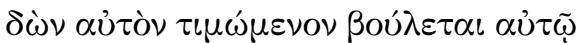

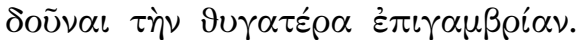

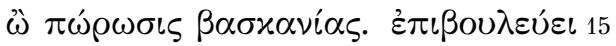

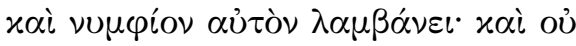

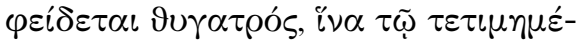

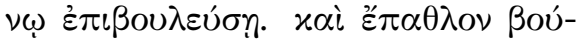

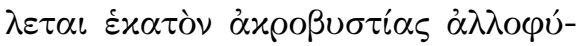

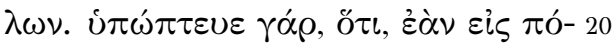

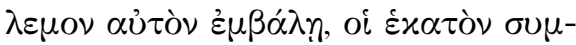

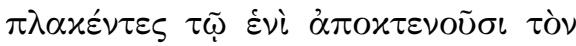

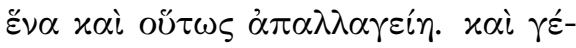

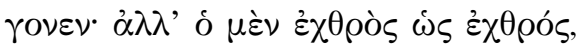

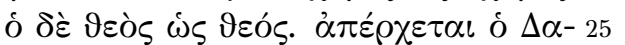

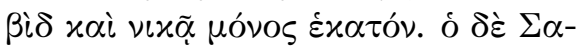

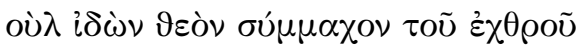

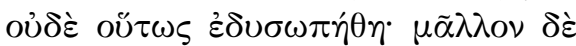

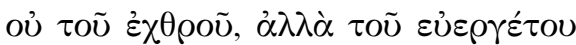

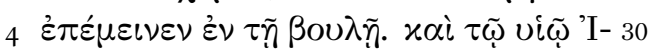

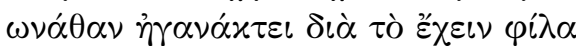

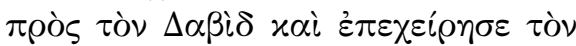

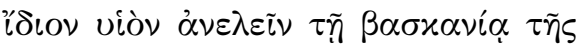

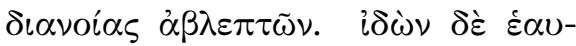

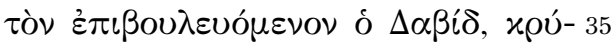

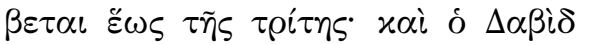

6 f. Ps 16,2 nachstellte! Saul beneidete also David und sah ihn nicht mehr mit rechten Augen. Denn so sind die Neider und so sind die Heuchler. Deswegen sagt dir die Schrift: »Deine Augen sollen recht sehen ", und nichts Schiefes, nichts Neidisches, oder etwas von Verlangen oder Wahnsinn oder dergleichen haben. Sieh den Freund recht an, ohne etwas zu verbergen, nicht giftsprühend. Doch Saul beneidete David und sah einen Ausweg: Als er sieht, wie David geehrt wird, will er ihm seine Tochter zur Frau geben. Oh, was für eine heuchlerische Verstocktheit! Er stellt ihm nach und nimmt ihn als Bräutigam auf; und er verschont nicht die Tochter, damit er dem Geehrten nachstelle. Und als Brautpreis will er hundert Vorhäute von Heiden. Denn er dachte bei sich, daß, wenn er ihn in den Krieg treibe, die Hundert, wenn sie mit dem einen zusammenstoßen, diesen einen töten werden, und er so befreit werde. Und es geschah: doch der Feind handelt wie ein Feind, Gott aber wie Gott. David geht weg und allein besiegt er Hundert. Als Saul aber sah, daß Gott Bundesgenosse seines Feindes war, da fürchtete er sich nicht einmal dann; vielmehr stellte er in seinem Plan nicht dem Feind, sondern dem Wohltäter nach. Und seinem Sohn Jonathan zürnte er, weil er Freundschaft mit David hielt, und versuchte, seinen eigenen Sohn zu töten, weil er ihn in seiner neidischen Gesinnung schief ansah. Als David sah, daß ihm nachgestellt wurde, verbarg er sich drei Tage lang. Und David wußte vom dritten (Tag) und da macht er einen Vertrag mit Jonathan, und so flieht

DN

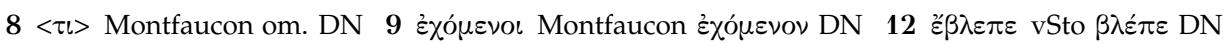

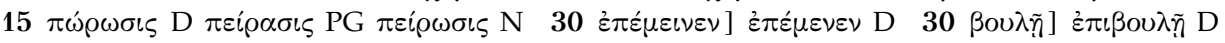
$34 \dot{\alpha} \beta \lambda \varepsilon \pi \tau \tilde{\omega} \nu$ PG $\dot{\alpha} \beta \lambda \varepsilon \pi \omega \nu$ N $\beta \lambda \varepsilon \dot{\pi} \omega \nu \mathrm{D}$ 


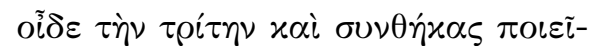

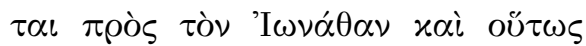

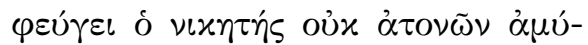

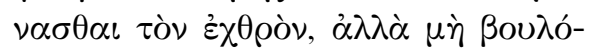

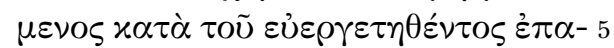

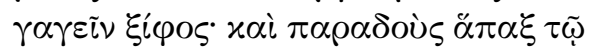

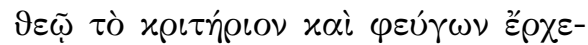

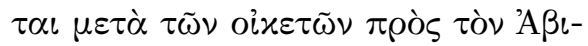

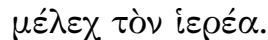

14,1 П'́́

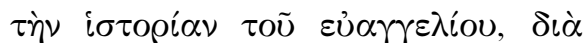

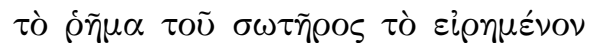

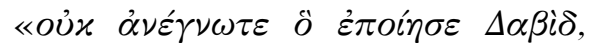

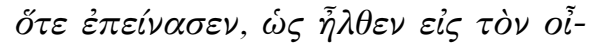

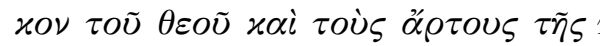

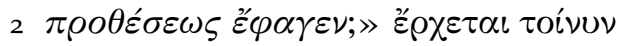

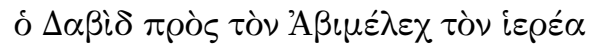

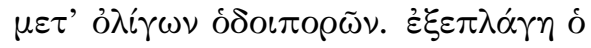

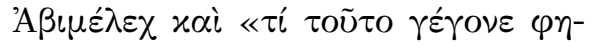

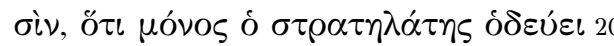

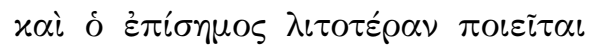
$\tau \grave{\eta े \nu ~ \delta \delta \delta o เ \pi o p i ́ \alpha \nu ; » ~} \delta \delta \dot{\varepsilon} \Delta \alpha \beta \grave{\imath} \delta$ oủ $\lambda \hat{\varepsilon}^{-}$

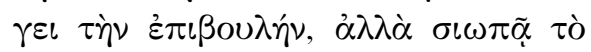

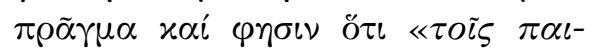

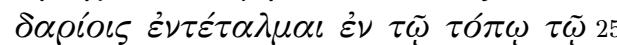

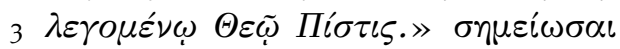

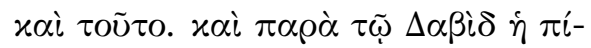

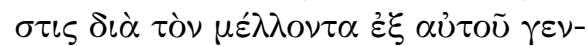

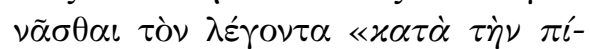

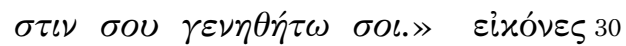

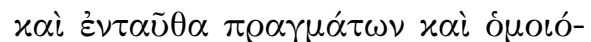

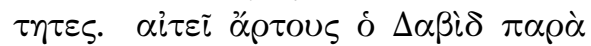
$\tau \sigma \tilde{~ ' A \beta \iota \mu \varepsilon ́ \lambda \varepsilon \chi . ~ o ́ ~ \delta \varepsilon ́ ~ \varphi \eta \sigma \iota ~ \pi \rho o ̀ \varsigma ~ \alpha u ̉ \tau o ́ v: ~}$

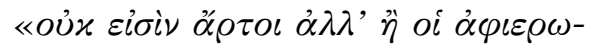

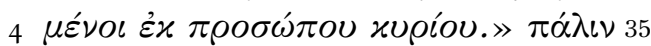

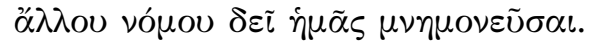

der Sieger, nicht weil er zu schlaff war, um sich gegen den Feind zu wehren, sondern weil er nicht gegen den, von dem ihm Gutes widerfahren war, das Schwert ziehen wollte. Und nachdem er einmal Gott das Gericht übergeben hatte und geflohen war, kommt er mit seinen Knechten zum Priester Abimelech.

Das alles sagen wir wegen der Ge- $13 \mathrm{M}$. schichte des Evangeliums, wegen des Wortes des Heilandes, das lautet: »Habt ihr nicht gelesen, was David tat, als es ihn hungerte, wie er in das Haus Gottes ging und die Schaubrote aß? «Es kommt also David mit wenigen Begleitern zum Priester Abimelech. Abimelech erschrak und sagt: „Was ist da geschehen, daß der Heerführer allein reist und der Berühmte ganz schlicht seinen Weg geht? « David aber nennt nicht die Nachstellung, sondern verschweigt die Sache und sagt: »Ich habe die Jünglinge an den Platz befohlen, der genannt wird 'Glaube an Gott .« Auch die ist zu bemerken. Auch 5 bei David ist der Glaube um dessentwillen, der aus ihm geboren werden soll, der sagt: »Nach deinem Glauben geschehe dir." Auch hier gibt es Vorbilder der Ereignisse und Ähnlichkeiten. David fordert Brote von Abimelech. Der aber sagt zu ihm: »Es gibt keine Brote außer denen, die vom Angesicht des Herren geheiligt sind.« Wiederum müssen wir an ein anderes Gesetz erinnern. Das Gesetz des Mose schrieb, daß bei den Zere35 monien des Gottesdienstes, die am Sabbat abgehalten werden, zwölf warme Brote ge-

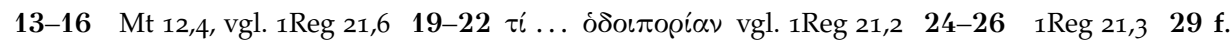
Mt 9,29 34 f. $\quad 1 \operatorname{Reg} 21,7$

DN

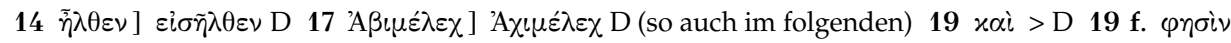

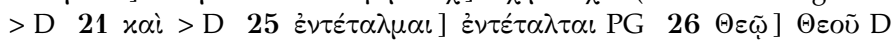




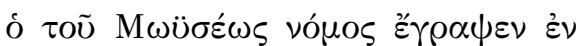

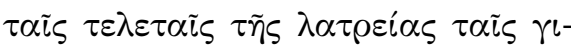

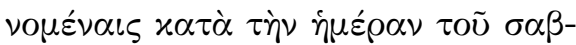

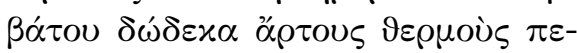

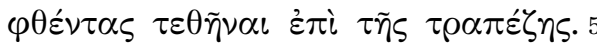

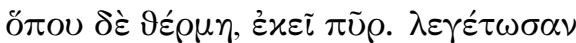

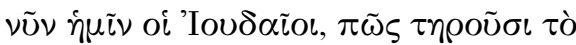

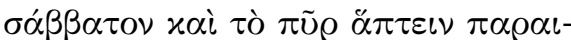

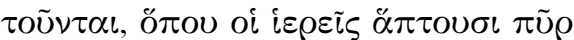

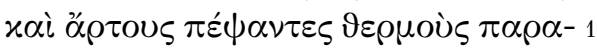

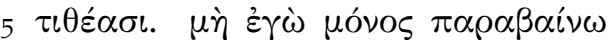

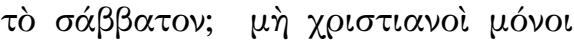

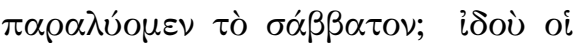

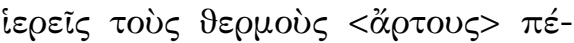

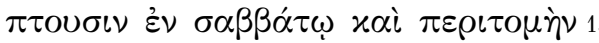

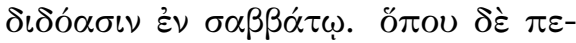

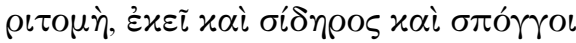

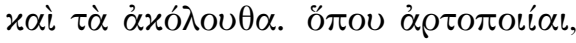

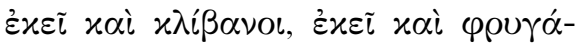

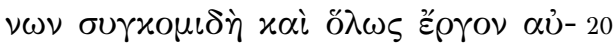

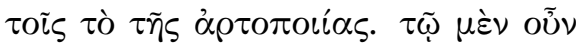

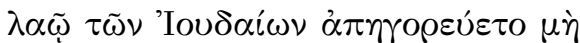

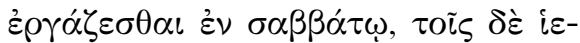

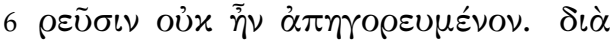

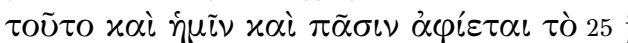

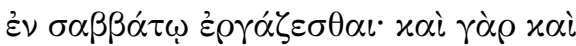

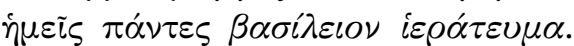

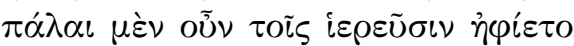

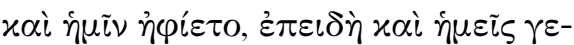

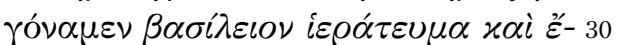

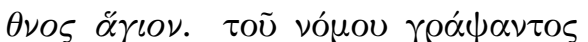

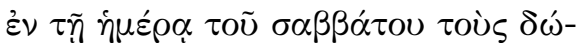

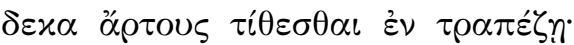

backen und dann auf den Tisch gelegt werden. Wo es aber Wärme gibt, dort ist auch Feuer. Nun sollen uns die Juden sagen, wie sie den Sabbat halten und dabei verbieten, das Feuer anzuzünden, wo doch die Priester das Feuer anzünden und warme Brote backen und auf (den Tisch) legen? Übertrete etwa nur ich den Sabbat? Lösen etwa nur wir Christen den Sabbat auf? Siehe, die Priester backen die warmen $<$ Brote $>$ am Sabbat und führen die Beschneidung am Sabbat durch. Wo es aber die Beschneidung gibt, dort sind auch Messer, Schwämme und das, was dazugehört. Wo es aber Brotbacken gibt, da sind auch Backöfen, dort ist auch Herbeischaffen von Reisig, und überhaupt haben sie Arbeit, nämlich die des Brotbackens. Dem Volk der Juden wurde also verboten, am Sabbat zu arbeiten; den Priestern aber war es nicht verboten. Deswegen ist es auch uns allen gestattet, am Sabbat zu arbeiten; denn auch wir alle sind ein königliches Heiligtum. Einst wurde es also den Priestern erlaubt und so wurde es auch uns erlaubt, da ja auch wir ein königliches Heiligtum und ein heiliges Volk geworden sind. Weil das Gesetz geschrieben hatte am Tag des Sabbat die zwölf Brote auf einen Tisch zu legen, forderte nämlich David von jenen geheiligten Broten vom Tisch die Nahrung. Abimelech aber sagte: »Wenn die Jünglinge sich enthalten haben der Frau.« So bekräftige mir nun - nebenbei gesagt -, Gläubiger, das Ge-

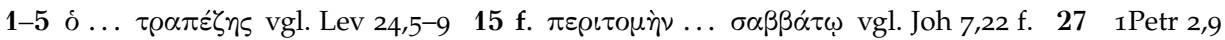

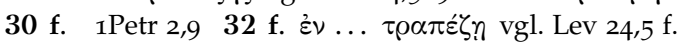

$\mathrm{DN}$

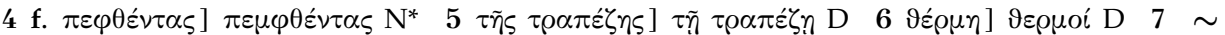

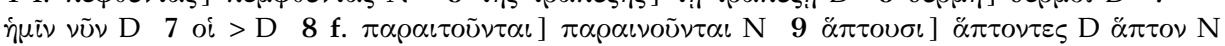

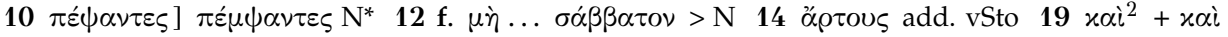

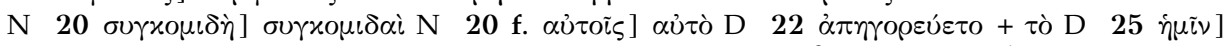

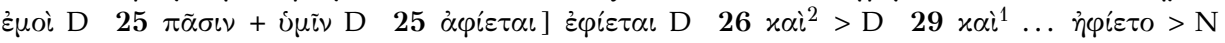
$33 \dot{\varepsilon} \nu+\tau \tilde{n} \mathrm{D}$ 


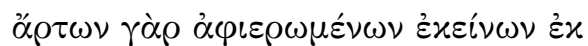

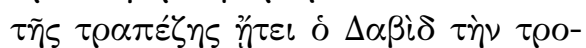

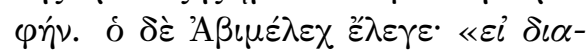

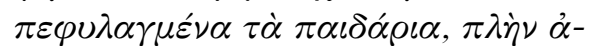

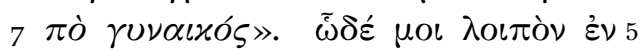

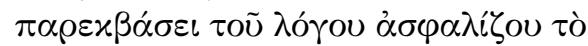

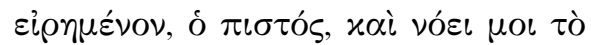

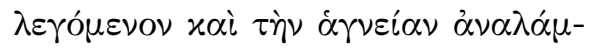

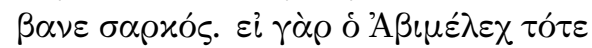

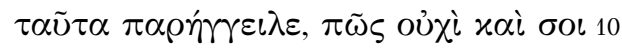

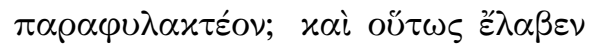

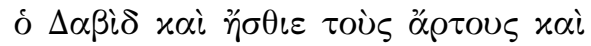

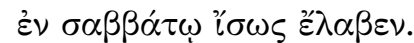

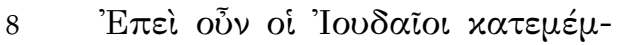

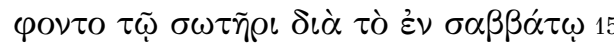

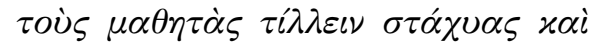

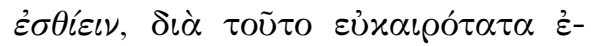

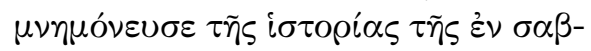

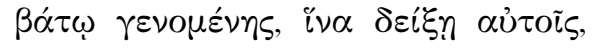

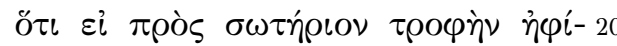

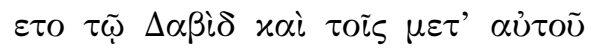

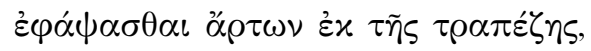

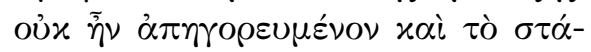

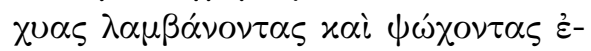

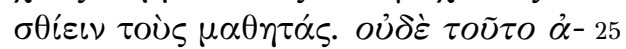

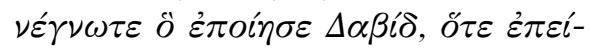

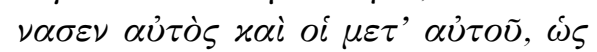

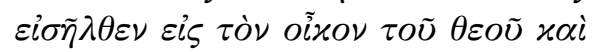

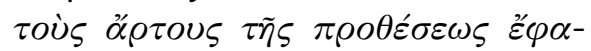
$\gamma \varepsilon \nu$;

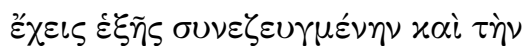

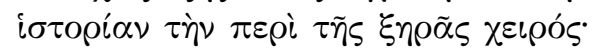

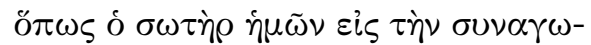

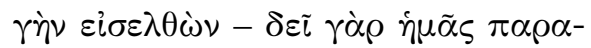

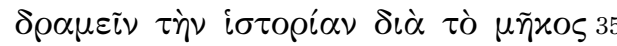

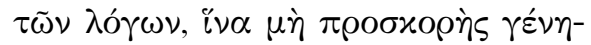

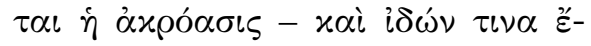

sprochene und bedenke mir das Gesagte und nimm die Enthaltsamkeit des Fleisches auf! Denn wenn Abimelech das damals anordnete, wie sollte es nicht auch von dir eingehalten werden? Und so nahm David und aß die Brote und nahm sie billigerweise am Sabbat.
Da also die Juden den Heiland tadelten, $14 \mathrm{M}$. weil die Jünger am Sabbat Ähren rauften und aßen, deswegen erinnerte er genau zur rechten Zeit an die Geschichte, die sich am Sabbat ereignete, damit er ihnen zeige, daß es, wenn es dem David und denen, die mit $0 \mathrm{ihm}$ waren, zur rettenden Speise erlaubt war, die Brote vom Tisch zu nehmen, dann auch nicht verboten war, daß die Jünger Ähren nahmen, sie mahlten und aßen. Habt ihr nicht das gelesen, was David tat, als es ihn 5 und die, die mit ihm waren, hungerte, daß er in das Haus Gottes ging und die Schaubrote $a ß$ ?

Du findest im Folgenden auch die Geschichte über die verdorrte Hand damit verbunden: Als unser Heiland in die Synagoge hineinging - denn wir müssen die Geschich5 te wegen der Länge der Worte übergehen, damit das Zuhören nicht lästig wird - und einen sah, der eine verdorrte Hand hatte,

3-5 1 Reg 21,4 16 f. Lk 6,1 25-30 Lk 6,3 32 vgl. Lk 6,6-11

DN

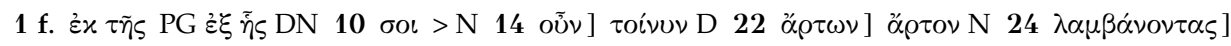
$\lambda \alpha \beta o ́ v \tau \alpha \varsigma$ D $32 \tau \dot{\eta} \nu>N 36 \mu \grave{\eta}>$ D 


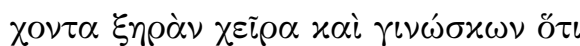

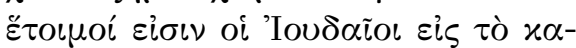

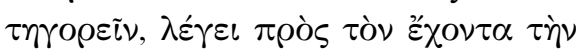

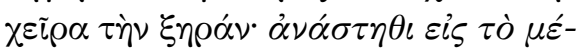

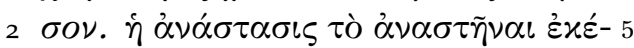

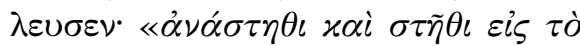

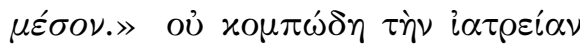

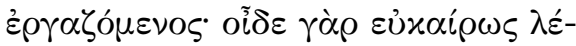

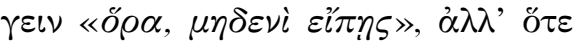

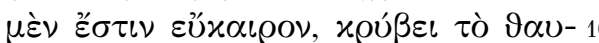

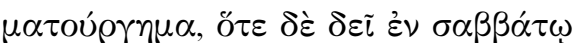

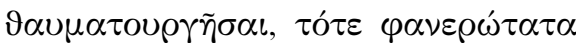

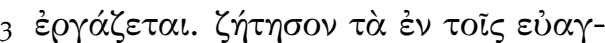

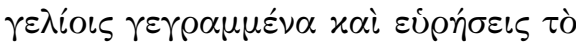

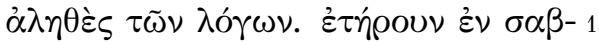
$\beta \alpha ́ \tau \omega \tau \dot{\alpha} \tau \tilde{\omega} \nu \vartheta \alpha v \mu \alpha \tau O v \rho \gamma \eta \mu \alpha \tau \omega \nu$ ह-

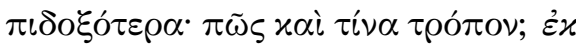

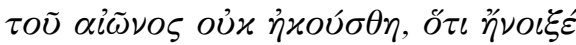

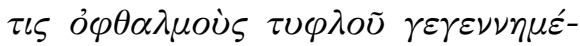

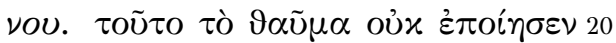

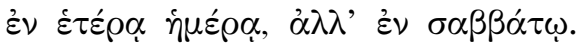

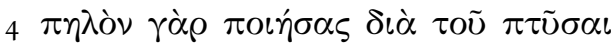

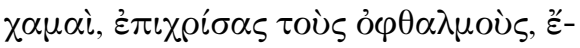

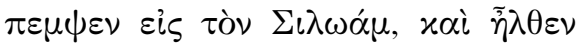

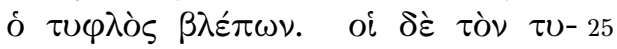

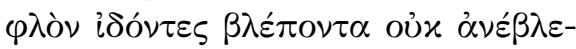

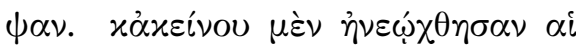

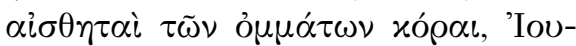

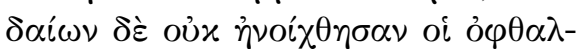

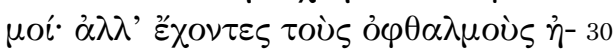

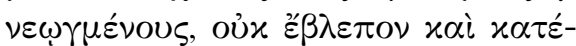

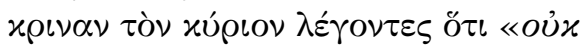

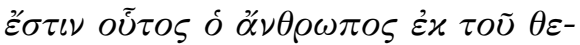

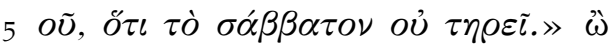

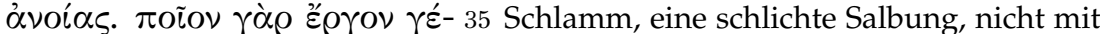
$\gamma O \nu \varepsilon ; \pi \tau \dot{\sigma} \sigma \mu \alpha \dot{\alpha} \pi \grave{\partial} \chi \varepsilon \iota \lambda \varepsilon^{\prime} \omega \nu, \dot{\alpha} \pi \grave{\partial} \delta \alpha-\quad$ medizinischen Werkzeugen, sondern allein

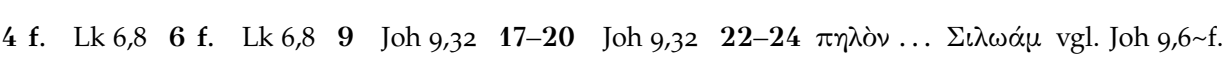
32-34 Joh 9,16

$\mathrm{DN}$

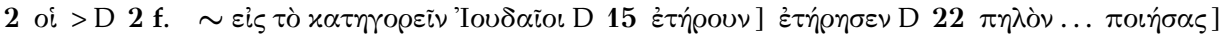

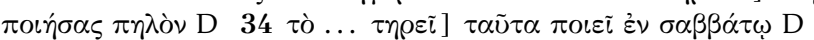

und erkannte, daß die Juden bereit zur Anklage waren, sagt er zu dem, der die verdorrte Hand hatte: »Stehe auf in die Mitte! « Die Auferstehung befahl das Aufstehen: »Stehe auf und stelle dich in die Mitte! Nicht, weil er prahlerisch die Heilung vollführen wollte, denn er wußte zum rechten Zeitpunkt zu sagen: »Siehe, sage es keinem!«, sondern wenn es die rechte Zeit ist, verbirgt er das Wunder, wenn er hingegen am Sabbat Wunder wirken muß, dann tut er es ganz offensichtlich. Suche das, was in den Evangelien geschrieben ist, und du wirst die Wahrheit der Worte finden. Sie hielten am Sabbat das, was wunderbarer als die Wundertaten war; wie und auf welche Art? Seit Ewigkeiten wurde es nicht gehört, daß einer die Augen eines blind Geborenen öffnete. Dieses Wunder tat er nicht an einem spuckte, salbte damit die Augen und schickte ihn dann zum Teich Siloah; und der Blinde kam und sah. Die aber, die den Blinden sehend sahen, schauten nicht auf. Jenem wurden die wahrnehmbaren Augäpfel geöffnet, die Augen der Juden wurden aber nicht geöffnet; sondern obwohl sie ihre Augen geöffnet hatten, sahen sie nicht und verurteilten den Herrn, indem sie sagten: »Dieser Mensch ist nicht von Gott, weil er den Sabbat nicht hält.« Oh, wie viel Ignoranz! Denn was für eine Arbeit ist geschehen? Spucken von den Lippen, von den Fingern allein der

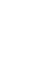




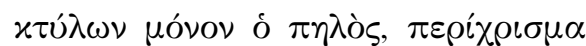

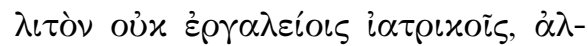

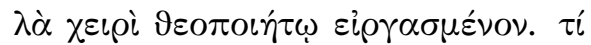

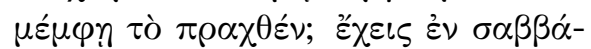

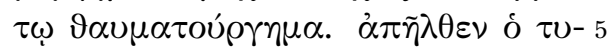

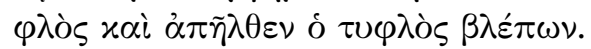

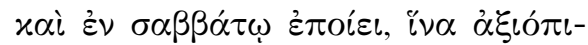

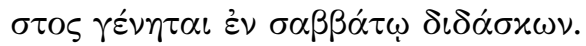
16,1 "Е

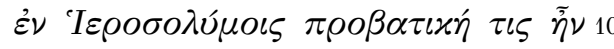

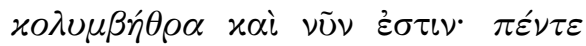

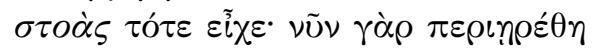

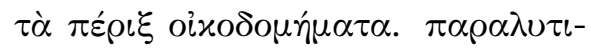

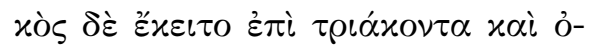

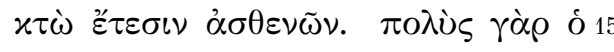

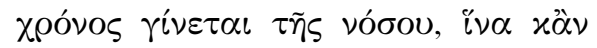

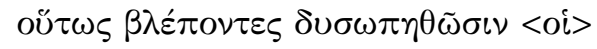

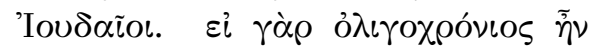

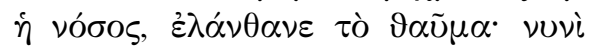

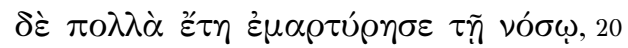

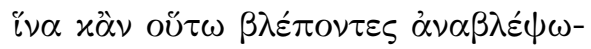

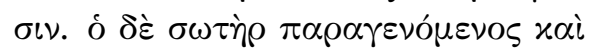

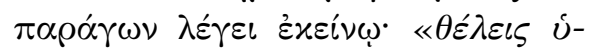

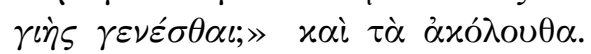

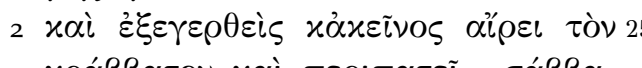

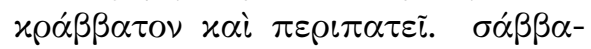

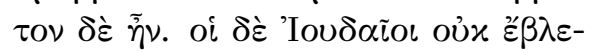

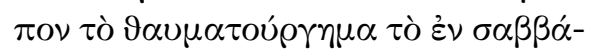

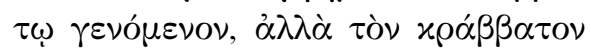

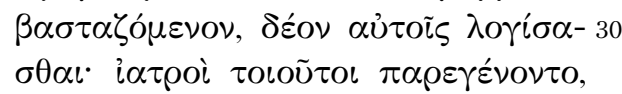

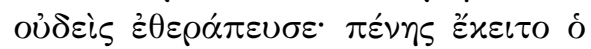

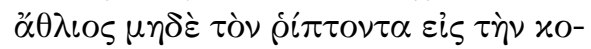

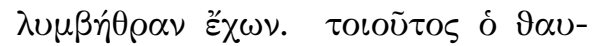

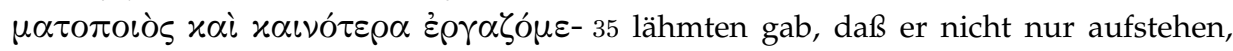

mit gottgeschaffener Hand ausgeführt. Was tadelst du das Getane? Du hast am Sabbat ein Wunder. Der Blinde ging weg und der Blinde ging sehend weg. Und er tat es am Sabbat, damit er glaubwürdig werde, wenn er am Sabbat lehrte.

Ich habe noch ein anderes Wunder. In $15 \mathrm{M}$. usalem war ein Schafsteich und ist es auch jetzt noch. Er hatte damals fünf Hallen; denn jetzt sind die Gebäude außen herum zerstört. Dort lag 38 Jahre lang ein Gelähmter krank da. Denn lange wurde die Dauer seiner Krankheit, damit die Juden, wenn sie es sehen, so besonders unwillig würden. Denn wenn die Krankheit kurz gewesen wäre, wäre das Wunder verborgen geblieben; nun aber legte er viele Jahre lang Zeugnis von seiner Krankheit ab, damit sie so besonders aufschauen, wenn sie es sehen. Der Heiland kam herzu und, als er vorbeiging, sagte er zu jenem: »Willst du gesund werden?", und so weiter. Und erweckt nahm jener seine Liege und ging herum. Es war aber ein Sabbat. Die Juden aber sahen nicht das Wunder, das am Sabbat geschehen ist, sondern die Liege, die getragen wurde, obwohl sie hätten nachdenken müssen: So gute Ärzte waren da gewesen, aber keiner heilte; arm lag der Elende da und hatte nicht einmal einen, der ihn in den Teich warf. Solcher Art war der Wundertäter und Unerhörtes Schaffende, der eine solche Kraft dem Ge-

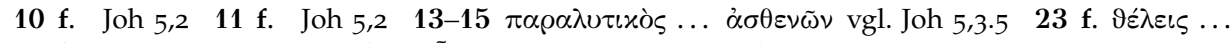

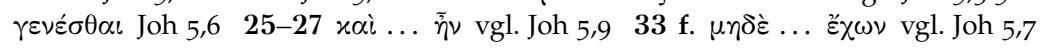

$\mathrm{DN}$

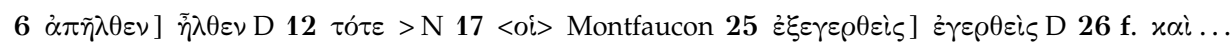

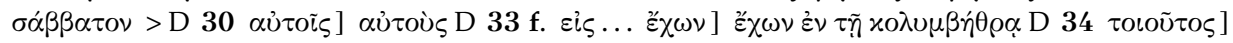

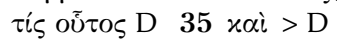




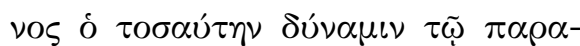

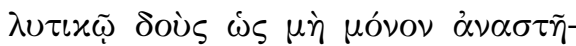

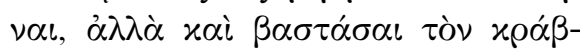

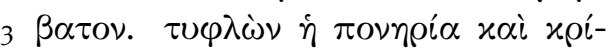

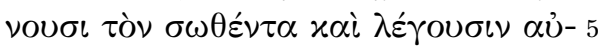

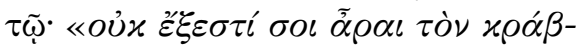

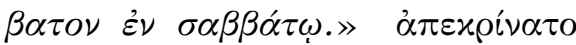

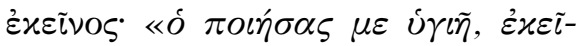

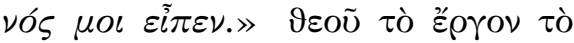

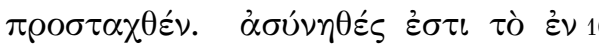

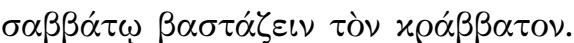

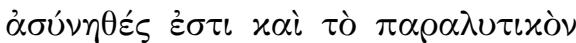

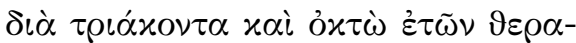

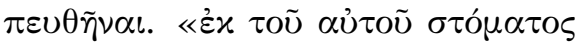

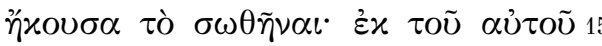

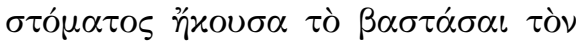

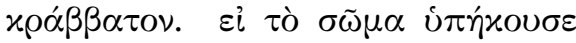

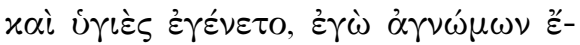

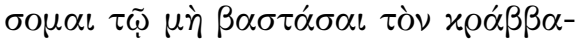

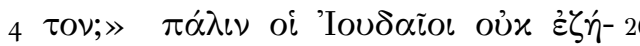

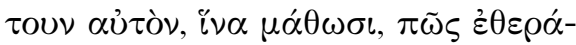

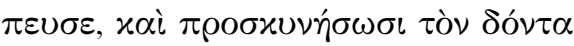

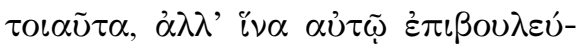

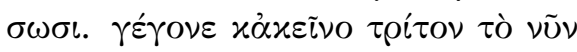

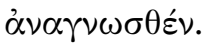

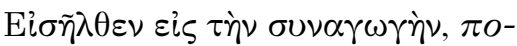

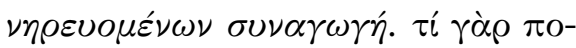

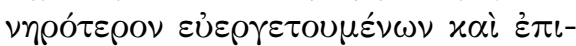

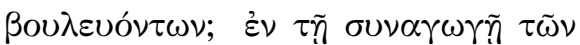

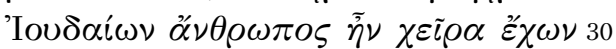

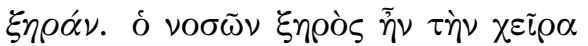

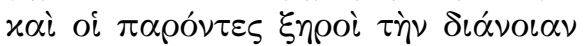

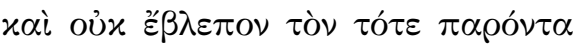

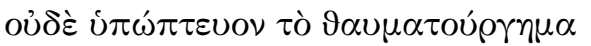

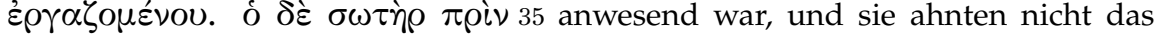

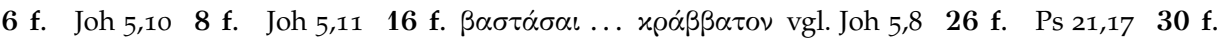
Mt 12,10

$\mathrm{DN}$

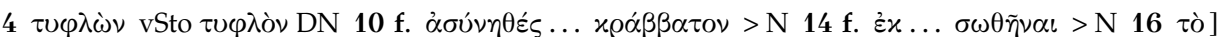

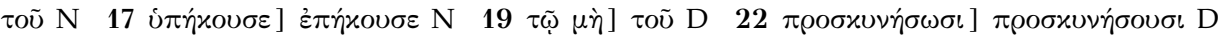

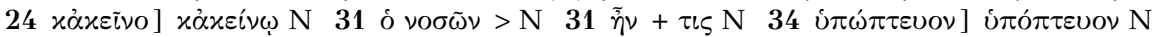

sondern auch seine Liege tragen konnte. Es ist die Schlechtigkeit von Blinden, und sie urteilen über den Geretteten und sagen ihm: »Du darfst die Liege am Sabbat nicht hochheben.« Da antwortete jener: »Der, der mich gesund gemacht hat, sagte es mir.« Gottes ist das Werk, das befohlen wurde. Unverständlich ist es, am Sabbat die Liege zu tragen. Unverständlich ist es auch, daß ein 38 Jahre lang Gelähmter geheilt wurde. »Aus seinem Mund hörte ich das gerettet Werden; aus seinem Mund hörte ich das Nimm die Liege! Wenn der Körper gehorchte und gesund wurde, werde ich da so eigensinnig sein, die Liege nicht zu tragen? «Wiederum suchten die Juden ihn nicht, damit sie lernten, wie er heilte und um den, der solches gab, anzubeten, sondern damit sie ihm nachstellten. Als Drittes ereignete sich auch jenes, was jetzt vorgelesen wurde.

Er ging in die Synagoge hinein, eine $16 \mathrm{M}$. Versammlung von Übeltätern. Denn was ist schlimmer als Leute, denen eine Wohltat erwiesen wurde und die (anderen) nachstellen? In der Synagoge der Juden war ein Mann, der eine verdorrte Hand hatte. Der Kranke war an seiner Hand verdorrt und die Anwesenden waren in ihrer Gesinnung verdorrt und sahen nicht den, der damals 


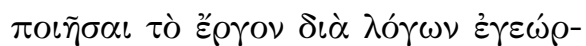

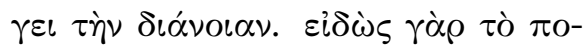

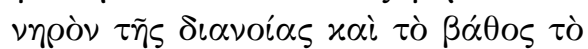

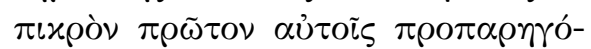

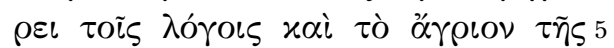

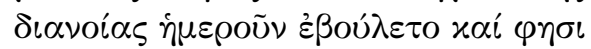

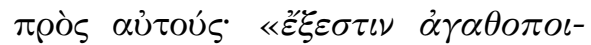

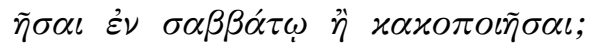

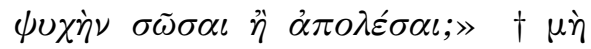

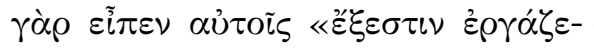

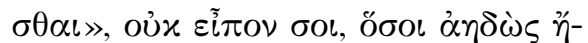

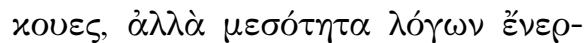

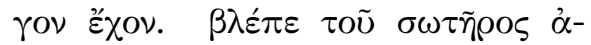

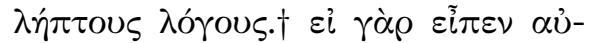

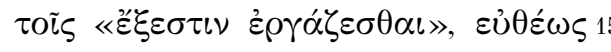

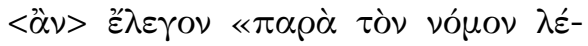

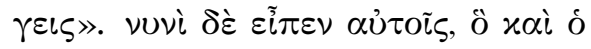

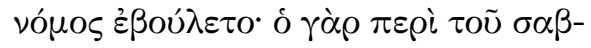

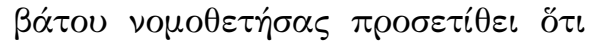

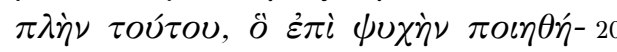

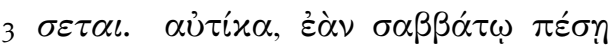

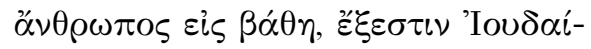

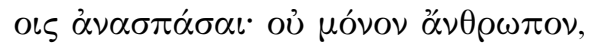

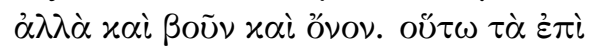

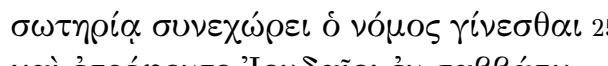

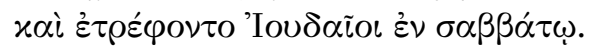

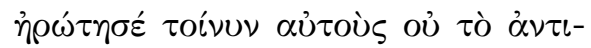

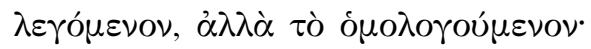

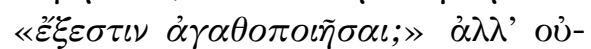

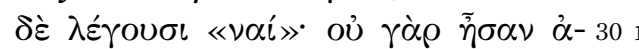

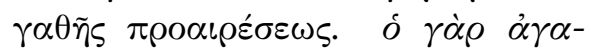

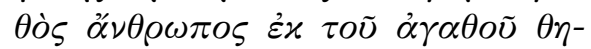

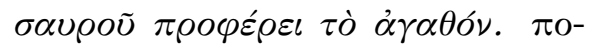

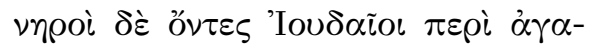

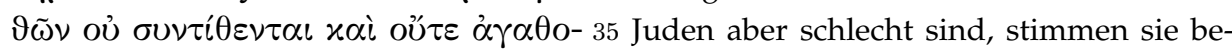
7-9 Lk 6,9 20 f. Ex 12,16 23 f. oủ ... óvov vgl. Mt 12,11; Lk 14,5 29 Lk 6,9 31-33 Mt 12,35

$\mathrm{DN}$

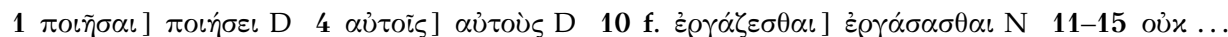

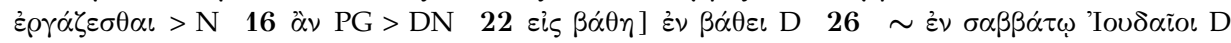

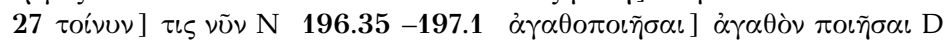

Wunder dessen, der es tat. Der Heiland aber beackerte, bevor er das Werk tat, mit Worten die Gesinnung. Denn, weil er das Schlechte ihrer Gesinnung kannte und die bittere Tiefe, redete er ihnen zuerst mit Worten zu und wollte die Wildheit ihrer Gesinnung zähmen und sagt zu ihnen: »Ist es erlaubt, am Sabbat Gutes zu tun oder Böses? Eine Seele zu retten oder zugrunde zu richten?« Denn wenn er ihnen nicht gesagt hätte: »Ist es erlaubt zu arbeiten? «, hätten sie dir nicht Worte gesagt, die du mit Widerwillen gehört hättest, sondern ein Mittelmaß an Worten, das Wirkkraft hat. Sieh die unangreifbaren Worte des Heilands! Denn wenn er ihnen gesagt hätte »Ist es erlaubt zu arbeiten?«, hätten sie sofort gesagt: »Du redest gegen das Gesetz.« Jetzt aber sagte er ihnen, was auch das Gesetz wollte; denn der, der über den Sabbat Gesetze gab, fügte hinzu: Außer dem, was zugunsten einer Seele gemacht werden wird. Wenn ein Mensch am Sabbat in die Tiefe fällt, ist es Juden erlaubt, ihn sofort hinauszuziehen; nicht nur einen Menschen, sondern auch ein Rind und einen Esel. So stimmt das Gesetz zu, daß etwas zur Rettung geschieht, und so wurden die uden am Sabbat genährt. Er fragte sie nun nicht nach dem Widersprochenen, sondern dem Zugestandenen: »Ist es erlaubt utes zu tun?« Doch nicht einmal da sagen sie »Ja«, denn sie waren nicht guten Vorsatzes. Denn der gute Mensch bringt aus dem guten Schatz das Gutes hervor. Da die uden aber schlecht sind, stimmen sie be-
gl. Mt 12,11; Lk 14,5 29 Lk 6,9 $\quad 31-33$ Mt 


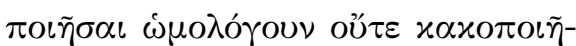

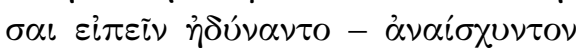
$\gamma \grave{\alpha} \rho \bar{\eta} \nu \tau \grave{\rho} \hat{\rho} \tilde{\eta} \mu \alpha-, \dot{\alpha} \lambda \lambda \grave{\alpha} \sigma \iota \omega \pi \tilde{\omega} \sigma \iota \nu$.

4 ö $\tau \varepsilon \delta \dot{\varepsilon} \delta i \grave{\alpha} \varphi \lambda v \alpha \rho i \alpha \nu, \pi 0 \lambda \lambda \dot{\alpha} \varphi \lambda v \alpha-$ 

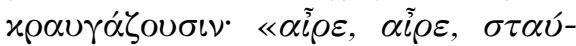

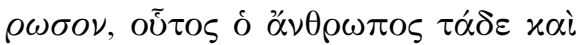

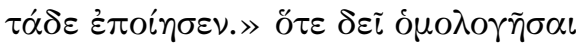

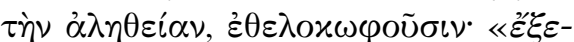

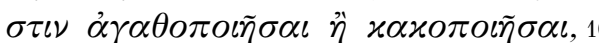
$\psi v \chi \grave{\eta} \nu \sigma \tilde{\omega} \sigma \alpha \iota \grave{\eta} \dot{\alpha} \pi o \lambda \varepsilon \dot{\varepsilon} \sigma l^{\circ} \gg$ oi $\mu \dot{\varepsilon} \nu$

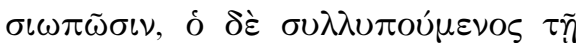

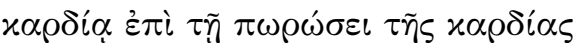

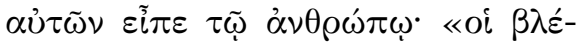

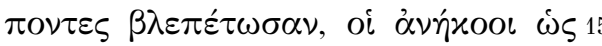

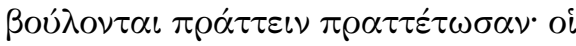

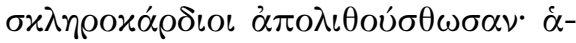

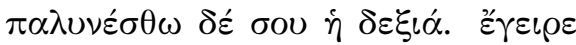

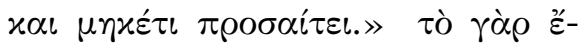

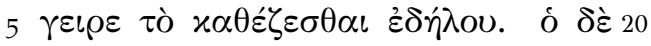

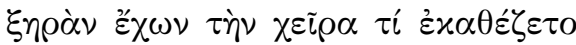

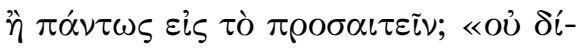

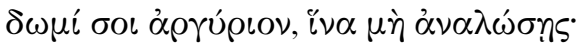

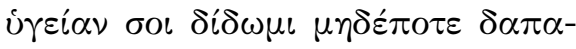

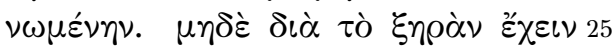

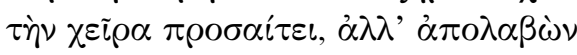

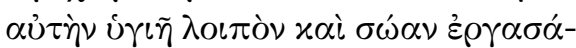

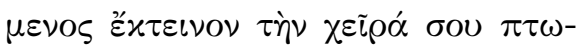

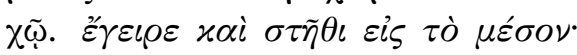

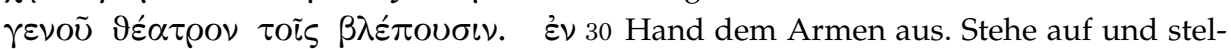

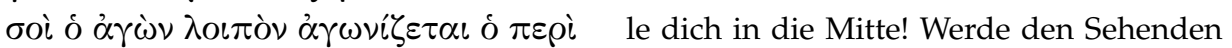

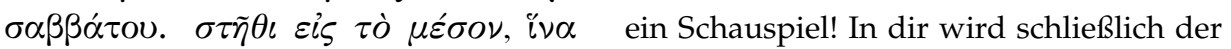

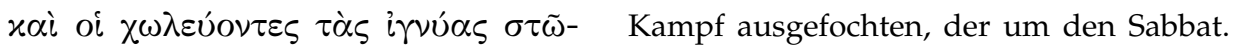

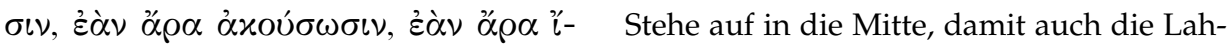

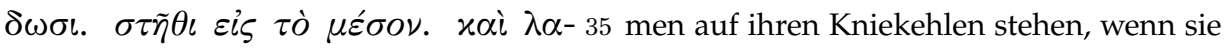
6 f. Joh 19,15 10 f. $\quad$ Lk 6,9 29 Lk 6,8 $32 \quad$ Lk 6,8 35 Lk 6,8

DN

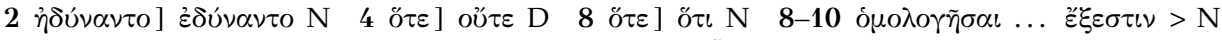

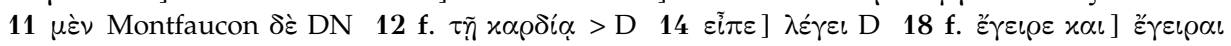

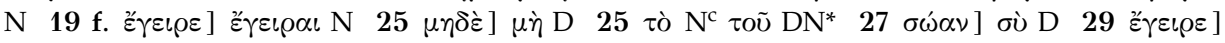

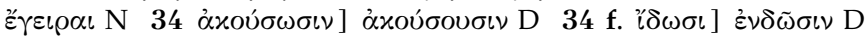

züglich des Guten nicht zu und konnten weder das Gutes zu tun einräumen noch konnten sie sagen "Schlechtes $\mathrm{zu}$ tun« denn das Wort wäre schamlos -, sondern sie schweigen. Wenn es aber um Geschwätz geht, schwatzen sie viel; wenn es um eine Anklage geht, schreien sie laut: »Hoch, hoch, kreuzige ihn!, dieser Mensch hat das und das getan.«Wenn es nötig ist, die Wahrheit es erlaubt, Gutes oder Schlechtes zu tun? Eine Seele zu retten oder zugrunde zu richten? Sie schweigen, er aber, der in seinem Herz mitbetrübt war über die Verhärtung ihHartherzigen sollen gesteinigt werden; deine Rechte aber soll besänftigt werden. Stehe auf! zeigte das (vorherige) Hinsetzen. Der, der die verdorrte Hand hatte, wozu setzte er sich, wenn nicht dazu, um zu betteln? »Ich gebe dir nicht Geld, damit du es nicht verbrauchst; ich gebe dir Gesundheit, die niemals aufgezehrt wird. Und bettle nicht, weil du eine verdorrte Hand hast, sondern, nachdem du sie nun gesund erhalten und heil gemacht bekommen hast, strecke deine . 


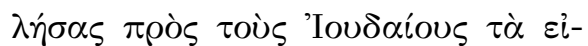

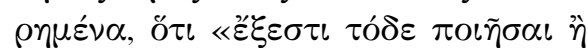

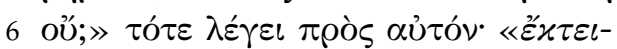

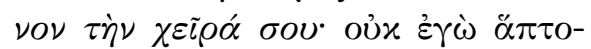

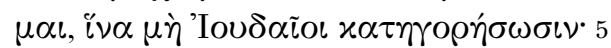

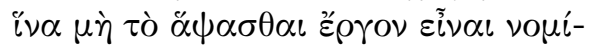

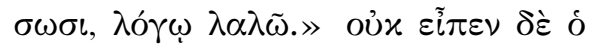

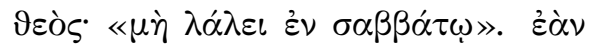

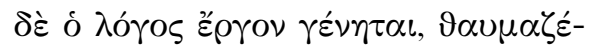

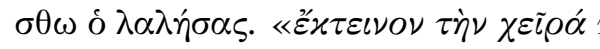

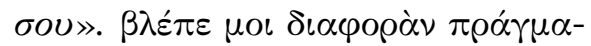

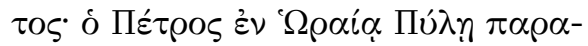

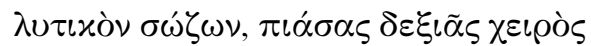

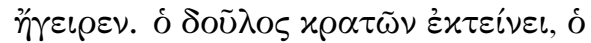

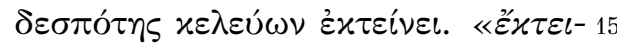

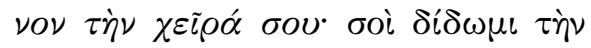

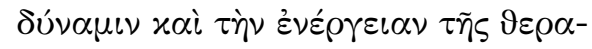

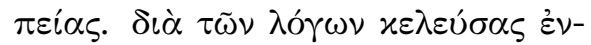

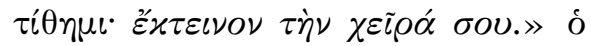

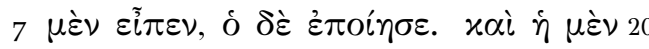

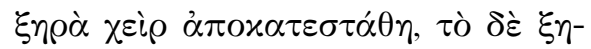

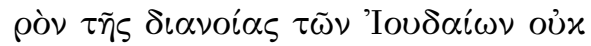
$\dot{\varepsilon} \theta \varepsilon \rho \alpha \pi \varepsilon \dot{\theta} \theta \eta^{\prime} \quad \dot{\alpha} \lambda \lambda \lambda^{\prime} \varepsilon \xi \xi \varepsilon \lambda \theta o ́ v \tau \varepsilon \varsigma$ $x \alpha \tau \grave{\alpha}$

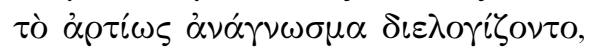

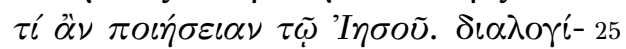

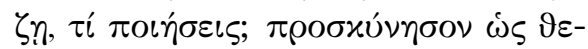

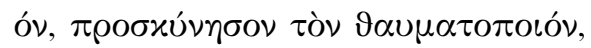

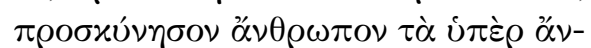

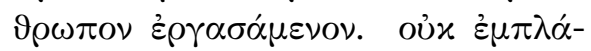

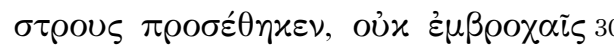

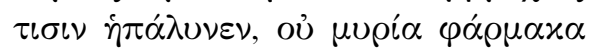

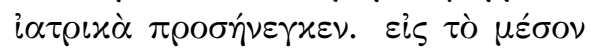

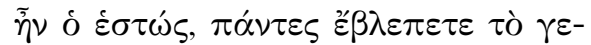

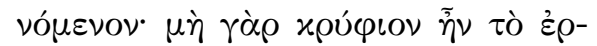

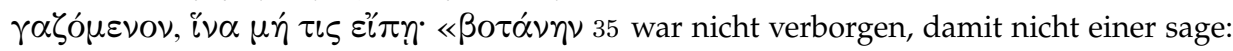

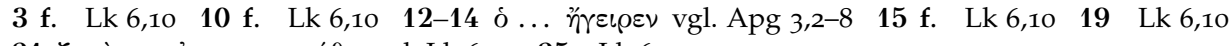

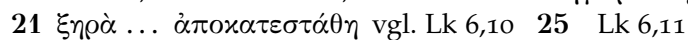

$\mathrm{DN}$

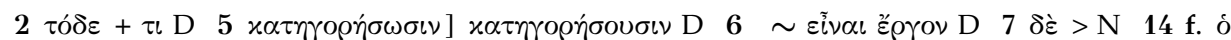

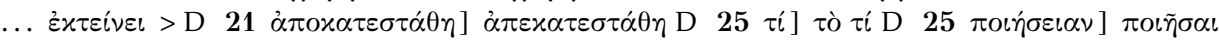

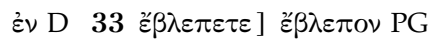




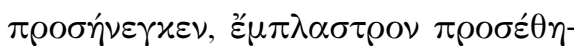

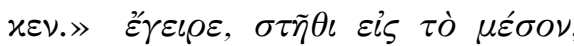

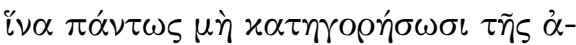

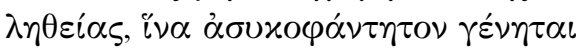
$\tau \grave{~} \pi \rho \tilde{\alpha} \gamma \mu \alpha$.

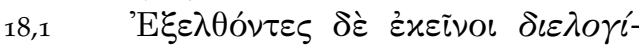

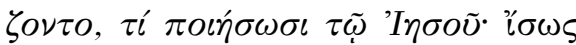

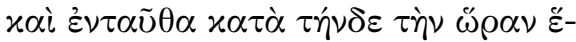

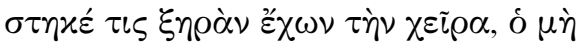

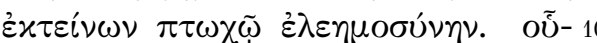

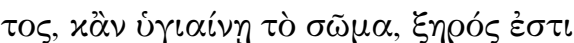

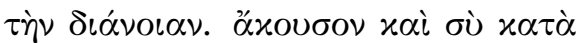
$\tau \dot{\eta} \nu \delta \varepsilon \tau \grave{\eta} \nu \omega ̈ \rho \alpha \nu \tau \tilde{\omega} \nu \sigma \omega \tau \eta \rho i \omega \nu \lambda o ́ \gamma \omega \nu$

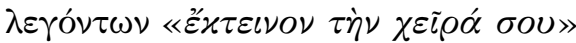

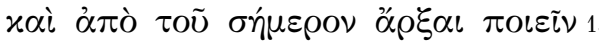

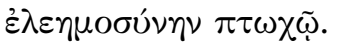

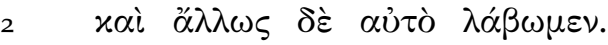

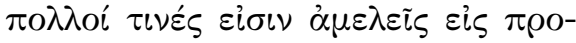

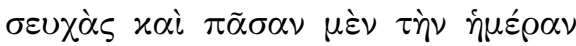

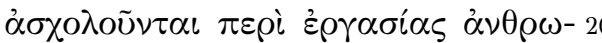

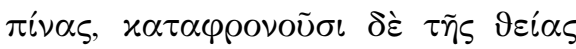

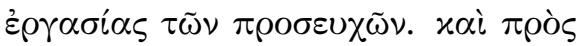

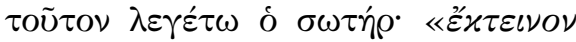

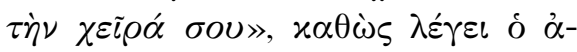

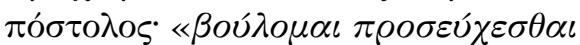

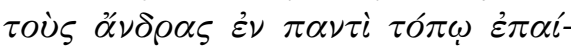


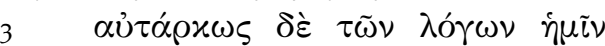

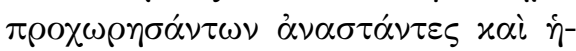

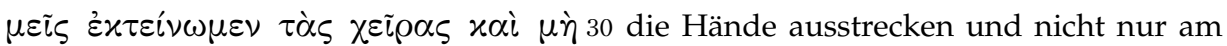

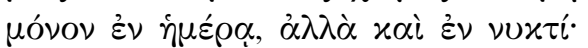

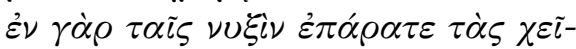

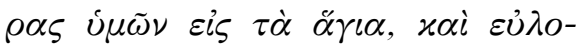

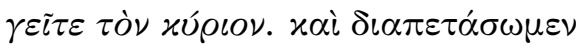

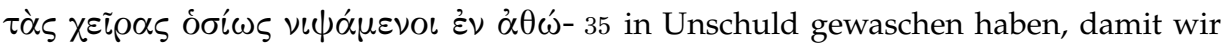

Eine Pflanze hat er aufgelegt, ein Pflaster aufgelegt. Steh auf, stelle dich in die Mitte, damit sie ganz und gar nicht die Wahrheit anklagen, damit die Sache ohne falsche An5 klagemöglichkeit geschieht.

Als jene hinausgingen, unterhielten sie $17 \mathrm{M}$. sich, was sie Jesus tun sollten. Vielleicht hat auch hier in dieser Stunde einer, der eine verdorrte Hand hat, sie ausgestreckt, einer, der einem Armen nicht Barmherzigkeit entgegenstreckt. Dieser ist, auch wenn er am Körper gesund ist, verdorrt in seiner Gesinnung. Höre auch du in dieser Stunde die rettenden Worte sagen: »Strecke deine Hand aus!«, und von heute an beginne einem Armen Barmherzigkeit widerfahren zu lassen.

Und laßt es uns noch anders begreifen: Viele sind sorglos in den Gebeten und beschäftigen sich den ganzen Tag mit menschlichen Tätigkeiten und verachten die göttlichen Werke der Gebete. Auch zu diesem soll der Heiland sagen: »Strecke deine Hand aus! «, wie der Apostel sagt: »Ich will, daß die Männer an jedem Ort anbeten, indem sie heilige Hände emporheben.«

Selbständig, da unsere Rede weit fortgeschritten ist, laßt auch uns aufstehen und Tag, sondern auch in der Nacht: In den Nächten hebt eure Hände zum Heiligen auf und preist den Herrn. Und laßt uns die Hände fromm ausbreiten, nachdem wir sie uns

2 Lk 6,8 6 f. Lk 6,11 14 Lk 6,10 23 f. $\quad$ Lk 6,10 25-27 1 Tim 2,8 32-34 Ps 133,2

$\mathrm{DN}$

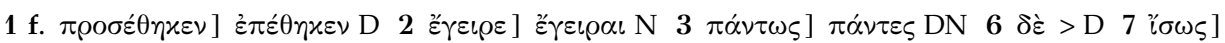

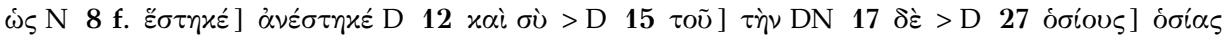

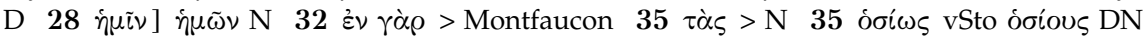




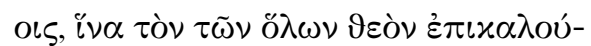

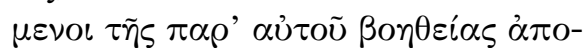

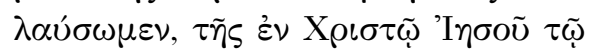

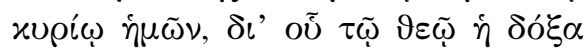

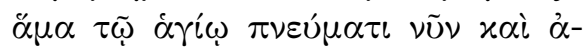

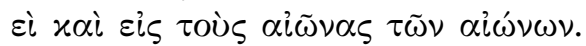

$\dot{\alpha} \mu \eta^{\prime} \nu$. den Gott des Alls anrufen und die Hilfe von ihm genießen, die in Christus Jesus, unserem Herrn ist, durch den Gott die Ehre zusammen mit dem Hl. Geist jetzt, immer und in alle Ewigkeiten sei. Amen.

DN

$4 \delta \iota^{\prime}>$ D 5 f. $\ddot{\alpha} \mu \alpha \ldots \varkappa \alpha \grave{\imath}>$ D 
Wortindex

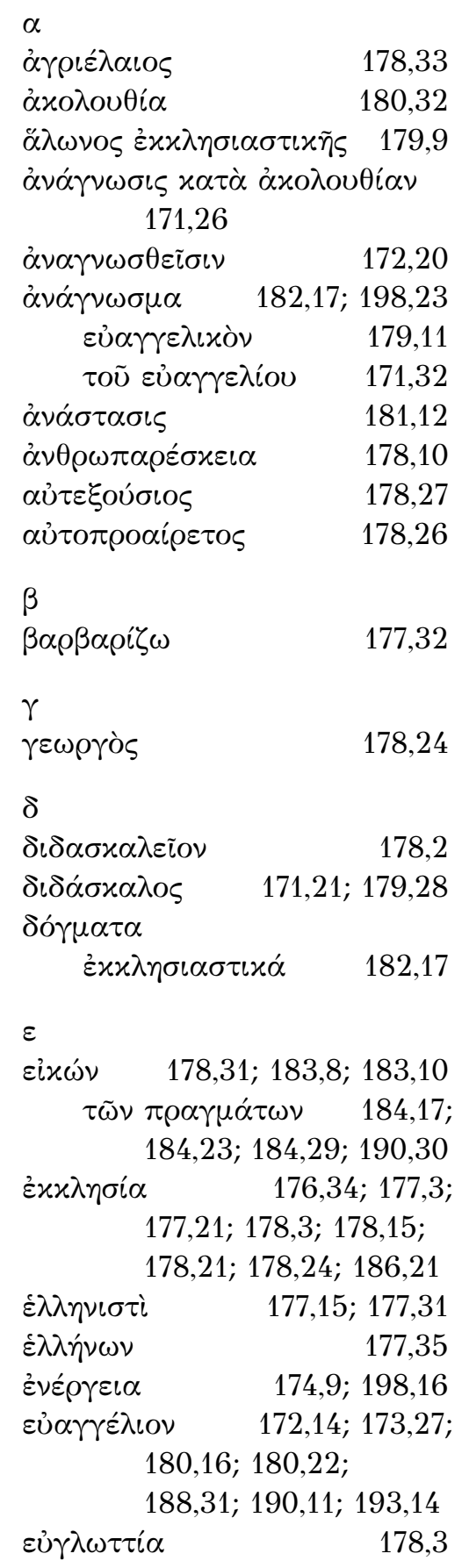

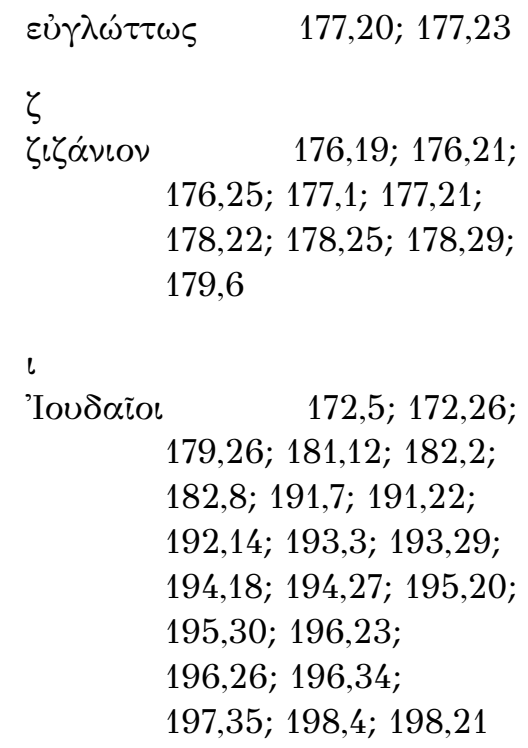


$v$ iं 173,30 ;

176,$25 ; 177,7 ; 183,27$

$\chi$

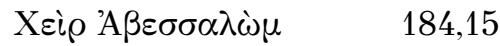

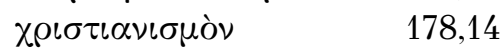
$\omega$ ¿ 186,$25 ; 188,13 ; 189,15$; 193,34

\section{Literatur}

Bacchiocchi, Samuele, Du Sabbat au Dimanche. Une recherche historique sur les origines du Dimanche chrétien, Paris 1984.

Bieberstein, Klaus und Hanswulf Bloedhorn, Jerusalem. Grundzüge der Baugeschichte vom Chalkolithikum bis zur Frühzeit der osmanischen Herrschaft. Band 3 (BTAVO.B Nr. 100/3), Wiesbaden 1994.

Brennecke, Hanns Christof, Uta Heil und Annette von Stockhausen, Athanasius Werke II 8. Die »Apologien«, Berlin/New York 2006.

Geyer, Paul, Itinera Hierosolymitana saeculi IIII - VIII (CSEL 39), Prag/Wien/Leipzig 1898.

Girardet, Klaus Martin, Vom Sonnen-Tag zum Sonntag. Der dies solis in Gesetzgebung und Politik Konstantins d. Gr. ZAC 11 (2007), 279-310.

Klostermann, Erich, Eusebius. Das Onomastikon der biblischen Ortsnamen (GCS III,1), Leipzig 1904.

Küchler, Max, Jerusalem. Ein Handbuch und Studienreiseführer zur Heiligen Stadt, Göttingen 2007.

Lewis, Agnes Smith und Margaret Dunlop Gibson, The Palestinian Syriac Lectionary of the Gospels. Re-edited from two Sinai Mss. and from P. de Lagarde's Edition of the "Evangeliarum Hierosolymitanum", Jerusalem 1971.

Mateos, Juan (Hrsg.), Le Typicon de la Grande Église. Ms. Saint-Croix $\mathrm{n}^{\mathrm{o}} 4 \mathrm{0}, \mathrm{X}^{\mathrm{e}}$ siècle (OCA 166), Rom 1963.

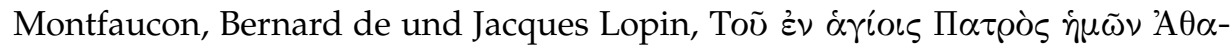

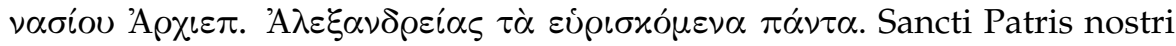
Athanasii Archiep. Alexandrini Opera omnia quae exstant vel quae ejus nomine circumferuntur, Ad mss. codices Gallicanos, Vaticanos, \&c. necnon ad Commelinianas lectiones castigata, multis aucta: nova Interpretatione, Praefationibus, Notis, variis lectionibus illustrata: novà Sancti Doctoris vitâ, 
Onomastico, \& copiosissimis Indicibus locupletata. Opera \& studio monachorum ordinis S. Benedicti è congretatione Sancti Mauri. Tribus Tomis in folio Graece et Latine, Paris 1698.

Nordberg, Henric, Athanasiana. Part I: The Texts (Societas Scientarum Fennica. Commentationes Humanarum Litterarum 30,2), Helsinki 1962.

Olivar, Alexandre, La Predicación cristiana antigua (Biblioteca Herder. Sección de Teología y Filosofía 189), Barcelona 1991.

Pierre, Marie-Joseph und Jourdain-Marie Rousée, Sainte-Marie de la Probatique, état et orientation des recherches, POC 31 (1981), 23-42.

Preuschen, Erwin, Origenes Werke IV. Der Johanneskommentar (GCS), Leipzig 1903.

Richard, Marcel, Bulletin de Patrologie. Saint-Athanase, MSR 5 (1948), 123-133.

Rondeau, Marie-Josèphe, Les commentaires patristiques du Psautier. Vol. I (Orientalia christiana analecta 219), Roma 1982.

Rondeau, Marie-Josèphe und Jean Kirchmeyer, Eusèbe de Césarée, DSp IV 2 (1961), 1687-1690.

Rordorf, Willy, Der Sonntag. Geschichte des Ruhe- und Gottesdiensttages im ältesten Christentum (AthANT 43), Zürich 1962.

Rousée, Jourdain-Marie, L'Église Sainte-Marie de la Probatique. Chronologie des sanctuaires à Sainte-Anne de Jérusalem d'après les fouilles récentes, in: Atti del VI Congresso Internazionale di Archeologia Cristiana. Ravenna 23-30 Settembre 1962 (SAC XXVI), Città del Vaticano 1965, 169-176.

Rupp, Joseph, S. Patris nostri Cyrilli Hierosolymorum archiepiscopi opera quae supersunt omnia. Volumen II, München 1860.

Schwartz, Eduard, Der s.g. Sermo maior de fide des Athanasius (SBAW.PPH 1924/6), München 1925.

Tetz, Martin, Zur Edition der dogmatischen Schriften des Athanasius von Alexandrien. Ein kritischer Beitrag, ZKG 67 (1955/56), 1-28.

Tsafrir, Yoram, Art. Jerusalem, RBK III (1978), 525-615.

Wallraff, Martin, Christus verus sol. Sonnenverehrung und Christentum in der Spätantike (JbAC.E 32), Münster 2001.

Wilkinson, John, Jerusalem Pilgrims before the Crusades, Warminster 2002. 